\title{
Review of Integrated Resource Bidding at Niagara Mohawk
}

\author{
Charles A. Goldman, John F. Busch, Edward P. Kahn, Steve S. Stoft \\ and Sam Cohen
}

\author{
Sponsored by \\ New York State Energy \\ Research and Development Authority \\ David R. Wolcott, Project Manager \\ and \\ Office of Conservation and Renewable Energy \\ U.S. Department of Energy \\ Dr. Robert San Martin, Program Manager
Energy \& Environment Division
Lawrence Berkeley Laboratory
University of California
Berkeley, CA 94720

May $19 \% 2$

The work described in this report was funded by the Assistant Secretary for Conservation and Renewable Energy, Office of Utility Technologies, Office of Energy Management of the U.S. Depariment of Energy under Contrapt N. DE-AC0376 SF00098 and by NYSERDA, under Contract No. 1515-EEED-BES-91. 


\section{Page}

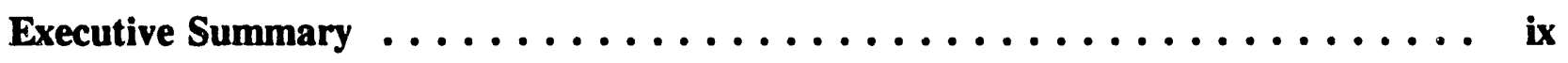

Chapter 1 Introduction .............................

Organization of the Study $\ldots \ldots \ldots \ldots \ldots \ldots \ldots \ldots$

Chapter 2 Evolution of Integrated Resource Bidding at Niagara Mohawk . . . . 5

Overview ............................. 5

Electricity Situation in New York . . . . . . . . . . . . . . . . 5

Regulatory Initiatives $\ldots \ldots \ldots \ldots \ldots \ldots \ldots$

NMPC's Bidding Program and Integrated Electric Resource Plan . . . . . . . 13

Final Regulatory Determination on NMPC's Bidding Program . . . . . . . . . . 15

Chapter 3 Design of Integrated Resource Bidding at Niagara Mohawk . . . . . 17

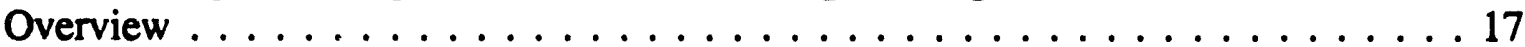

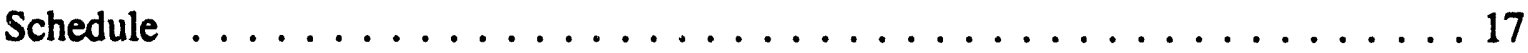

Resource Block . . . . . . . . . . . . . . . . . . . . . . 17

Demand and Supply Integrated Auction $\ldots \ldots \ldots \ldots \ldots$

Bid Evaluation and Selection Process . . . . . . . . . . . . . . . . 18

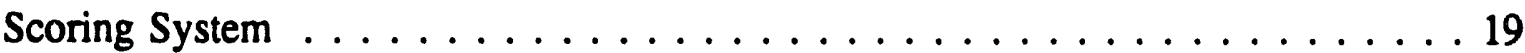

Chapter 4 Phase One Bid Evaluation Process ... . . . . . . . . . . . . 25

Response to the Solicitation . . . . . . . . . . . . . . . . . . 25

Process and Outcome of Initial Screening ................. 30

Nominal vs. Effective Weights in the Scoring System . . . . . . . . . . . 32

Issues in the Phase One Process .................... 33

Chapter 5 Phase Two Bid Evaluation Process .................. 55

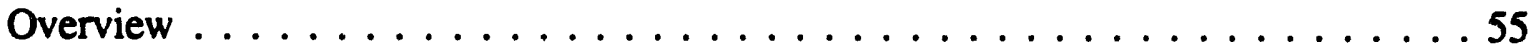

Description of the Phase Two Evaluation Methodoingy . . . . . . . . . . 55

Outcome of Final Screening . . . . . . . . . . . . . . . . . . 69

Culmination of Phase Two: Contract Negotiations . . . . . . . . . . . . . . . 69

Issues in the DSM Evaluation Process . . . . . . . . . . . . . . . . . 70

Integration and Policy Issues $\ldots \ldots \ldots \ldots \ldots \ldots$

(continued) 
Chapter 6 Reactions to Niagara Mohawk's DSM Bidding Program . . . . . . . . 79 Overview . . . . . . . . . . . . . . . . . . . . . . . 79

Survey of Prospective and Actual DSM Bidders . . . . . . . . . . . 79

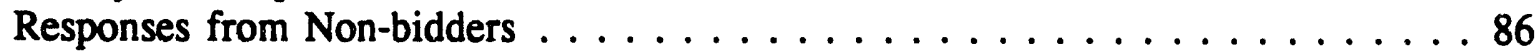

Reactions of Utility Staff $\ldots \ldots \ldots \ldots \ldots \ldots$

Chapter 7 Relationship Between DSM Bidders and NMPC's Other DSM

Programs .........................889

Overview . . . . . . . . . . . . . . . . . . . . . . . . .89

Niagara Mohawk's DSM Plan and Programs . . . . . . . . . . . . . . 89

Marketing Plans and Implementation Activities of DSM Bidders . . . . . . . . 95

Overlap Between DSM Bidding and Other Company-sponsored DSM Programs . . 98

Chapter 8 Policy Issues and Recommendations . . . . . . . . . . . . 101

Overview . . . . . . . . . . . . . . . . . . . . . . . 101

Balancing Regulation with Competition: What Role

for the Utility and the Regulator? . . . . . . . . . . . . . . . . . . . . 101

Program Design and Implementation Issues . . . . . . . . . . . . . . . 104

Acknowledgements . . . . . . . . . . . . . . . . . . 117

References ................................ 119

Appendix A Survey of DSM Bidders $\ldots \ldots \ldots \ldots \ldots \ldots \ldots \ldots \ldots \ldots$

Appendix B Survey of DSM Non-bidders . . . . . . . . . . . 133

Appendix C Questionnaire to Niagara Mohawk Staff Involved in Bidding Program ........................ 137 
2-1 NYPP Load Growth and Reserve Margin . . . . . . . . . . . . . . . . . 6

2-2 Summary of Utility Summer Period Reserve Margin Deficiency Dates

And Amount of Capacity Surplus or Deficiency . . . . . . . . . . . . . . . 7

2-3 Origins of DSM Bidding in New York . . . . . . . . . . . . . . 10

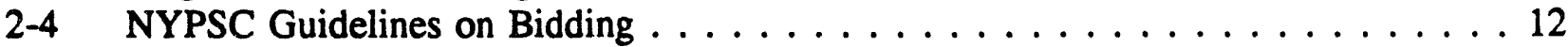

2-5 Comparison of NMPC's Initial and Final Bidding RFP . . . . . . . . . . . . 14

3-1 Schedule of Milestones in NMPC Bidding Program . . . . . . . . . . . 17

3-2 Point Values in NMPC Scoring System . . . . . . . . . . . . . . 22

3-3 Minimum Requirements for Submitting a Bid . . . . . . . . . . . . . . . . . . 24

4-1 Revised Bid Scores for All Bidders (DSM and Supply) . . . . . . . . . . . 25

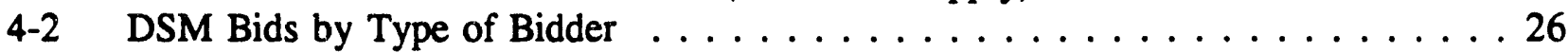

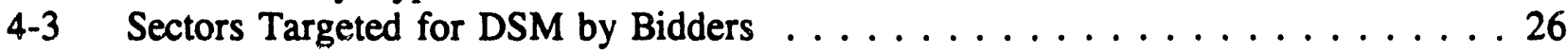

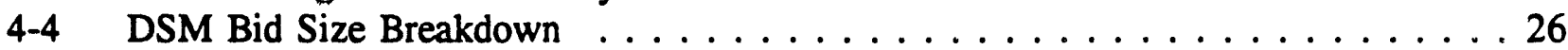

4-5 Revised DSM Bid Scores (All DSM Bids) . . . . . . . . . . . . . . . 27

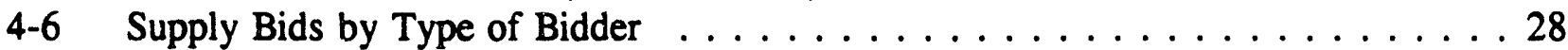

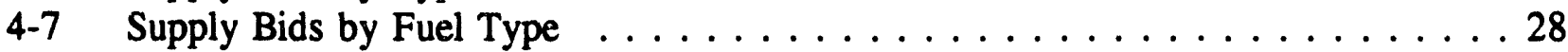

4-8 Supply Bids by Technology . . . . . . . . . . . . . . . . . . . . . 29

4-9 Supply Bid Size Breakdown . . . . . . . . . . . . . . . . . . . . 29

4-10 Revised Supply Bid Scores (All Supply Bids) . . . . . . . . . . . . . . . . 30

4-11 Comparison of Two Hypothetical Price Bids . . . . . . . . . . . . . . . . 38

4-12 Environmental Scores for Hypothetical Plants Meeting NSPS . . . . . . . . . . 41

4-13 Average Environmental Scores of Supply-Side Technologies . . . . . . . . . . 42

4-14 Emissions Abatement Costs Adopted in New York . . . . . . . . . . . . . . 44

4-15 Rank Order of Bids by Score . . . . . . . . . . . . . . . . . . . 53

5-1 Planning Scenarios Used in Phase Two Bid Evaluation . . . . . . . . . . . 56

5-2 Components of Economic Tests of DSM Bids . . . . . . . . . . . . 58

5-3 Reasons Given by NMPC for Rejecting DSM Bids . . . . . . . . . . . 62

$5-4 \quad$ Final Award Group DSM Bids . . . . . . . . . . . . . . . . . 63

$5-5 \quad$ B/C Ratios of Supply Bids Screened Individually $\ldots \ldots \ldots \ldots \ldots$

5-6 Portfolio Analysis Results: Base Need Scenario . . . . . . . . . . . . . . . 66

5-7 Portfolio Analysis Results: High Need Scenario . . . . . . . . . . . . . . . 67

5-8 Portfolio Analysis Results: Low Need Scenario . . . . . . . . . . . . . . . . . 68

5-9a 20-60-20 Weighting of Scenario Results . . . . . . . . . . . . . . . 78

5-9b $\quad 30-60-10$ Weighting of Scenario Results . . . . . . . . . . . . . . . 78

6-1 Services Provided by Bidding ESCOs . . . . . . . . . . . . . . . . 82

6-2 Attrition Among Non-bidder Sample . . . . . . . . . . . . . . . 86

(continued) 
7-1 NMPC's Projected DSM Expenditures (Million \$) . . . . . . . . . . . . . 90

7-2 Rebates Offered in NMPC's C/I Lighting DSM Programs . . . . . . . . . . . . . 92

7-3 Overlap Between Winning Bids and Other NMPC DSM Programs . . . . . . . . 98

8-1 Competitors in Alternate Bidding Approaches . . . . . . . . . . . . . 110 


\section{List of Figures}

Figure

Title

Page

ES-1 Average Phase One Scores for DSM and Supply Projects . . . . . . . . . . . xi

2-1 Chronology of New York Regulatory and Utility Actions . . . . . . . . . . 8

3-1 Demand-Side Scoring System ... . . . . . . . . . . . . . . . 20

3-2 Supply-Side Proposals Scoring System . . . . . . . . . . . . . . 21

4-1 Supply Bid Scoring in NMPC Solicitation . . . . . . . . . . . . . 31

4-2 Marginal Energy Cost Duration Curve . . . . . . . . . . . . . . . 37

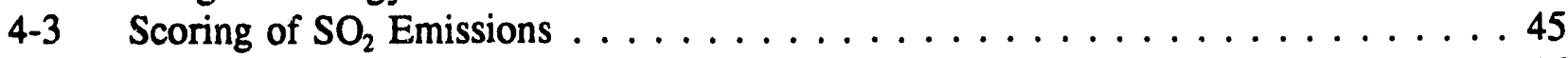

$4-4$ Scoring of $\mathrm{NO}_{\mathrm{x}}$ and $\mathrm{CO}_{2}$ Emissions $\ldots \ldots \ldots \ldots \ldots \ldots$

4-5 Implicit Incentive Payment for $\mathrm{NO}_{\mathrm{x}}$ Reduction $\ldots \ldots \ldots \ldots \ldots$

4-6 Damage Cost Curve ... . . . . . . . . . . . . . . . . . . 48

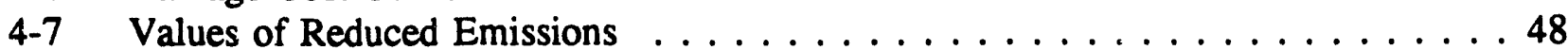

4-8 Emissions Control Cost and Damage Values . . . . . . . . . . . . . . . . . . 49

4-9 Damage Functions for Aggregate and Individual Pollution Sources . . . . . . . . 50

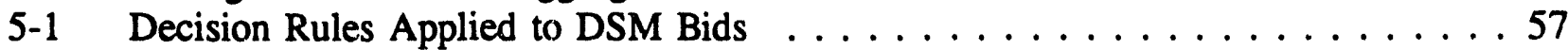

$7-1 \quad$ Niagara Mohawk DSM Saving Estimates . . . . . . . . . . . . . . 91

7-2 NMPC's Projected Expenditures on DSM . . . . . . . . . . . . . . 93

7-3 NMPC's Projected Savings From DSM . . . . . . . . . . . . . . . . . 94

8-1 Alternative Models for the Relationship Between

Planning and Competition . . . . . . . . . . . . . . . . 106 


\section{Executive Summary}

In June 1988, the New York Public Service Commission (PSC) ordered the state's investorowned utilities to develop competitive bidding programs that included both supply and demandside resource options. The New York State Energy Research \& Development Authority (NYSERDA), the New York Department of Public Service, and the Department of Energy's Integrated Resource Planning program asked Lawrence Berkeley Laboratory (LBL) to review the integrated bidding processes of two New York utilities, Niagara Mohawk and Consolidated Edison. This interim report focuses on Niagara Mohawk (NMPC).

In November 1989, NMPC issued a Request for Proposals (RFP) that requested offers from potential supply-side and DSM bidders to supply $350 \mathrm{MW}$ of capacity by October 1994 . In terms of the RFP development process, it is important to note that the PSC order permitted Department of Public Service staff and other interested parties to file comments on and critique features of NMPC's initial bidding guidelines. The order also provided for informal meetings among the parties for the purpose of reducing the number of contested issues. The PSC then ruled on contested issues among the parties. The degree of involvement by the Commission, as well as input from other interested parties, was deemed appropriate given the PSC's perspective that the program was experimental and all parties would "learn by doing", and that it was important to implement bidding relatively quickly.

In May 1990, NMPC received 108 bids, consisting of 33 DSM projects representing 165 MW of capacity and 75 supply-side bids offering 7,115 MW of capacity. An evaluation of bids was conducted in two steps, consisting of Phase One and Phase Two. An independent third-party contractor, retained by NMPC reviewed, developer's own scoring of their bids, revised scores as necessary and then ranked bids according to objective criteria specified in the RFP. Based on this Phase One screening, NMPC announced an Initial Award Group of 39 projects representing approximately $1,100 \mathrm{MW}$ of capacity (30 DSM projects and 9 supply bids). As part of the Phase Two bid evaluation, NMPC then conducted a detailed assessment of each remaining project. The Phase Two bid evaluation process involved use of additional criteria to evaluate DSM projects and modeling of portfolios of supply and DSM projects. Based on its judgment of the best mix of projects, the Company selected a Final Award Group in July 1990 . The Final Award Group consisted of seven DSM bids offering $36 \mathrm{MW}$ of capacity and two supply projects representing $405 \mathrm{MW}$ of capacity. NMPC's Phase Two bid evaluation process and selection decision were quite controversial. Two DSM bidders formally protested the utility's actions, which were considered and ultimately dismissed by the PSC. NMPC has signed contracts with most winning DSM and supply bidders, and negotiations are continuing with one remaining project, although the company has recently announced that its own winning bid, a life extension of Huntley 67 , has been withdrawn.

In terms of overall approach, our analysis is intended as a critical review of a large-scale experiment in competitive resource acquisition implemented by New York utilities at the direction of their state regulators. The study is not a formal impact or process evaluation. Based on priorities established jointly with project sponsors, the report focuses on selected 
topics: analysis of the two-stage scoring system used by NMPC, ways that the scoring system can be improved, an in-depth review of the DSM bidding component of the solicitation including surveys of DSM bidders, relationship between DSM bidding and other utility-sponsored DSM programs, and major policy issues that arise in the design and implementation of competitive resource procurements.

The major findings of this report are:

\section{Phase One Scoring Outcome}

- NMPC's solicitation elicited an impressive response from private power developers and energy service companies. Gas-fired projects were dominant in terms of fuel choice, accounting for over half of the bids and capacity on the supply-side. Generation projects ranged in size from $9 \mathrm{MW}$ to $300 \mathrm{MW}$, averaging $96 \mathrm{MW}$ overall. On the demand-side, NMPC received 27 bids from energy service companies and 6 proposals from customers. Most DSM projects targeted customers in the commercial/industrial (C/I) sector.

- In the initial ranking of bids, DSM projects were awarded significantly more points on price and environmental factors compared to supply-side bids (see Fig. ES-1). The average scores on other lion-price factors were comparable between supply and DSM projects, with bidders typically obtaining about two-thirds of the available points in these categories. DSM and-supply bids were effectively separated from one another by price.

- $\quad$ NMPC's scoring system gave approximately twice as much weight nominally to price as to non-price factors (850 vs. 460 points). However, for a given set of bids, the effective or "real" weight of a factor in influencing the ultimate outcome (i.e., ranking of projects) is determined by the variation in bid scores for that factor. We use the standard deviation as a measure of the variability of factor scores. Differences in bid price played an even larger role in determining the outcome of Phase One than anticipated in NMPC's RFP as reflected by the fact that the standard deviation of price scores was about four times greater than the standard deviation of non-price factor scores (195 vs 52 points).

\section{Analysis of Phase One Bid Evaluation Criteria}

\section{Attributes of DSM projects not properly represented.}

- There were serious problems with the Phase One scoring approach for DSM bids for both price and non-price factors. Many of these problems were a by-product of the integrated "all-sources" approach. The scoring system for DSM bids essentially mimicked the factor categories and relative weights of NMPC's supply-side bid evaluation. In practice, the scoring system failed to effectively 
Figure ES-1. Average Phase One Scores for DSM and Supply Projects

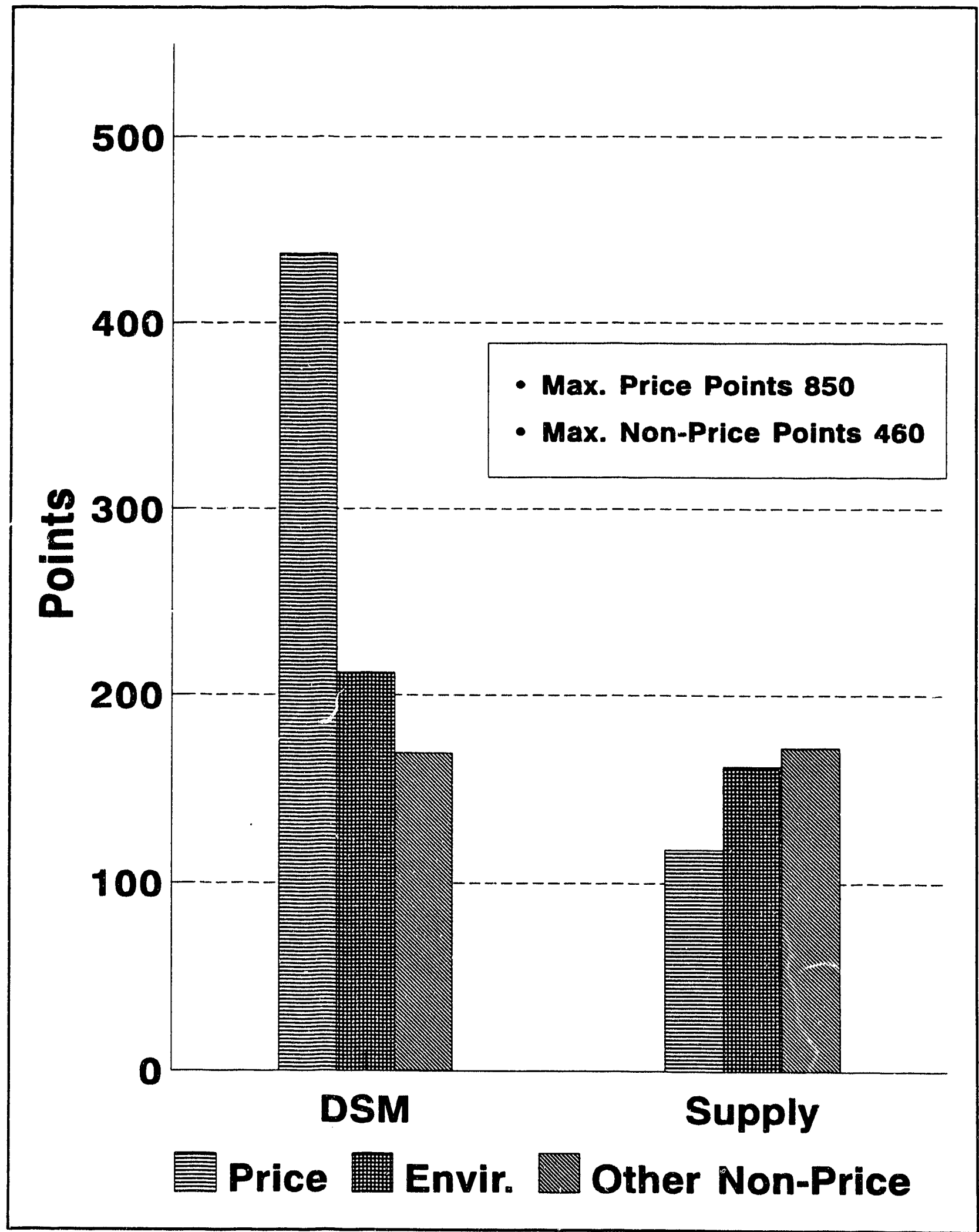


discriminate among DSM bids because the overall framework constrained adequate valuation of individual attributes that were critical for evaluation of DSM projects.

- Inadequate weights were assigned to non-price factors such as experience and qualifications of the DSM project team (3\% of total points) as well as attributes that linked payments to bidder's willingness to measure, verify, and guarantee savings ( $4 \%$ of total points). In the future, it would be preferable to develop bid evaluation criteria for DSM projects separately from supply-side projects.

- In Phase One, the price score for DSM bids was based on a single metric, which was comparable to the Total Resource Cost (TRC) Test. However, in its cost/benefit analysis in Phase Two, NMPC evaluated DSM projects from several economic perspectives (e.g., utility, non-participating ratepayers, and society) and compared bid prices to the estimated costs of its own DSM programs. NMPC was particularly concerned about costs to the utility of DSM bids. In hindsight, it is apparent that many DSM bidders misread the scoring signal on price implied by NMPC's sole reliance on the TRC test in Phase One. In the future, the utility's RFP should be more explicit regarding the relative importance of various economic perspectives in bid evaluation and methods that will be used to compare DSM bids to existing utility DSM programs.

Price scoring technique not discriminating.

- In Phase One, NMPC scored and ranked bid prices based on the ratio of the present value of bid prices to the present value of avoided cost. However, a shortcoming in the "ratio price score" approach is that it fails to distinguish among projects whose operating profiles differ. Projects whose optimal dispatch differ do not have equal value to the utility, yet their bid prices may yield the same percentage of avoided cost (i.e., the same "ratio price score"). For example, baseload bids (or high load factor bids on the demand-side), which operate for most hours of the year, produce more benefits per $\mathrm{kW}$ than intermediate or peaking bids with an equal ratio score, but whose optimal hours of operation are less. This shows that the ratio score is biased against baseload bids. Conversely, peaking supply bids (or low load factor DSM bids) will be unambiguously over-valued compared to baseload supply bids by the ratio score method.

The use of "add-on" points for dispatch and unit commitment corrects the problem only to a very limited degree. The weight assigned to these operational features is much lower than their value as has been found in detailed studies. The low weight given to dispatchability works against peaking or intermediate projects. This limitation works in the opposite direction of the ratio scoring bias. 
because these two limitations work in opposite directions, however, is no reason to argue that the system is neutral. Rather, it is uninformative.

These problems are largely solvable by using production simulation models, which formed the basis of NMPC's approach in Phase Two of the bid evaluation process. Phase One was designed to identify only the most promising bids, however, it is not reassuring to find such poor approximations at this stage because it is possible that Phase One errors eliminated a project that would look even better with more accurate analysis in Phase Two.

Scoring of environmental factors could be improved to comply with PSC policies.

- Environmental factors accounted for the majority of non-price points, and thus were an important area of competition among projects. The NYPSC intended that the maximum differential of 220 points in the environmental category correspond to a credit to a clean, pollution-free technology of $1.4 \mathrm{c} / \mathrm{kWh}$ over a coal plant minimally complying with New Source Performance Standards (NSPS). Instead, the way the scoring system was designed, a NSPS plant would, in fact, be awarded some points, thus lowering the actual credit to only $65-75 \%$ of that intended.

- The environmental scoring system relied on a limited number of bins for scoring air emissions. We recommend that the bins be discarded for a linear scoring function instead. Bins introduce distortions in the incentives of bidders to reduce pollutant emissions because depending on starting and ending emissions levels, bidders could be either over-rewarded or under-rewarded.

- Many supply-side bidders did respond to the signals sent by the substantial number of points for environmental factors. For example, on average, gas combined cycle and coal projects received $76 \%$ and $57 \%$, respectively, of the available environmental points.

\section{Inconsistencies in Initial A ward Group size.}

- In the RFP, NMPC stated that the size of the Initial Award Group would be determined by three objective criteria. Our analysis indicates that NMPC's third party evaluator included one additional supply project with a lower score in the Initial Award Group, which was inconsistent with the RFP criteria. This project, a $216 \mathrm{MW}$ combined cycle plant proposed by PG\&E/Bechtel, was ultimately selected for the Final Award Group. Thus, the decision to accept this project initially had $a \Omega$ obvious detrimental impact on other eligible projects that failed to make it into the Final Award Group. 


\section{Analysis of Phase Two Bid Evaluation Process}

NMPC's decision to select only one ESCO that offered multiple measures in the C/I sector was unfortunate.

- $\quad$ NMPC made separate evaluations of DSM and supply bids to screen for the portfolio analysis. The methods applied to DSM bid screening were unnecessarily stringent. ESCO bids were rejected if there was a lower cost bid of similar type or a competing NMPC program which had lower estimated costs to the utility (based on the Utility Cost Test). The effect of this procedure was particularly harsh for ESCO bids which proposed multiple measures targeted at commercial/industrial customers. Because it is difficult to guarantee that payments match a particular mix of measures in bids of this kind, NMPC rejected all but one of these offers.

- The result of the Phase Two screening procedure for DSM bids was that a single portfolio of seven DSM bids was combined with various supply bids to test for the best combination for the Final Award Group. The DSM portfolio was always a part of any subsequent portfolio analysis, but there was no competition between marginal DSM bids and marginal supply bids.

- In Phase Two, NMPC eliminated the majority of DSM bids because of their high costs to the utility. NMPC's heavy reliance on the Utility Cost Test and use of its internal estimates of marginal costs, which were about $30 \%$ lower than the long-run avoided costs (LRACs) published in the RFP, contributed significantly to this result. Our analysis suggests that there are some inconsistencies between NMPC's decision criteria for DSM bids compared to methods used to evaluate other utility DSM programs (e.g., utilities must use PSC-approved LRACs and environmental credits in evaluating benefits). The PSC may want to clarify its position on the range of acceptable approaches to ensure that there is consistency in evaluating the merits of utility programs and DSM bids.

- While we are critical of NMPC's DSM bid evaluation and selection process, the New York PSC ultimately has to share much of the responsibility for confusion on these issues because it provided insufficient policy guidance. In effect, the utilities were left to grapple with conflicts between PSC-mandated core DSM programs and DSM bidders' proposals and can not be unduly faulted for the approach that they adopted.

Expected net benefits is the best figure of merit in selecting among resource portfolios.

- The integrated portfolio analysis was methodologically ambiguous. NMPC cites analytic results using three economic figures of merit: benefit/cost ratios, net 
benefits, and net benefits per $\mathrm{kW}$. It is impossible to tell which measure NMPC used. Our analysis suggests that the best overall measure is expected net benefits; the other two measures are less useful.

- $\quad$ NMPC performed uncertainty analysis of resource portfolios using three scenarios: Low Need, Base Need and High Need. NMPC does not say how these scenarios were weighted. The choice of projects in the Final Award Group is shown to be consistent with a stronger weighting on the Low Need scenario than the High Need.

Use of contingency planning in a bidding context.

- As a hedge against the risk of project failures, NMPC stated that the Final Award Group coild be as high as $125 \%$ of the resource need block ( $350 \mathrm{MW})$, or 438 MW. NMPC's portfolio analysis treated this as a "floor" on the size of portfolios, rather than as a "ceiling". Smaller portfolios (e.g., less than 438 MW) could have been analyzed using fewer supply projects and more DSM bids. These alternative portfolios would have been more consistent with NMPC's apparent emphasis on the Low Need scenario and use of marginal cost estimates which were significantly lower than PSC-approved LRACs in screening DSM bids. NMPC ignored these alternatives.

\section{Reactions of DSM Bidders}

- DSM bidders' overall assessment of the program was greatly influenced by relative outcome (i.e., winners or losers). However, all DSM participants had extremely high initial expectations for the NMPC program, which wvas reinforced by the high scores received by virtually all DSM bids in NMPC's Phase One ranking. Many DSM bidders were disappointed and surprised at NMPC's selection of so few DSM bids for its Final Award Group.

- DSM bidders generally felt that NMPC's RFP was well-designed overall. Eligibility and threshold requirements were reasonable. DSM bidders had few problems with the scoring criteria used in the Phase One bid evaluation and agreed in theory that a Phase Two evaluation process which involved more indepth review and analysis of a "short list" of projects was not unreasonable. However, most DSM bidders were quite critical of NMPC's implementation of the Phase Two bid evaluation. DSM bidders felt that the Phase Two criteria were not explained adequately in the RFP, that the criteria were inconsistent between the two stages in certain areas (e.g., price), and that they were not told that their bids would compete with NMPC's other DSM programs.

- Bidders offered four major suggestions that could improve future programs. First, customers/bidders stressed that the process needed to be simplified in order 
to reduce transaction costs. Second, criteria that will be used in a second stage evaluation process that involves utility judgments should be more explicit and articulated in advance in the RFP. Third, the utility's RFP should spesify how bid proposals will be evaluated relative to the utility's own DSM programs. Fourth, some bidders recommended that the Phase Two bid evaluation process should place more emphasis on direct negotiations between utilities and possible winners to refine and clarify proposals. This might involve negotiations on price in response to substantive changes in other bid features, rather than making price non-negotiable.

\section{Current Status of DSM Bidding Program}

- There is relatively little overlap between DSM bids selected for the Final Award Group and other utility-sponsored DSM programs in terms of end uses and sectors targeted. The lack of overlap is principally a by-product of NMPC's Phase Two decision criteria.

- Winning DSM bidders are aggressively marketing their programs iil the field. The three ESCOs that have signed contracts report progress toward achieving contract goals. For example, Planergy estimates that it has achieved between 10-15\% of its contractual goal for its refrigerator roundup program. All ESCOs indicated that NMPC staff have been very cooperative in working out issues and unanticipated problems that arise in pilot programs. Overall, they give NMPC staff high marks during initial implementation Phase of the program.

\section{Bidding Policy Issues and Recommendations on Program Design}

- Competitive bidding represents an attempt to introduce the benefits of competition into a largely regulated framework. However, "all-sources" integrated bidding creates real or potential conflicts which involve placing the utility in both the buyer and seller role. Our analysis suggests that "self-dealing" problems, even if they are primarily perceptual, undermine the credibility of competitive processes. Competitive processes work best when applied to a set of competitors that have relatively equal market power. Thus, an alternative model of the relationship between planning and bidding should be examined in which the PSC makes an initial determination of resource and supplier mix issues as part of their review of a utility's Integrated Resource Plan (IRP). The effort to determine market share in advance would allow participation of the utility and their resources on a priority basis, reserving the competitive process for residual needs. On the demand-side, the utility would offer a combination of its own programs and ESCO-delivered programs. The primary advantages of this "preferred resources" approach would be to reduce the potential for self-dealing by the utility. This administrative approach is admittedly "second best" but it would then allow competitive bidding processes among Independent Power Producers 
(IPPs) to function more efficiently and fairly. These more targeted and structured solicitations would still preserve the "yardstick" function of competition in regulated industries, as well as a potential "second-sourcing" capability in the event of poor utility performance.

Separate solicitations for DSM and supply-side resources are preferable given inherent differences in resource characteristics and market structure. This allows utilities to design scoring systems which are sperifically tailored to evaluate the attributes and distinctive features of each resource.

In structuring future demand-side procurement processes, the role(s) of ESCOs need to be more explicitly discussed with respect to policy goals and then reflected in program design. Conceptually, "partnership" and "replacement" bidding represent contrasting approaches, which highlights differences implied by various objectives. In "partnership" bidding, utility and ESCO activities are viewed as complementary, solicitations focus on proposals from ESCOs that supplement and expand existing utility programs, and the primary competition occurs among ESCOs during the selection phase. Partnership bidding programs are more likely to emphasize qualifications, performance guarantees for savings, comprehensiveness and value of services provided rather than price. In DSM "replacement" bidding, ESCOs compete explicitly with the utility, and ESCO bids are compared to either a planned utility DSM program or head-to-head structured competitions occur in the field in targeted market segments. In this approach, a primary objective is to have ESCO bids provide a "price check" on the utility's estimated or actual DSM program costs. In most situations, we believe that "partnership bidding" types of programs are the preferred approach.

Few customers are likely to participate in DSM bidding programs as currently structured. Customers should either be encouraged to participate directly in other DSM programs offered by utilities or separate, simplified bidding processes should be considered which are specifically tailored to customers. However, having customers as "resource suppliers" complicates the utility's traditional relationship which is based on customer service and poses additional monitoring problems for regulators. Thus, we are not convinced that bidding-type programs are best suited for customers.

- The most important element of a scoring system is that the buyer's preferences and relative valuations of major bid evaluation criteria are explicitly communicated in the RFP; however, this can be accomplished without relying on self-scoring. "Closed" bid evaluation systems represent an alternative approach which emphasize discretion for the utility in selecting the optimal mix of projects and negotiated solutions with bidders. In our view, the preferred approach is strongly influenced by the utility's decision regarding its own participation as a seller in the bidding process. Objective, self-scoring systems are probably the 
most appropriate bid evaluation process in situations where utility affiliates are allowed to participate or utility life-extension/repowering projects are included. 


\section{Chapter 1 \\ Introduction}

Since the mid-1980s, many U.S. utilities and regulatory agencies have been experimenting with competitive resource procurement procedures as a more efficient way to encourage private electricity supply. DSM bidding has also been proposed, but experimentation has been more limited. In June 1988, the New York Public Service Commission issued a decision which ordered the state's investor-owned utilities to develop competitive bidding programs that included both supply and demand-side resource options (NYPSC 1988a). The Commission concluded that bidding was a useful way to choose among third-party producers and that it also provides a valuable yardstick against which to judge other power supply proposals offered in the future by utilities or other entities. In a practical sense, the Commission's challenge to the utilities represents a major experiment in resource acquisition policy. Moreover, the design and implementation of competitive resource procurement processes raises fundamental policy issues regarding the underlying vision and role of utilities and private third-party producers in providing electric power and energy services:

- Should unregulated utility subsidiaries be allowed to participate in these bidding processes and what, if any, additional rules should be applied if they participate to protect against the potential for anti-competitive practices?

- Is the utility's role in builüing new generation under traditional ratemaking limited to being "the supplier of last resort"? How should potentially attractive resource options, such as life extension and repowering projects, be treated?

- What is the relationship between the utility demand-side management (DSM) programs and DSM bidders?

The New York State Energy Research \& Development Authority (NYSERDA), the New York Department of Public Service, and the Department of Energy's Integrated Resource Planning program asked Lawrence Berkeley Laboratory (LBL) to review the integrated bidding processes of two New York utilities, Niagara Mohawk and Consolidated Edison. This interim report focuses on Niagara Mohawk, principally because the company's bidding implementation process is more advanced. In November 1989, NMPC issued a Request for Proposals (RFP) that requested offers from potential supply-side and DSM bidders to supply $350 \mathrm{MW}$ of resources by October 1994. NMPC indicated that about $50 \mathrm{MW}$ would be provided by third parties or customers offering DSM options. NMPC received 108 bids in May 1990, consisting of 33 DSM bids representing $165 \mathrm{MW}$ and 75 supply-side bids offering 7,115 MW of capacity. NMPC's independent third-party contractor then screened and ranked bids using the self-scoring criteria specified in the RFP. NMPC used this Phase One screening to determine an Initial Award Group of 39 projects representing about 1,100 MW (30 DSM projects and nine supply bids). NMPC then conducted a detailed assessment of each remaining project as part of a Phase Two evaluation. The Phase Two bid evaluation process included use of additional criteria to evaluate DSM projects, modeling of portfolios of supply and DSM projects, leading to the Company's 
selection of a Final Award Group based on its judgment of the best mix of projests. In July 1990, NMPC announced that seven DSM bids offering $36 \mathrm{MW}$ of savings and two supply projects representing $405 \mathrm{MW}$ had been selerted for the Final Award Group. NMPC's Phase Two selection process and decision was quite controversial, particularly among losing DSM bidders. Two DSM bidders formally protested the utility's actions, but the PSC dismissed their complaint after holding hearings (NYPSC 1991b). As of March 1992, NMPC had signed contracts with four DSM bidders and negotiations are continuing with remaining projects.

Our analysis builds on and is intended to complement more formal process and impact evaluations that are being conducted by the utilities themselves as well as activities of the Bidding Working Group (supply-side and demand-side) being conducted under the direction of the New York Department of Public Service's Office of Regulatory Economics and Office of Energy Efficiency and Environment. At the outset, it should be noted that most of our efforts were directed toward analyzing the ways in which demand-side options have been incorporated into these bidding programs. The principal reason for this selective treatment is that inclusion of demand-side options in bidding programs was controversial in New York (as well as other states), and raises some implementation issues that are unique compared to supply-side procurements (e.g., coordination with existing utility DSM programs). Thus, it was deemed more important to focus attention on this aspect if the utility's bidding programs. We conducted formal interviews with utility and regulatory staff, surveyed DSM bidders and a selected sample of DSM non-hidders. In addition, we reviewed relevant Commission decisions, utility filings, and testimony offered by various parties, a process evaluation of NMPC's DSM bidding program, and a confidential report prepared by NMPC's third party evaluator, which scored and verified all submitted bids.

\subsection{Organization of the Study}

In Chapter 2, we describe the evolution and context for integrated resource bidding at Niagara Mohawk, highlighting those factors that shaped the program: the company's overall integrated resource planning process as well as regulatory initiatives undertaken by the New York Public Service Commission. Chapter 3 describes the key features of Niagara Mohawk's Integrated Resource Bidding program. In Chapters 4 and 5, we examine phases one and two of the bid evaluation process in some detail. In Chapter 4, we der "ribe bidder's initial response to the solicitation, examine the way that the self-scoring systen. worked in practice in the company's selection of an Initial Award Group. We also analyze three aspects of the self-scoring system in detail and suggest possible improvements in the approach to scoring bid price, dispatchability and environmental factors. In Chapter 5, we explore the company's Phase Two bid evaluation process and discuss issues that arose in contract negotiations with winning bidders. Our review of the Phase Two bid evaluation process is quite detailed, in part because it was not a transparent process, involved substantial amounts of judgment by the Company, and proved to be quite controversial. In Chapter 6, we discuss reactions to Niagara Mohawk's DSM bidding program based on interviews with bidders, a small sample of non-bidders, and utility and regulatory staff. The focus of Chapter 7 is a preliminary comparison of markets and end uses targeted by winning bidders and Niagara Mohawk's other utility-sponsored DSM programs. We 
summarize marketing plans and implementation activities of energy service companies (ESCOs) and customers that have signed contracts, and discuss potential overlap with existing utility DSM programs as well as coordination issues. In Chapter 8, we discuss key policy issues and offer preliminary recommendations, which are based on our analysis of Niagara Mohawk's pilot bidding program as well as the experience and lessons learned from other utilities that are implementing competitive resource procurements. 


\section{Chapter 2 \\ Evolution of Integrated Resource Bidding at Niagara Mohawk}

\subsection{Overview}

In this chapter, we discuss the context in which utilities in New York developed competitive resource procurements implementing Commission rulings on bidding. We briefly review the New York Power Pool's long-term forecast of load growth, available resources, and the timing and need for new resources, which highlights the state's changing resource balance. In the late 1980s, there was general agreement among New York's utilities, regulators and State Energy Office that New York's utilities would need additional electricity resources by the early to mid1990s. In response, the Public Service Commission (PSC) initiated a proceeding (Case 29409) to examine plans for meeting future electricity needs in the state, which produced a series of orders, including the Commission's rulings on bidding. We summarize the PSC's orders on bidding, the relationship between bidding and integrated resource planning, as well as related initiatives that directed utilities to pursue cost-effective demand-side resource options more aggressively. During this period, the PSC directed utilities to file long-range DSM plans, offer full-scale, system-wide DSM programs to various customer classes, and suggest ratemaking mechanisms that would overcome financial barriers to promoting energy efficiency options. The PSC consciously chose to implement bidding quickly and recognized that its "learning by doing" approach would inevitably lead to some mistakes which would be corrected as part of an iterative process. The PSC provided general guidelines on bidding but it was left to the utilities to sort out and ultimately reconcile the consequences of these DSM policy initiatives with bidding guidelines that required inclusion of demand-side providers.

\subsection{Electricity Situation in New York}

To get a sense of the electricity outlook in New York during the late 1980s, we draw upon the 1988 New York Power Pool (NYPP) long-term forecast as well as the 1989 New York State Energy Plan. Table 2-1 shows existing utility generation capacity in 1988 (over 30,700 MW), planned capacity additions, along with the New York Power Pool's low, base, and high load growth forecast (NYPP 1988). Non-utility sources of supply are not included. Depending on load growth, the NYPP projected that statewide reserve margins would drop below twenty percent between 1991 and 1996, without acquisition of additional generating capacity. During this same period, the New York State Energy Plan forecasted that new electricity resources would be necessary by 1992 under the most likely statewide forecast of peak electric demand (NYSEO 1989). However, the actual need could be earlier or later depending on uncertainties associated with assumed supply and demand-side options. In addition, the State Energy Plan noted that the need for new resources varied significantly among utilities (see Table 2-2). The table indicates the year in which individual utilities are deficient in summer or winter capacity 


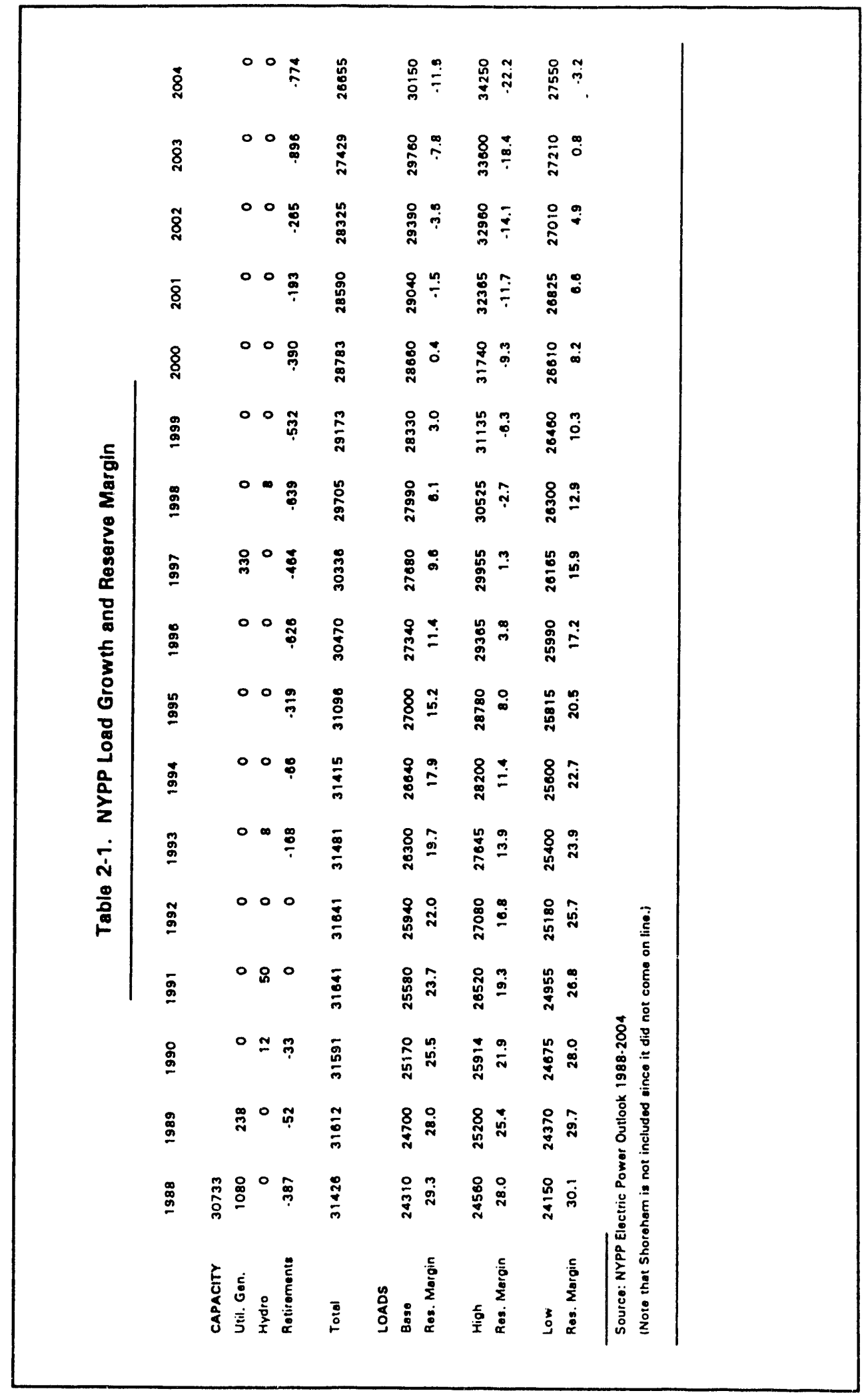


compared to their established reserve margin target as well as the amount of capacity deficiency in 1998 and 2008.'

During the late 1980s, the prevailing view was that several of the state's utilities would need to add additional resources by the mid-1990s with the principal uncertainties being actual load growth, level of independent power production, achievement of DSM savings, and approval of utility plans for life extension of existing oil and coal-fired generating units.

\section{Table 2-2. Summary of Utility Summer Period Reserve Margin Deficiency Dates And Amount of Capacity Surplus or Deficiency}

\begin{tabular}{|c|c|c|c|}
\hline Utility & $\begin{array}{l}\text { Date of First } \\
\text { Summer } \\
\text { Period } \\
\text { Capacity } \\
\text { Deficiency }\end{array}$ & $\begin{array}{c}\text { Reserve Margin } \\
\text { Capacity (MW) } \\
\text { Deficiency } \\
\text { in } 1998\end{array}$ & $\begin{array}{c}\text { Reserve Margin } \\
\text { Capacity (MW) } \\
\text { Deficiency } \\
\text { in 2008 }\end{array}$ \\
\hline Central Hudson & 1997 & -4 & -105 \\
\hline Consolidated Edison & 1991 & -412 & -3432 \\
\hline Long Island Lighting Co. & $1994^{1}$ & -187 & -1920 \\
\hline NYSEG & 1998 & -25 & -827 \\
\hline Niagara Mohawk & 1997 & -196 & -2034 \\
\hline Orange \& Rockland & $1989^{2}$ & -139 & -582 \\
\hline Rochester Gas \& Electric & 1991 & -259 & -784 \\
\hline \multicolumn{4}{|c|}{$\begin{array}{l}\text { A small projected deficiency occurs for two years in } 1990 \text { and } 1991 \text {. Small surpluses occur in } 1992 \text { and } 1993 \\
\text { as a result of increased DSM, IPPs and planned purchasf of Gilboa capacity from NYPA and completion of Long } \\
\text { Island Sound Cable Project. Deficiencies resume and cuntinue in 1994. }\end{array}$} \\
\hline
\end{tabular}

Source: NY State Energy Plan 1989

As with all long-term forecasting exercises, the overall resource outlook had changed significantly by $1990-1991$, which is the period when Niagara Mohawk was evaluating and selecting winning bids received in its first RFP. Specifically, the need to acquire additional resources was perceived to be less urgent due to a combination of factors. To illustrate, the 1991 update of the State Energy Plan concluded that the electricity situation had improved over the past two years from concern about meeting future load growth to having adequate capacity to meet anticipated load growth throughout the planning period, primarily because of lower energy

' NMPC and New York State Electric and Gas (NYSEG) are winter-peaking utilities. 
demand and aggressive utility DSM programs (NYSEO 1991). This provides the backdrop for regulatory initiatives on IRP and bidding.

\subsection{Regulatory Initiatives}

Figure 2-1 provides a chronology of major regulatory decisions in New York on integrated resource planning, bidding, and demand-side management (DSM). The New York PSC developed its policies on bidding and DSM in two major proceedings, Case 29409 and Case 28223.

Figure 2-1. Chronology of New York Regulatory and Utility Actions

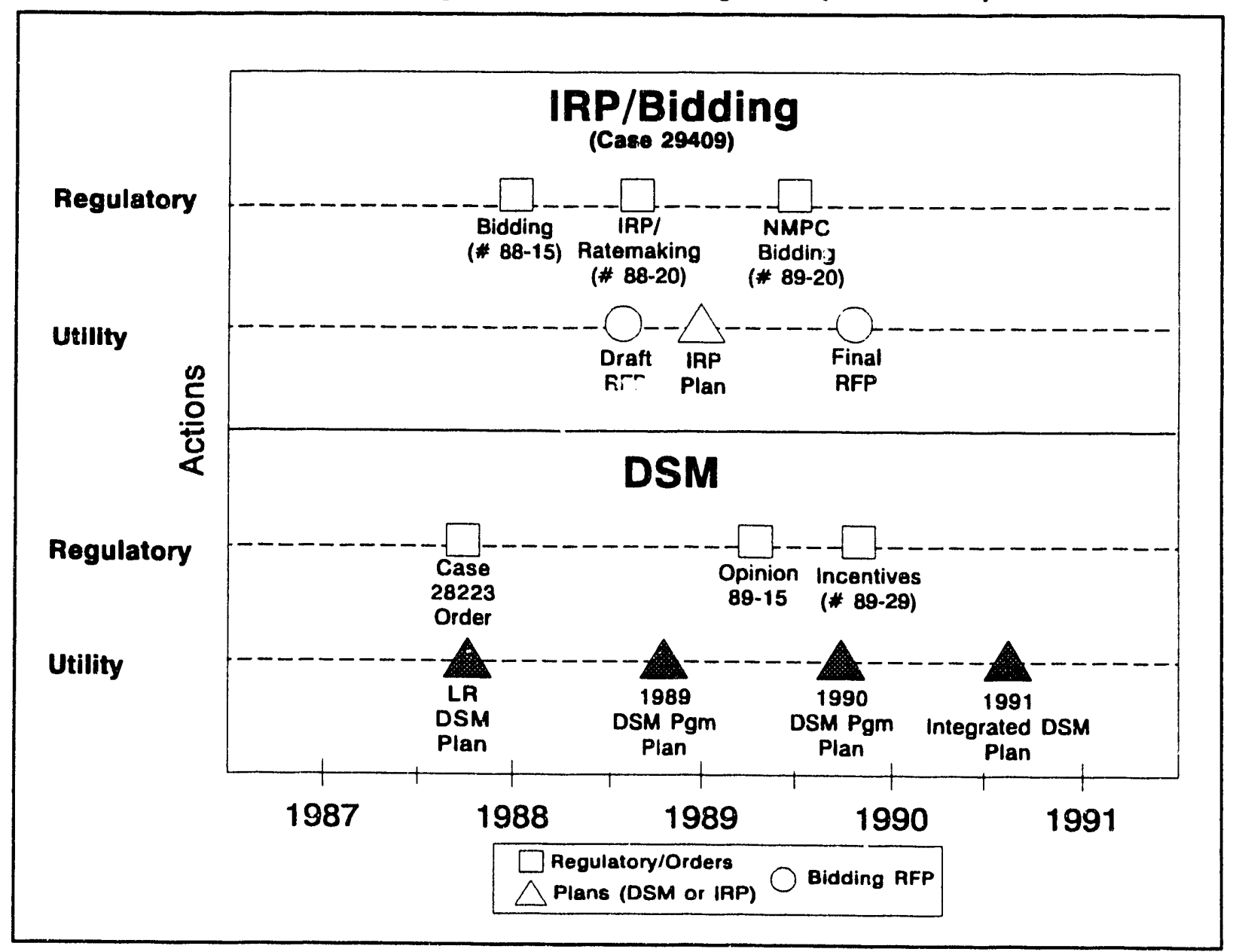

\subsubsection{PSC Activities on IRP and Bidding}

In Case 29409, the Commission investigated ways that New York's utilities could meet their future electric needs (NYPSC 1986). The format was non-adversarial and involved working groups that investigated specific issues and developed position papers on a range of topics. For 
example, working groups examined the use of competitive bidding systems, the appropriate basis for pricing power supplied by independent producers, the virtues of wholesale and retail wheeling, suggested approaches and guidelines on integrated resource planning, and ratemaking treatment of construction expenses of utility-built generation. One of the Commission's objectives was to develop an integrated resource planning framework which the utilities would then use in defining, prioritizing and selecting among various future resource options. At a minimum, the Commission wanted to ensure that utilities considered a wide range of supply-side and demand-side options on an equal basis in their planning process. In a strategic sense, the utilities and independent power producers (IPPs) were looking to establish the decision criteria as well as the rules of the game under which the next generation of utility-owned generation or non-utility generation would be built. These parties were particularly interested in resolving problems that they perceived were adversely affecting their preferred option(s). For example, utilities wanted to develop new guidelines and cost recovery procedures to mitigate the risk of disallowances for utility-built generation. IPPs wanted the Commission to establish "wheeling out" policies that would permit IPPs to sell their production outside the utility territories in which they are located.

The Commission's deliberatiuns on bidding were shaped to a great extent by existing federal and state laws (i.e., Public Utility Regulatory Policies Act [PURPA] and NY Public Service Law 66-C). PURPA obligates utilities to purchase power from Qualified Facilities (QFs) at the utility's avoided cost. ${ }^{2}$ Enacted in 1981, Section 66-C provided Qualified Facilities in New York with a guaranteed minimum purchase price of six $\mathrm{c} / \mathrm{kWh}$ for their power. In September 1987, the New York PSC adopted a policy requiring utilities to offer QFs a contract that guaranteed a levelized payment stream of six $\mathrm{c} / \mathrm{kWh}^{3}{ }^{3}$ This offer has proved quite attractive for QFs. However, most New York utilities, as well as other parties, have argued that this level of payment is excessive because avoided costs are currently much lower and future energy costs are uncertain. Moreover, utilities are concerned that the six $\mathrm{c} / \mathrm{kWh}$ guaranteed price has contributed to a glut of small power projects (NYPP 1991b). As in other states, one of the reasons that NY utilities were attracted to bidding is that they hoped it would provide a means to ration capacity offered by private producers, thus alleviating the perceived glut.

In Opinion 88-15, the Commission decided that utilities would negotiate long-term contracts with winning bidders (Fig. 2-1). However, the PSC stated that utilities were still obligated to purchase electricity from losing QFs, but the price may be limited to avoided energy costs. These contracts would be of sufficient duration so that levelized avoided energy costs would equal six c/kWh (NYPSC 1988a). The relatively attractive standard offer available to "energy-

\footnotetext{
${ }^{2}$ The incremental cost of alternative electric energy (i.e., avoided cost) is defined as the cost to the utility of the electric energy which, but for the purchase from the QF, the utility would have to generate or purchase from another source.

${ }^{3} \mathrm{~A}$ QF could receive a guaranteed stream of six $\mathrm{c} / \mathrm{kWh}$ payments for the period of time over which the present value of total payments received equals the present value of payments that would have been made at rates equal to avoided capacity and energy costs.
} 
only" QFs outside of bidding (i.e., six c/kWh levelized) has made it much more difficult for utilities to predict (and control) the level of private power development. It also affects the decision processes of private producers, who can periodically reassess the relative attractiveness of their bid price offered in a capacity bidding program compared to the long-run avoided energy cost option.

The activities of the Bidding Working Group also played an influential role in the ultimate development of the Commission's guidelines on bidding. Table 2-3 provides a summary of key events prior to the Commission's decision. The Bidding Working Group initially focused only on issues related to the selection of generation resources. The feasibility and desirability of adding a demand-side component to the bidding program, principally involving third-party energy service contractors, was proposed in the summer of 1987 by New York State Energy Research Development and Authority (NYSERDA), NY State Energy Office (SEO), and Department of Public Service staff. These state agencies were interested in testing the concept of DSM bidding in New York, influenced in part by pilot performance contracting and DSM bidding programs that Pacific Northwest and New England utilities were in the process of implementing.

Table 2-3. Origins of DSM Bidding in New York

Date

1987

Summer 1987

October 1987

December 1987

December 1987

Early 1988

March 1988
Activity

Working group focuses on supply issues

NYSERDA, SEO, and DPS propose that bidding for DSM resources be considered

Conference on bidding held

Bidding Working group identifies 15 issues for DSM bidding

ALJ recommendation on bidding: proceed with capacity bidding but DSM resources should not be included

State agencies and several intervenors active in working group file briefs opposing ALJ recommendation on DSM bidding

Workshop on DSM Bidding

Source: ERCE 1990

Proponents of DSM bidding intensified their efforts after the Administrative Law Judge (ALJ) recommended that DSM resources not be included in bidding in December 1987. Staff from various NY state agencies filed briefs opposing the ALJ's position (ERCE 1991). In Opinion 
and Order 88-15, the Commission accepted the principal argument raised by these parties, that demand-side projects should not be excluded from bidding. Specifically, the PSC decided that:

Bidders of demand-side management (DSM) projects are not precluded from participating in utilities' auctions... If DSM options are not included alongside supply-side options in a single auction, a system of separate, parallel auctions should be established. In designing the details of their specific auction processes, the utilities should set forth proposals for including DSM options in an overall auction process, or if separate auctions are required, set forth the details of the DSM auction and its links to the supply-side auction (NYPSC 1988a).

Ironically, the Commission's solution was more far reaching than that proposed by some proponents. For example, PSC staff argued that the issue of DSM bidding should be transferred to the Commission proceeding on DSM (Case 28223) for additional consideration, while the State Energy Office favored accepting demonstration bids from large commercial and industrial customers (NYPSC 1988b). Ultimately, the Commission's decision that the utilities should develop bidding processes applicable to both supply and demand-side projects comes closest to the position put forward by Pace University. The point is that the Commission's decision forced utilities and DSM bidding proponents to grapple with implementing DSM bidding on a much larger scale and faster track than anticipated (i.e., all seven utilities vs. one or two pilot demonstration programs).

The Bidding Working Group did not discuss policy and implementation issues associated with DSM bidding at nearly the same level of detail compared to supply-side options. Inclusion of demand-side projects was melded into the evolving supply-side resource acquisition framework. The Commission's guidelines on bidding, which are summarized in Table 2-4, also reflect this basic thrust directed toward supply-side considerations (NYPSC 1988a). The Commission's guidelines on eligible participants mentions only QFs and non-QF producers, while demand-side providers are discussed in the order under additional considerations. The ranking criteria refer principally to attributes that are relevant to supply-side projects. There is extensive discussion regarding conditions under which utility subsidiaries can bid as well as utility life extension projects, but utility DSM activities are not mentioned. ${ }^{4}$

\subsubsection{Evolving Regulatory Policies on DSM}

During this period, the PSC also issued a series of decisions as part of Case 28223 that required utilities to pursue cost-effective demand-side resource options more aggressively (see Fig. 2-1). In September 1987, the PSC directed utilities to submit long-range demand-side plans. In December 1988, based on a review of these initial plans, the PSC ordered utilities statewide to develop and implement eight full-scale programs called the Consumers Energy Efficiency Program (NYPSC 1988b). The program areas were to include:

\footnotetext{
${ }^{4}$ Life extension projects requiring significant capital investment should compete with third party purchases and with DSM proposals.
} 


\section{Issue}

Eligible Participants

Bid Process Evaluation and Selection

Ranking Criteria

Ceiling Price

Performance Security

Participation of

Utility Subsidiaries

Availability of Information

New Utility Generation

\section{Guideline}

QF, IPP

RFP should use objective ranking system, but utility is permitted to exercise subjective judgement

RFP should include the following factors and their weights: price, payment: stream, dispatchability, fuel diversity, location, availability of production, environmental impacts, likelihood of project completion

Cost of utility's own optimal generating plan, including price and non-price factors

Required

Participation allowed with aclditional procedural safeguards:

1) sealed bids opened by independent party

2) ratemaking adjustment on utility earnings will be imposed if unfair or abusive practice is discovered

Utility must provide information on utility system planning to IPFS on timely basis and in sufficient detail

"Supplier of Last Resort"

Source: NYPSC 1988a

- commercial/industrial (C/I) lighting efficiency incentives

- commercial high efficiency space conditioning equipment inceritives

- $\mathrm{C} / \mathrm{I}$ energy audit program

- demand management cooperatives

- residential low-income/renter electric conservation programs

- not-for-profit organization conservation programs

- consumer energy information

- innovative rate design programs (peak activated and real time rates) 
The PSC order signaled its frustration with the DSM activities of several utilities. In their initial long-range plans, most NY utilities relied heavily on load management (rather than conservation measures). Moreover, the utilities' assessment of the DSM technical and market potential was not comprehensive, and their program offerings tended mostly to be pilot and informational programs. The PSC acknowledged the potential conflict in ordering utilities to implement fullscale DSM and bidding programs:

We are proceeding to require these new statewide DSM programs recognizing that there may be a conflict between this initiative and our simultaneous steps to acquire new service capacity by means of all source bidding systems. While the all source bidding systems include provisions for acquiring DSM resources, we recognized at the outset that we do not yet know the extent to which bidding systems can effectively deliver DSM services. Accordingly, we intend to proceed with plans for utilities to design and administer the delivery of DSM services. We will observe the interplay of the two approaches and change our approach if lessons of experience indicate change makes sense (NYPSC 1988b).

Thus, the utilities were given the challenge of resolving and defining the relationship between DSM bidder's projects and PSC mandated utility DSM programs. The Commission did not provide specific guidance on this issue. However, the PSC believed that they had eliminated a major financial disincentive which could adversely affect DSM bidding by allowing NMPC to recover "lost revenues" and providing incentives to utility shareholders for successfully implementing both types of DSM activities (NYPSC 1989c).

\subsection{NMPC's Bidding Program and Integrated Electric Resource Plan}

In order to comply with the Commission's bidding orders, NMPC filed guidelines on bidding along with illustrative RFPs for supply and DSM resources in October 1988 (NMPC 1988a). ${ }^{5}$ Initially, NMPC viewed their RFP as illustrative because the need for additional resources was highly uncertain, and NMPC maintained that they had no immediate need to seek bids. The PSC order permitted interested parties to file comments and critique features of NMPC's bidding guidelines and sample contract. The company issued a revised Request for Proposals in January 1989 (New York Department of Public Service 1988). Informal meetings were then held between NMPC and interested parties in an attempt to narrow differences on remaining issues. The PSC then ruled on contested issues among the parties. In a number of areas, the Company proposed significant alterations to key elements of their original proposal in response to filed comments or negotiations with PSC staff. For example, NMPC initially proposed parallel processes for the screening and scoring of supply and DSM resources, while environmental factors were not explicitly included among bid evaluation criteria (see Table 2-5). The PSC ultimately adopted staff's proposal on environmental scoring and NMPC revised its scoring system so that the scoring criteria for DSM and supply resources were directly comparable in the first phase

\footnotetext{
${ }^{5}$ NMPC's bidding guidelines explained the company's overall resource acquisition strategy, addressed specific policy and implementation issues (e.g., treatment of Company bids), and provided the rationale for NMPC's bid evaluation and selection process.
} 
evaluation. NMPC also made changes to its DSM bidding program design based on concerns raised by PSC staff and others (e.g., threshold requirements, tailoring RFP response package so that individual customers could participate more easily).

Table 2-5. Comparison of NMPC's Initial and Final Bidding RFP

\begin{tabular}{|c|c|c|c|c|}
\hline Feature & \multicolumn{2}{|c|}{ October 1988 Draft } & \multicolumn{2}{|c|}{ November 1989 RFP } \\
\hline Resource Block Size & \multicolumn{2}{|l|}{ Unspecified } & \multicolumn{2}{|l|}{$350 \mathrm{MW}$} \\
\hline Type of Auction & \multicolumn{2}{|c|}{$\begin{array}{l}\text { Separate screening for DSM } \\
\text { and supply resources; parallel } \\
\text { 2-stage evaluation process }\end{array}$} & \multicolumn{2}{|c|}{$\begin{array}{l}\text { Integrated ranking of all-sourc- } \\
\text { es (supply and DSM) in first } \\
\text { phase }\end{array}$} \\
\hline $\begin{array}{l}\text { Bid Evaluation Criteria and } \\
\text { Relative Weights }\end{array}$ & $\begin{array}{l}\text { Price } \\
\text { Econ. Risk } \\
\text { Success } \\
\text { Longevity } \\
\text { Operational } \\
\text { Environmental }\end{array}$ & $\begin{array}{l}73 \% \\
7 \% \\
9 \% \\
3 \% \\
8 \% \\
0 \%\end{array}$ & $\begin{array}{l}\text { Price } \\
\text { Econ. Risk } \\
\text { Success } \\
\text { Longevity } \\
\text { Operational } \\
\text { Environmental }\end{array}$ & $\begin{array}{c}65 \% \\
6 \% \\
5 \% \\
2 \% \\
5 \% \\
17 \%\end{array}$ \\
\hline
\end{tabular}

\subsubsection{NMPC's Integrated Electric Resource Plan}

In February 1989, NMPC produced its first Integrated Electric Resource Plan which examined resource acquisition strategies over a 15-year planning horizon (NMPC 1989b). It is beyond the scope of this study to review the plan in detail, but we would like to summarize several points that are particularly relevant for NMPC's bidding program: the timing and size of resource additions, the proposed method(s) for acquiring the proposed resources, and assessment of DSM resources.

- First, in the plan, NMPC concluded that bidding is the preferred method for acquiring new capacity with the exception of certain resources and the company favors a time-phased acquisition strategy. ${ }^{6}$

- Second, NMPC favored issuing its first RFP in 1989 for $350 \mathrm{MW}$ in order to test the viability of the overall bidding strategy and because of potential resource needs. NMPC's analysis showed that new capacity would not be needed until 1999 in the base case scenario. Nonetheless, due to significant uncertainty surrounding IPP contributions, and in particular, the concern that IPP capacity might be much less than forecast from natural-gas-fired cogeneration facilities, the decision was made to

\footnotetext{
6 Those resources which Niagara Mohawk recommended for acquisition outside of the bidding process were re-licensing of existing hydro resources and unanticipated major repairs.
} 
hedge this bet by issuing the initial RFP calling for capacity by October 1994 . Niagara Mohawk used the low IPP forecast rather than the base forecast in determining the timing of the need for resource additions.

- Third, NMPC notes the importance of developing policies about which type of DSM programs should be implemented through bidding processes vs. programs that should be conducted directly by the Company. NMPC stated that both demand-side management and the general bidding process are new activities for the Company. Because of PSC directives, NMPC will proceed with the implementation of Company-sponsored DSM programs that will not necessarily be displaced by projects proposed by bidders. The Company envisions that both types of activities can be pursued because of "the untapped potential for DSM" (NMPC 1989b).

- Fourth, while NMPC believes that the technical potential for DSM is very large, the Company argued that DSM market potential is uncertain and possibly small. NMPC stated that "the potential savings associated with the DSM programs that passed screening in the development of this plan are small- less than $300 \mathrm{GWh}$ per year and roughly a $60 \mathrm{MW}$ reduction in winter peak load. It is not clear at this time whether substantially greater savings are possible." As a result, NMPC plans to use bidding to determine both the size and cost of the savings that are achievable.

- Fifth, we note that the resource screening method used in the IRP resembles the methodology employed in NMPC's Phase Two evaluation of projects from the Initial Award Group. In the first step, demand and supply options were separately screened. Then, demand options passing the screening were further evaluated under different scenarios and later combined as a package for scenario analysis together with the best supply options.

\subsection{Final Regulatory Determination on NMPC's Bidding Program}

As discussed previously, development of the bidding guidelines and RFP was an iterative and rather lengthy process, in which the PSC staff had significant input. In Opinion 89-20, the PSC finally approved NMPC's Bidding Guidelines and RFP and resolved contested issues between NMPC and various other parties (see Fig. 2-1). The PSC's discussion of the process for selecting the Final Award Group is worth focusing on in some detail, given the later controversy that ensued. The Commission stated:

The Final Award Group would be selected by Niagara Mohawk to produce what it considers to be the best overall mix of capacity additions and DSM measures. The company reserves the right to use judgment to select this group from among the projects in the Initial Award Group. The company anticipates that most judgments with respect to supply options would involve either identifying projects that score well in isolation but do not combine well with other projects to match capacity requirements, or selecting a diversified set of resource additions... 
The selection of the Final Award Group of DSM bidders would involve a more complex analysis. Niagara Mohawk would evaluate all DSM projects -including company-sponsored projects-in the manner outlined in its "Amendment to the 1988 Long Range Demand-side Management Plan", which was prepared in response to our decision in Case 29409.

The Commission then summarizes NMPC's proposed approach for determining the impact of DSM proposals on participating customers, non-participating customers, and the company as a whole through a cost benefit analysis. Options that failed the utility cost or total resource cost test would be rejected by the company unless they would yield exceptional non-market benefits. The Commission's discussion is illuminating because it suggests that the PSC expected NMPC to evaluate the merits of DSM bids against company-sponsored DSM programs in a consistent fashion (e.g., interpreting the various cost benefit tests in a similar manner) in its phase two evaluation.

The Decision on NMPC's bidding guidelines and RFP highlights the role played by the Commission in resolving disagreements between NMPC and other parties as well as the active role played by Commission staff and, to a lesser extent, other parties in altering NMPC's preferred approach. Our review suggests that regulatory agency staff had a strong influence in shaping key elements of the Company's bidding program. This level of involvement was deemed to be appropriate and necessary given the experimental nature and potential for controversy in competitive resource acquisition programs. 


\section{Chapter 3 \\ Design of Integrated Resource Bidding at Niagara Mohawk}

\subsection{Overview}

This chapter summarizes the key design features of the bidding program conducted by Niagara Mohawk in their first solicitation. The program was designed to accept both supply-side and DSM bids and to evaluate them on a comparable basis in two phases. The first phase employed an objective scoring system in which bidders self-scored their projects. An independent third party reviewed bid scores and ranked all projects, which formed the basis for NMPC's selection of the Initial Award Group. In the second phase the utility used various analysis techniques and its own judgement to select the Final Award Group. Most of the information presented is drawn from the competitive bidding guidelines and RFP issued by Niagara Mohawk (NMPC 1989a).

\subsection{Schedule}

Table 3-1 summarizes key milestones in NMPC's bidding program. Following issuance of the RFP, bidders were given six months to complete and submit bids. Initial Award Group winners were announced two months later after the first phase bid evaluation was completed. The second phase bid evaluation followed with the Final Award Group chosen after three months. Contract negotiations were more protracted than expected, with the last contract expected to be signed by the first quarter of 1992, 17 months after Final Award Group winners were announced.

Table 3-1. Schedule of Milestones in NMPC Bidding Program

RFP No. 1 Issued

Pre-Bid Conference

Bid Submittal Deadline

Initial Award Group Selected

Final Award Group Selected

Contracts Signed

Deadline for Project Completion
20 November 1989

15 December 1989

21 May 1990

12 July 1990

19 October 1990

first quarter of 1992 (expected)

1 October 1994

\subsection{Resource Block}

Niagara Mohawk requested $350 \mathrm{MW}$ of capacity to be in service by 1 October 1994 . Attracting $50 \mathrm{MWs}$ of winning demand-side projects was a stated goal in the RFP as well as NMPC's IRP plan. 


\subsection{Demand and Supply Integrated Auction}

Niagara Mohawk's solicitation called for both supply and demand projects to be evaluated together in an integrated auction. By design, there was no a priori allocation of the resource block between the two types of resources. Theoretically, Niagara Mohawk could have filled the entire capacity block with either supply or demand projects.

NMPC's bid scoring system, which featured parallel and consistent treatment of project attributes for supply and DSM bids and an objective ranking of projects in the first stage, was the primary mechanism used to establish the proverbial "level playing field". However, design of scoring systems is still more of an "art" than a science, and it was not obvious at the inception of the program how well the scoring "metric" would work to evaluate projects.

\subsection{Bid Evaluation and Selection Process}

NMPC relied on a two-stage bid evaluation process. The rationale for this approach was to partake of the advantages of an "open" and objective-self-scoring to produce a "short list" of projects, which would then be analyzed in more detail by NMPC in a second stage using modeling and analysis methods established by the utility. Phase Two allowed for significant utility discretion in choosing the best combination of projects.

In the first phase, developers submitted sealed bids to an independent third-party firm where they would be ranked using an objective self-scoring system (see below). NMPC then used three criteria to select a subset of bids which would enter into the Initial Award Group. The three criteria for determining the size of the Initial Award Group were:

- At least $150 \%$ of the solicited resource block (350 MW).

- At least $250 \%$ of the largest project qualifying for the Initial Award Group as per the first criteria.

- Projects scoring within 5\% of the lowest scoring project in the Initial Award Group as defined by the first two criteria will also be included. This can be expanded to include projects scoring within $10 \%$ of the lowest scoring project provided the cumulative MWs of all projects do not exceed $125 \%$ of the group size as defined by the first two criteria.

In the second phase, Niagara Mohawk evaluated projects in the Initial Award Group independently from one another and in combination with other projects under different scenarios about future load growth, fuel prices, and expectations of non-utility generation. The cumulative capacity of projects picked for the Final Award Group was to be at least $125 \%$ (i.e., $438 \mathrm{MW}$ ) of the resource block requirement, apparently to allow for the "lumpiness" of projects, and for attrition in the contract negotiation phase. 


\subsection{Scoring System}

Initially, bidders scored their proposals in response to criteria provided in the RFP. Different response packages were provided for demand and supply options; however, the primary structure and point values of the scoring system were the same for both types of resources (see Figs. 3-1 and 3-2). Adopting the nomenclature of the Bidding Working Group organized by the NYPSC, the scoring system can be broken down into categories known as "factors" as depicted in Table 3-2 (NYPSC 1991a). The scoring system uses points assigned to each factor for calculating the overall score. The number of points assigned to each factor represents the relative (nominal) weighting or valuation of that factor in choosing among projects. As discussed in Chapter 2, factor point assignments reflect one outcome of the bidding program development process in which many parties participated, including regulators, intervenors, and utility staff.

Price, with its 850 points out of a total 1310 , is by far the dominant factor (see Table 3-2). The price score is the net present value of the stream of proposed payments to the bidder calculated in relation to long-run avoided costs of NMPC (see Chapter 4 for a more detailed discussion). In practice, it was inconceivable that bidders could earn the maximum number of points because they would have to offer a zero bid price. Economic Risk, Success, and Performance or Operational factors each receive a comparable proportion of the total points (i.e., $5 \%$ to $6 \%$ ). The Economic Risk factor measures the extent to which the bid requires the utility to extend payments to bidders in advance of benefits accruing to the utility rate payers, otherwise known as "front-loading". The Success factor measures the likelihood of the project coming on-line, sometimes referred to as "project viability", while the Performance/Operational factor measures the benefits of the project to the NMPC system. Longevity, which receives the fewest proportion of points of any factor, measures the likelihood that the project will perform as promised over the contract term, also known as "persistence". The Environmental factor received the second largest block of points (17\%) after price.

While the categories and point values for scoring supply and demand projects are identical at the factor level, they differ markedly in the underlying sub-categories, known as "components" that make up those factor scores. Given the disparate characteristics of supply and demand resources, it is reasonable that the scoring system would be designed to capture and value these essential differences, even in an integrated auction. Inspection of Figs. 3-1 and 3-2 reveals how they differ, where the factor breakdown into components and their maximum point values for demand and supply bids, respectively, are presented.

Price and Economic Risk are treated similarly between supply and demand bids. In contrast, the Success factor is scored very differently for supply and demand projects. For supply projects, the major component of this factor, comprising two-thirds of the 64 points, is technical feasibility, which includes site control, engineering design, permit and licensing, and the maturity of the technology. For demand projects, over half of the points for the Success factor are defined by the project team experience. 


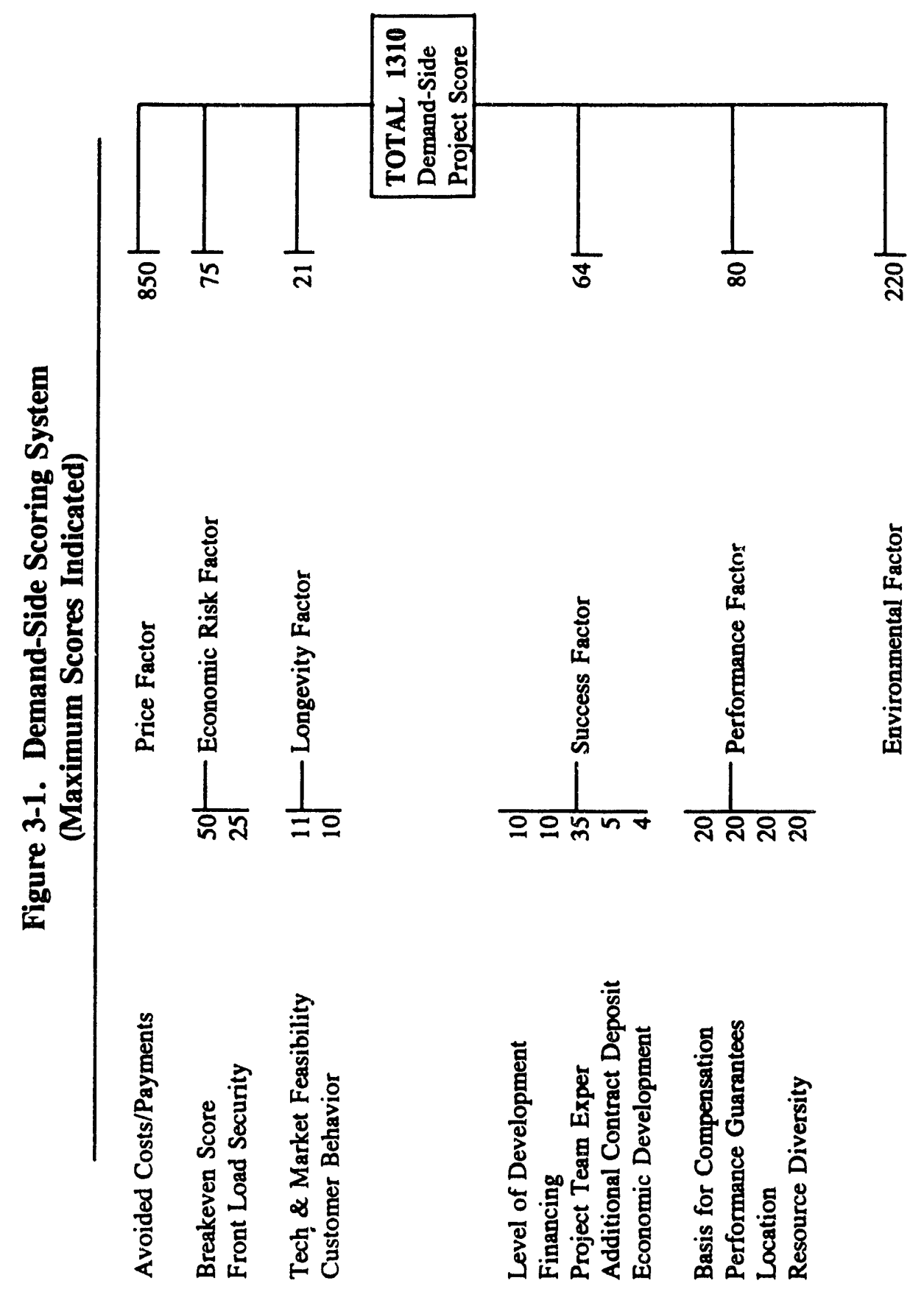



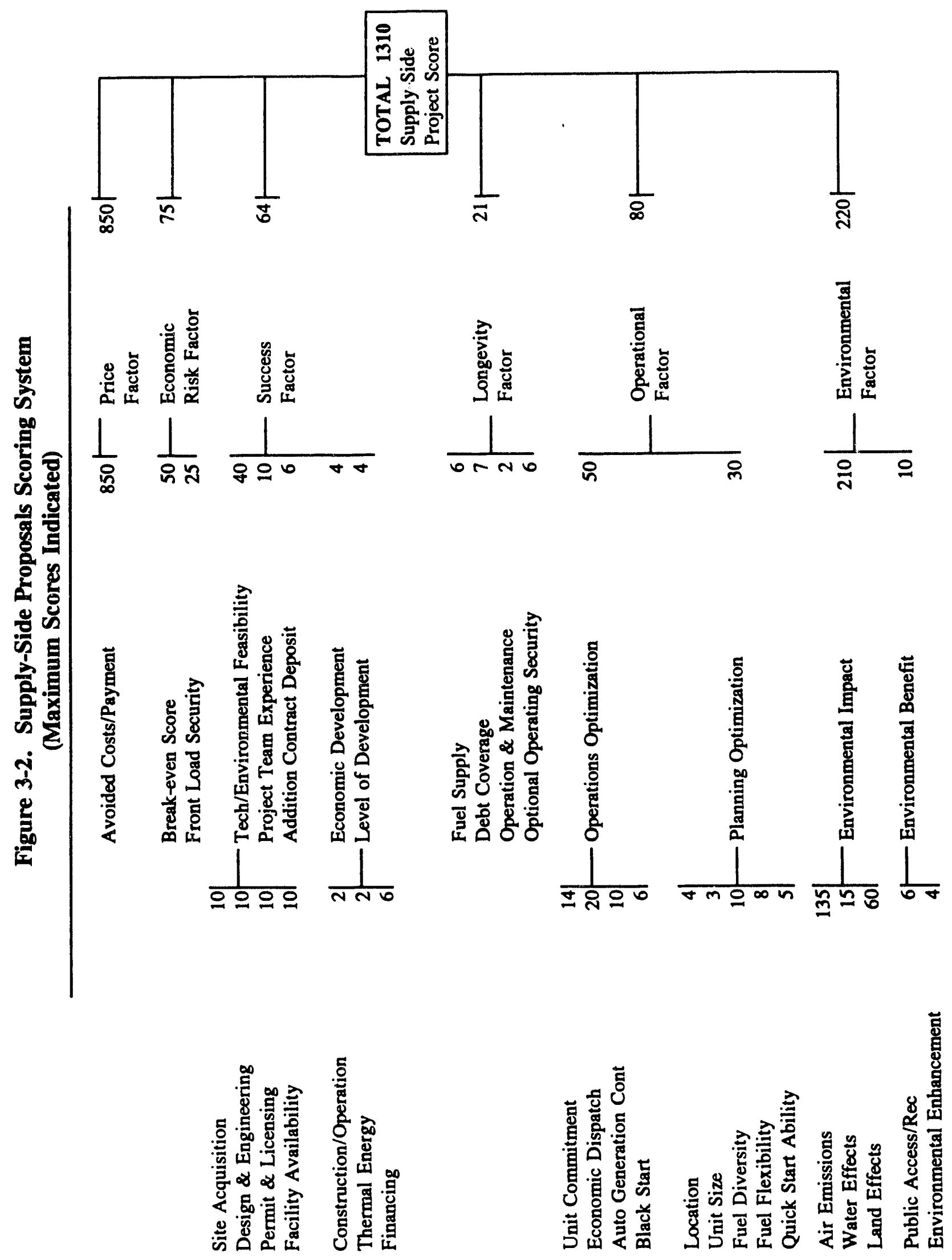
Table 3-2. Point Values in NMPC Scoring System

\begin{tabular}{lcc}
\cline { 2 - 3 } Factor & Score & $\%$ of Total \\
\hline Price & 850 & $65 \%$ \\
Economic Risk & 75 & $6 \%$ \\
Success & 64 & $5 \%$ \\
Longevity & 21 & $2 \%$ \\
Performance (demand) or & 80 & $6 \%$ \\
Operational (supply) & 220 & $17 \%$ \\
Environmental & 1310 & $100 \%$ \\
TOTAL Possible Points & & \\
\hline
\end{tabular}

The Operational factor for supply projects divides points between Operations Optimization, which addresses dispatchability concerns, and Planning Optimization, which addresses the perceived planning needs of NMPC. This same factor, called Performance for demand projects, awarded points in equal shares divided among four components: (1) for proposing compensation on measured savings over estimated savings, (2) for guaranteeing the savings, (3) for projects located in specific locations within NMPC's service territory, and (4) for conservation projects, as opposed to load-management projects.

On the supply-side, the Longevity factor included points for having solid debt coverage, for evidence of securing access to fuel, for entering into an 10-year O\&M contract, and for offering a security deposit to NMPC. For demand projects, the Longevity factor divided points equally into two components: Technical and Market Feasibility, and Customer Behavior. The former component tested whether the measure or program concept had been demonstrated elsewhere and proven successful. The latter component gave credit for designing a project that eliminated the possibility of customer "take-back" or other behavior that would lower actual savings, or that accounted for such customer interactions in the savings estimates.

\subsubsection{Environmental Scoring}

After reviewing Niagara Mohawk's initial bidding proposal, the Commission directed Niagara Mohawk to, among other things, include an environmental scoring factor and assign significant points to this attribute (NYPSC 1989). The PSC further instructed NMPC to give air emissions greater weight than land and water impacts. In the environmental scoring area, the PSC relied on an overall approach that it had adopted in approving Orange \& Rockland's bidding program. Specifically, the PSC adopted staff's estimate that the environmental mitigation cost for a coalfired plant was $1.4 \mathrm{c} / \mathrm{kWh}$ on a levelized basis (NYPSC 1989d). 
Commission staff proposed the following approach to establish the relative weight for environmental factors in the overall scoring system. They assumed that supply projects, on average, would submit price bids equivalent to $90 \%$ of long-range avoided costs (NYPSC 1989). For Niagara Mohawk, the levelized avoided cost for the period between 1989 and 2003 is 6.34 $\mathrm{c} / \mathrm{kWh}, 90 \%$ of which amounts to $5.7 \mathrm{c} / \mathrm{kWh}$ (NYPSC 1989a). Therefore, the earlier mandated $1.405 \mathrm{c} / \mathrm{kWh}$ environmental mitigation cost equals about $25 \%$ of the anticipated average price bid (i.e., $1.405 / 5.7=0.25$ ) (NYPSC 1989b). In NMPC's revised bidding system, with 850 price points available, this translates into an environmental score of 213 points, close to the 220 points ultimately assigned to the factor.

For supply projects, nearly all the points are in the Environmental Impact component, with the remainder of points available under Environmental Benefit. Within the Environmental Impact, two-thirds of the points go towards ameliorating air emissions, while land effects get $30 \%$, and water effects are assigned about $7 \%$ of the points in this category. For demand projects, the assignment of the environmental score is straighiforward. Conservation and peak clipping technologies receive the maximum score of 220. Load shifting technologies are awarded a score of 167. We discuss the actual workings of the environmental scoring system in greater detail in Chapter 4.

\subsubsection{Utility Can Bid Own Projects}

The PSC's order on bidding allowed utilities to submit bids for their own proposed projects which would undergo the same evaluation procedure as all other third party bids with some additional safeguards. One exception to this parity of treatment is that any company-sponsored project would incur a $10 \%$ premium on its price score as a penalty for the perceived risk of cost overruns associated with projects receiving traditional rate base treatment. The company indicated its intention to submit two supply-side bids in the RFP, both life extensions of existing units (Huntley 64 and 67).

\subsubsection{Eligibility, Submission, and Threshold Requirements}

Bidders were required to meet certain minimum criteria in order to qualify for participation in the bidding program. Table 3-3 outlines these requirements, many of which differed for demand or supply bids.

The minimum bid size was $2 \mathrm{MW}$ for supply projects and $100 \mathrm{~kW}$ for demand projects. The preferred contract term was for 15 years, although NMPC would consider others. All projects, whether supply or demand, were required to submit cost estimates and to substantiate them. While supply projects had the option of locating outside NMPC borders, they were required to provide proof of access to transmission to the service territory border. Supply projects were also required to submit preliminary design and engineering studies, identify all necessary permits and licenses, have plans for waste disposal, fuel, O\&M, and project management, and agree to meter the site. 
DSM projects were required to be located within the NMPC service territory. There were some restrictions on the type of demand projects that could be bid. Projects that proposed to relocate load outside the NMPC territory, or lower production (and therefore load), or involved new electricity rate designs, were ineligible. Also, any cogeneration, self-generation, or fuelswitching proposal was ineligible.

Table 3-3. Minimum Requirements for Submitting a Bid

$\begin{array}{ll}\text { Minimum Size (MW) } & 2 \text { (supply); } 0.1 \text { (demand) } \\ \text { Contract Term (years) } & 15 \text { preferred } \\ \text { Location } & \text { Within service territory (demand) } \\ \text { Design \& Engineering } & \text { (supply) } \\ \text { Permits \& Licenses } & \text { (supply) } \\ \text { Qualifying Technologies \& Programs } & \text { (demand) } \\ \text { Cost Estimation } & \text { disclosure of project costs } \\ \text { Waste Disposal Plan } & \text { (supply) } \\ \text { Management Plan } & \text { (supply) } \\ \text { O\&M Schedule } & \text { (supply) } \\ \text { Metering } & \text { (supply) } \\ \text { Fuel Plan } & \text { (supply) }\end{array}$

\subsubsection{Required Supporting Documentation}

In addition to scoring projects under the aforementioned system, bidders were required to document their assumptions and otherwise justify their self-scored choices. For supply projects this took the form of engineering design plans, site control documentation, environmental permitting 'plan, fuel contracts, operations and maintenance plans, and others. For DSM projects, the information requirements were different, including detailed cost and performance figures, assumptions about the market their proposed measures would be implemented in, measurement and verification of savings plans, to name a few. 


\section{Chapter 4 \\ Phase One Bid Evaluation Process}

\subsection{Response to the Solicitation}

Niagara Mohawk received 108 bids, totaling nearly $7300 \mathrm{MW}$. Thirty-three DSM bids were submitted for a total of $163 \mathrm{MW}$. Of the 75 supply bids offered, 26 were multiple bids at the same site, but with lower scores, leaving 49 unique supply projects. Even so, the supply-side capacity offered from this latter subset dwarfed the demand-side $-4700 \mathrm{MW}$. In the following sections, information on characteristics of supply-side bidders is based on the 49 unique projects.

Table 4-1 displays summary statistics on the scores of all 108 bids based on our analysis of the report by Burns and McDonnell (1990), NMPC's third-party evaluator. ${ }^{7}$ Scores are reported by the major bid evaluation criteria, with sub-totals for price and non-price factor scoring. The first three columns in the table show the maximum points obtainable for each factor along with the mean and standard deviation of the scores for all bids. The next column shows the coefficient of variation (COV), which is the ratio of the standard deviation to the mean score. $\mathrm{COV}$ is useful for scaling the variation in scores to the mean value and provides a relative indicator of the spread in a particular category. The last column gives the ratio of the mean score to the maximum possible points, which gives a sense of how well the group of projects was able to capture points in the scoring system.

Table 4-1. Revised Bid Scores for All Bidders (DSM and Supply)

\begin{tabular}{lccccc}
\cline { 2 - 5 } \multicolumn{1}{c}{ Factor } & $\begin{array}{c}\text { Maximum } \\
\text { Possible }\end{array}$ & Mean & $\begin{array}{c}\text { Standard } \\
\text { Deviation }\end{array}$ & $\begin{array}{c}\text { Coefficient of } \\
\text { Variation }\end{array}$ & $\begin{array}{c}\text { Mean:Max. } \\
\text { Ratio }\end{array}$ \\
\hline Price & 850 & 231 & 195 & 0.84 & 0.27 \\
Economic Risk & 75 & 62 & 26 & 0.42 & 0.82 \\
Success & 21 & 44 & 12 & 0.27 & 0.68 \\
Longevity & 64 & 13 & 5 & 0.40 & 0.62 \\
Operational & 80 & 52 & 19 & 0.37 & 0.65 \\
Environmental & 220 & 184 & 37 & 0.20 & 0.84 \\
Non-price Subtotal & 460 & 355 & 52 & 0.15 & 0.77 \\
Total Score & 1310 & 586 & 221 & 0.38 & 0.45
\end{tabular}

\footnotetext{
${ }^{7}$ The scores are based on the corrected scores as determined by Burns and McDonnell (1990) and are not necessarily identical to original scores submitted by bidders. NMPC provided this report to LBL under a confidentiality agreement in which we would not discuss the disaggregated scores and details of proposals of individual bidders.
} 
Table 4-2. DSM Bids by Type of Bidder

\begin{tabular}{lrrr}
\hline & $\begin{array}{c}\text { No. of } \\
\text { Bids }\end{array}$ & $\begin{array}{c}\text { Winter Peak } \\
\text { Savings (MW) }\end{array}$ & $\begin{array}{r}\text { Energy } \\
\text { (CiWh) }\end{array}$ \\
\hline National ESCOs & 24 & 151.5 & 1094 \\
Local ESCOs & 3 & 7.1 & 32 \\
Customers & 6 & 4.5 & 34
\end{tabular}

Table 4-3. Sectors Targeted for DSM by Bidders

\begin{tabular}{lcccc}
\multicolumn{1}{c}{ Sector } & No. of Bids & $\begin{array}{c}\text { Winter Peak } \\
\text { Savings (MW) }\end{array}$ & $\begin{array}{c}\text { Energy } \\
\text { (GWh) }\end{array}$ & $\begin{array}{c}\text { Conservation } \\
\text { Load Factor }\end{array}$ \\
\hline Commercial only & 2 & 2.5 & 4 & .23 \\
Industrial only & 7 & 18.5 & 122 & .75 \\
C\&I & 15 & 82.9 & 327 & .45 \\
Residential only & 8 & 53.4 & 275 & .59 \\
R\&C & 1 & 5.8 & 27 &...
\end{tabular}

Table 4-4. DSM Bid Size Breakdown

\begin{tabular}{cc}
\hline Winter Peak Savings & No. of Bids \\
\hline$<1 \mathrm{MW}$ & 5 \\
$1.5 \mathrm{MW}$ & 12 \\
$>5 \mathrm{MW}$ & 16 \\
\hline
\end{tabular}

Tables 4-2 to 4-4 display some characteristics of the DSM bids offered in this solicitation. The overwhelming majority of DSM bids were placed by national ESCOs (24), both in terms of the number of bids and also the savings offered. ${ }^{8}$ Niagara Mohawk customers submitted 6 bids, while local energy service companies offered 3 bids. Most projects targeted customers in both the commercial/industrial (C/I) sectors (15), but some bids focused on one or the other of these two sectors (2 and 7, respectively). Eight bidders proposed to focus exclusively on residential customers. Conservation load factors were highest for the industrial sertor bids $(0.75)$, closely

\footnotetext{
"See Chapter 6 for definitions of "national" energy service firms vs. "local" energy service providers.
} 
followed by those targeting the residential sector (0.59) (see Table 4-3). ${ }^{9}$ The lowest load factors were associated with commercial sector bids (0.23). As shown in Table 4-4, DSM projects were small, with the largest projects offering between 5-15 MW of winter peak demand savings.

Table 4-5. Revised DSM Bid Scores (All DSM Bids)

\begin{tabular}{lccccc}
\cline { 2 - 5 } \multicolumn{1}{c}{ Factors } & $\begin{array}{c}\text { Maximum } \\
\text { Possible }\end{array}$ & Mean & $\begin{array}{c}\text { Standard } \\
\text { Deviation }\end{array}$ & $\begin{array}{c}\text { Coefficient } \\
\text { of Variation }\end{array}$ & $\begin{array}{c}\text { Mean:Max } \\
\text { Ratio }\end{array}$ \\
\hline Price & 850 & 410 & 180 & 0.44 & 0.48 \\
Economic Risk & 75 & 49 & 33 & 0.67 & 0.66 \\
Longevity & 21 & 47 & 14 & 0.29 & 0.73 \\
Success & 64 & 14 & 6 & 0.43 & 0.65 \\
Performance & 80 & 58 & 14 & 0.23 & 0.73 \\
Environmental & 220 & 220 & 0 & 0.00 & 1.00 \\
Non-price & & & & & 0.12 \\
Subtotal & 460 & 388 & 45 & 0.23 & 0.61 \\
Total Score & 1310 & 798 & 185 & & 0.84 \\
& & & & &
\end{tabular}

Table 4-5 shows scores for all DSM bids. DSM bids garnered, on average, 798 points out of a total 1310. Over half of these points derived from price factor scores. In the non-price factor category, most of the points came from the environmental factor, where $100 \%$ of the possible points were achieved by conservation projects. DSM bids captured from :wo-thirds to threequarters of the possible points on other non-price attributes.

On the supply-side, the majority of bids came from developers proposing Qualifying Facilities (QFs) (see Table 4-6). ${ }^{10}$ Utility companies, including Niagara Mohawk, submitted six proposals. Independent power producers (IPPs), who are not classified as a QF under PURPA, made up the balance of bidders. Table 4-6 shows that supply bids were typically envisioned to operate as baseload projects, as evidenced by the high capacity factors.

${ }^{9}$ Conservation load factors are calculated by the formula CLF $=$ ES/ (Peak * 8760) where ES is energy savings, Peak is winter peak savings, and 8760 is the number of hours in a year.

${ }^{10}$ The QF designation originated in the Public Utilities Regulatory Policy Act of 1978 (PURPA), which set criteria for electric generating facilities whose output would be eligible for favorable treatment under the Act, notably from renewable energy and cogeneration technologies. 
Table 4-6. Supply Bids by Type of Bidder

\begin{tabular}{lcccc} 
& & & & \\
& No. of Bids & Capacity (MW) & $\begin{array}{c}\text { Energy } \\
\text { (GWh) }\end{array}$ & $\begin{array}{c}\text { Capacity } \\
\text { Factor }\end{array}$ \\
\hline QF & 29 & 3126 & 22418 & .82 \\
IPP & 14 & 1150 & 7027 & .70 \\
Utility & 6 & 451 & 3041 & .77
\end{tabular}

A diverse mix of fuels were bid by developers in this solicitation, as presented in Table 4-7. In terms of fuel choice, gas-fired projects were dominant, accounting for over half of the bids and capacity on the supply-side. Coal-fired and nuclear projects were also well-represented (eight and four bids respectively), followed by a handful of projects based on renewable fuels (hydro, biomass). In terms of the type of generation technologies, Table 4-8 shows that combined cycle was the largest category, followed by steam turbines and combustion turbines. Fluidized bed technology also constituted a sizable portion of the supply bids. Projects bid ranged in size, from $9 \mathrm{MW}$ to $300 \mathrm{MW}$, averaging $96 \mathrm{MW}$ overall. Table 4-9 displays the breakdown of supply projects binned by bid size. ${ }^{.1}$

Table 4-7. Supply Bids by Fuel Type

\begin{tabular}{lccc} 
& No. of Bids & Capacity (MW) & Energy (GWh) \\
\hline Coal & 8 & 943 & 5960 \\
Natural Gas & 27 & 2928 & 21399 \\
Oil & 1 & 96 & 170 \\
Uranium & 4 & 490 & 3584 \\
Hydro & 4 & 87 & 160 \\
Biomass & 2 & 37 & 279 \\
Refuse & 2 & 100 & 793 \\
Butane & 1 & 45 & 244 \\
\hline
\end{tabular}

\footnotetext{
"Note that in some cases bids were submitted for less capacity than the project. In these cases, the residual capacity and energy generated by the project would presumably be sold elsewhere.
} 
Table 4-8. Supply Bids by Technology

\begin{tabular}{lcccc} 
& No. of Bids & Capacity (MW) & Energy (GWh) \\
\cline { 1 - 3 } Combustion Turbine & 6 & 444 & 1766 \\
Combined Cycle & 21 & 2606 & 19892 \\
Steam Turbine & 11 & 878 & 6498 \\
Fluidized Bed & 4 & 522 & 2956 \\
Hydro Turbine & 3 & 37 & 160 \\
Reversible Hydro Turbine (PS) & 1 & 50 & $\mathrm{n} / \mathrm{a}$ \\
Pressurized Water Reactor & 1 & 50 & 329 \\
Boiling Water Reactor & 2 & 140 & 887
\end{tabular}

Table 4-9. Supply Bid Size Breakdown

\begin{tabular}{lccc} 
& No. of Bids & Capacity (MW) & Energy (GWh) \\
\hline 2-20 MW & 6 & 73 & 429 \\
$>20-80 \mathrm{MW}$ & 16 & 782 & 5061 \\
$>80 \mathrm{MW}$ & 27 & 3873 & 26997
\end{tabular}

Summary statistics for the scores received by all supply bids appears in Table 4-10. Supply projects averaged 452 points, three-quarters of which came from non-price factors. Roughly half of the non-price points were awarded for environmental factor, where supply projects were able to claim $73 \%$ of the possible points from this category. Another area in which supply bidders were especially successful in capturing available points was on the economic risk factor. Front-loading of payments to bidders is the essence of economic risk in the NMPC scoring system, and so it appears that the utility was successful in shifting this risk onto the bidders in this solicitation. In the other non-price categories, supply bids were able to capture over $60 \%$ of the available points.

The spread in factor scoring, as measured by the COV in Table 4-10, shows that price, longevity, and operational factors have the largest variation in scores among supply projects, ranging from 0.38 to 0.78 . For the other factors, the scores were more tightly distributed, most noticeably on the environmental attribute $(0.19)$. 
Table 4-10. Revised Supply Bid Scores (All Supply Bids)

\begin{tabular}{lccccc}
\cline { 2 - 5 } \multicolumn{1}{c}{ Factor } & $\begin{array}{c}\text { Maximum } \\
\text { Possible }\end{array}$ & Mean & $\begin{array}{c}\text { Standard } \\
\text { Deviation }\end{array}$ & $\begin{array}{c}\text { Coefficient of } \\
\text { Variation }\end{array}$ & $\begin{array}{c}\text { Mean:Max. } \\
\text { Ratio }\end{array}$ \\
\hline Price & 850 & 118 & 92 & 0.78 & 0.14 \\
Economic Risk & 75 & 69 & 15 & 0.21 & 0.93 \\
Success & 64 & 42 & 10 & 0.24 & 0.65 \\
Longevity & 21 & 13 & 5 & 0.38 & 0.61 \\
Operational & 80 & 48 & 21 & 0.44 & 0.61 \\
Environmental & 220 & 162 & 30 & 0.19 & 0.73 \\
Non-price Subtotal & 460 & 334 & 46 & 0.14 & 0.73 \\
Total Score & 1310 & 452 & 109 & 0.24 & 0.34 \\
\hline
\end{tabular}

The principal distinction between DSM and supply projects was on bid price: the mean price score for DSM bids was 410 points, whereas for supply bids it was 118 points. This advantage on price is the principal reason that DSM projects scored almost twice as many points on average (452 vs. 798 ) overall compared to supply projects. In addition, DSM projects also obtained a significant edge on environmental factor scores (58 points) compared to generation projects. Interestingly, average scores on the other non-price factors were comparable between supply and DSM projects. In the next section, we discuss the results of NMPC's phase one screening process in selecting a short list of Initial Award Group projects.

\subsection{Process and Outcome of Initial Screening}

Project developers submitted bids to Burns and McDonnell, an independent third-party evaluator that was retained by Niagara Mohawk. Burns and McDonnell checked to make sure that projects passed threshold and eligibility guidelines, verified that bidders had correctly scored their projects, requested additional documentation if necessary, and ultimately ranked bids on the basis of the corrected scores. ${ }^{12}$ Burns and McDonnell then provided the Initial Award Group to NMPC, following the guidelines given in the RFP (NMPC 1989a). Projects included in the Initial Award Group were then subjected to further evaluation by Niagara Mohawk in the Phase Two analysis described in Chapter 5.

\footnotetext{
12 Morgan Systems was hired by Burns and McDonnell to review demand-side bids.
} 
The Initial Award Group was comprised of 39 bids: 30 DSM bids for $140 \mathrm{MW}$ and nine supply bids for $972 \mathrm{MW}$. Overall, the capacity or winter peak savings chosen in Phase One amounted to $1112 \mathrm{MW}$. On the demand-side, all but three, or $91 \%$ of the bids passed the Phase One screen. Two of the rejected DSM projects were relatively high scoring bids (i.e., in the top five), but were proposing peak-shaving measures in combination with supply bids, and were ultimately disqualified. The other rejected DSM bid was simply low scoring. On the supply-side, the situation was quite different. Only $18 \%$ of the bids were selected for the Initial Award Group. Six out of nine projects in this group proposed gas-fired combined-cycle technology, two were hydro projects, and the remaining project was one of Niagara Mohawk's own submittals for refurbishment of an existing coal-fired plant (Huntley 67). Because of the predominance of DSM projects in the Initial Award Group, the aggregate scores closely resemble those of the DSM bids (see Table 4-5).

Figure 4-1 shows the mean scores and standard deviation in each major bid evaluation category for winning and losing supply-side projects. It is more useful to review the supply-side because the scoring system actually screened out many projects. Differences in bid price appeared to be the dominant factor in determining the outcome between winning and losing projects, while differences in environmental scores had lesser influence. Interestingly, on average, losing supply-side projects scored as well as projects selected for the Initial Award
Figure 4-1. Supply Bid Scoring in NMPC Solicitation

Initial Award Group Winners

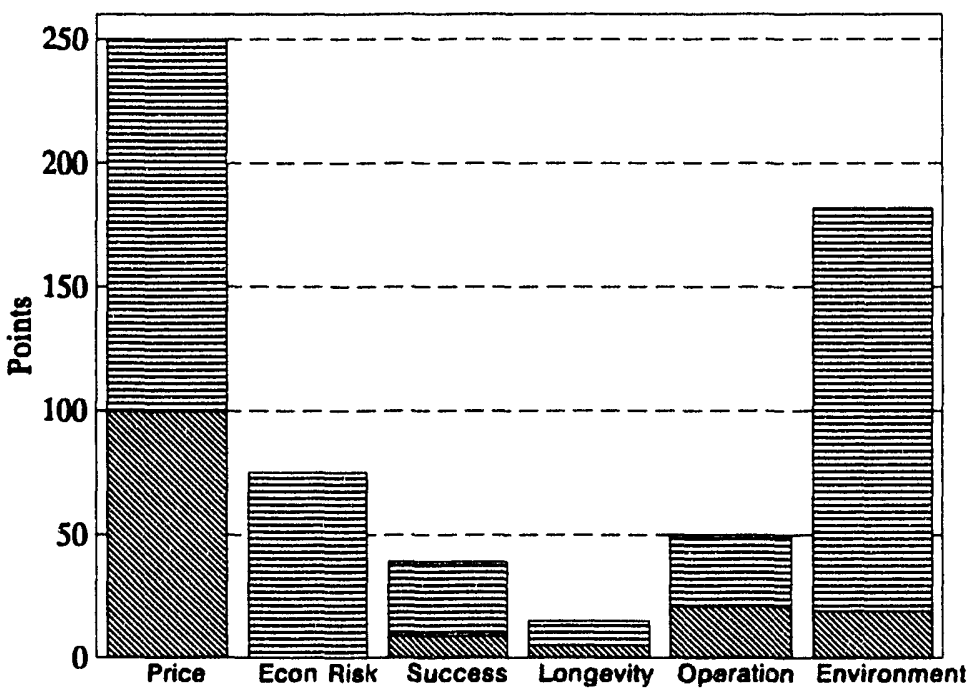

Initial Award Group Losers

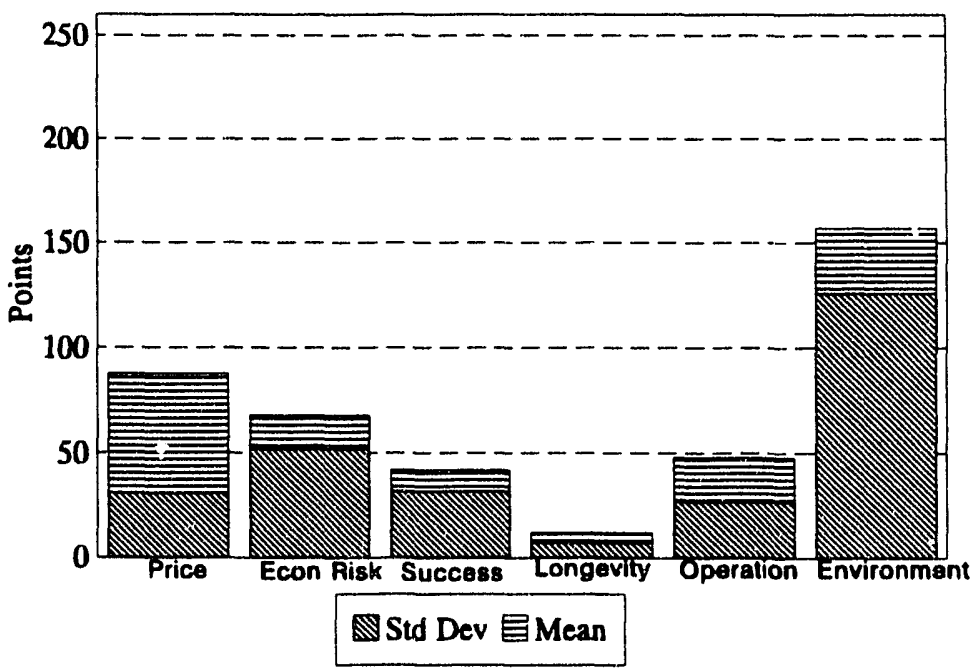


Group on factors related to economic risk, to chances for successful development and longevity, and to compatibility with utility system operation.

\subsection{Nominal vs. Effective Weights in the Scoring System}

Embodied in the design of the scoring system used by Niagara Mohawk is an implicit valuation of each factor, expressed in terms of the fraction of total points assigned to each category (i.e., relative weight). These "nominal" scoring weights are assigned with the intention of promoting projects that have the valued characteristics over those that do not (EPRI 1990). However, the assigned weight of a factor is not necessarily reflected in the ability of that factor to distinguish among projects. If all bids score similarly on a given factor, and regardless of the weight assigned by the scoring system, that factor's impact in determining the ultimate outcome of the ranking among projects is zero. If, on the other hand, there is significant variation among bid scores on a given factor, then that factor's "real" or effective weight in determining the ranking of bids will be great. ${ }^{13}$

This distinction between the nominal weights implicit in NMPC's scoring system, and the "real" weights that emerged from the actual distribution of bid scores in the solicitation can be observed in Table 4-1. NMPC's scoring system gave approximately twice as much weight nominally to price as to non-price factors ( 850 vs. 460 pts), as shown under the "Maximum Possible" points column in Table 4-1. We use the standard deviation as a measure of the variability of the factor scores. For the set of actual bids received, the absolute value of the standard deviation of the price scores is about 3.8 times the standard deviation of the non-price scores (195 vs. 52 points). Price score determined the outcome because all bidders looked more or less alike (in relative terms) on non-price factors, irrespective of the fact that the absolute level of the mean non-price score is about 1.5 times greater than the mean price score (355 vs. 231 points). Thus, differences in bid price played an even larger role in determining the outcome of Phase One than anticipated in the original RFP design.

One result that emerges from comparing Tables 4-5 and 4-10 is that DSM and supply bids were effectively separated from one another by price. By this we mean that the price scores of DSM bids were so much higher than supply bids, and non-price scores so similar in the two groups, that effectively the highest priced DSM bids competed with the lowest priced supply bids for marginal acceptance into the Initial Award Group. In reviewing the mean and standard deviation of the price scores for DSM and supply bids, we observe that the top $15 \%$ (mean plus one standard deviation) supply price scores were 210 and above, while the worst DSM price scores were 230 and below (the bottom $15 \%$, i.e., mean minus one standard deviation). As we show in section 4.4.2, NMPC's choice of price scoring metric influences these results and over-values the DSM bids which have low load factors relative to baseload supply projects.

13 In practice, scoring factors that are assigned a significant number of points may also act as an implicit threshold requirement in that bidders feel compelled to respond to the signals in the scoring system. If many points are applied to a factor, it can lead bidders to offer what is needed to receive points in that category. If all bidders respond, then the factor serves the same purpose as would a threshold requirement. 
For supply projects only, price variation is roughly twice that of non-price ( 92 vs. 46 points), which is identical to the nominal weighting in the scoring scheme (see Table 4-10). Thus, in terms of the price/non-price breakdown, the scoring system for the actual set of bids received was consistent with nominal weights in distinguishing among supply projects.

\subsection{Issues in the Phase One Process}

In the next sections, we discuss a number of problems that arose in the initial phase of the bid evaluation process and propose several areas in which the self-scoring system could be improved. Topics that are reviewed include failure of the scoring system to differentiate among DSM bids, analysis and limitations of NMPC's approach to scoring bid price, dispatchability, and environmental attributes, and apparent inconsistencies in NMPC's determination of the size of the Initial Award Group.

\subsubsection{Failure to Differentiate Among DSM Bids}

One obvious shortcoming in the scoring system was its inability to discriminate effectively among DSM bids. Our analysis suggests that this problem is principally a by-product of NMPC's decision to conduct an integrated auction with supply and DSM resources competing in a common resource block, in response to policy directives of New York's regulators. The scoring system for DSM bids was patterned after, and essentially mimicked, the categories and relative weights of its supply-side bid evaluation. Specific elements of the Phase One scoring system also bear a strong regulatory imprint as evidenced by the relative weight and scoring of environmental factors.

We believe that there were serious problems with NMPC's scoring approach for both price and non-price factors for DSM projects. Payments from the utility plus proposed customer cost contribution relative to the published long-run avoided costs (LRACs) were used to determine a DSM bidder's price score. This approach is analogous to the total resource cost (TRC) test used in the economic evaluation of DSM programs. ${ }^{14}$ However, NMPC's cost/benefit analysis in Phase Two evaluated DSM projects from several economic perspectives (e.g., utility, nonparticipating ratepayers, society). As we shall see in Chapter 5, NMPC was particularly concerned about the costs to the utility of DSM bids. In hindsight, it is apparent that DSM bidders misread the scoring signal on price implied by NMPC's sole reliance on the TRC test in Phase One (CPUC 1987). ${ }^{15}$

\footnotetext{
14 In the California Standard Practice Manual, costs included in the TRC test are the incremental cost of the measure plus utility costs to administer the program.

is It is easy to see how DSM bidder's reading the RFP would conclude that price factor scores for individual projects would be determined from avoided costs provided in the RFP; see pgs. 5, 30, 35-36 of NMPC's bidding RFP.
} 
In the future, if NMPC continues to conduct bid evaluation in two stages, then there should be an explicit linkage between the approaches used to conduct the economic evaluation in the two phases. If the utility intends to rely heavily on the Utility Cost (UC) Test, then this signal should be transmitted clearly to bidders in the RFP prior to their preparation of proposals. If a self-scoring system is used, other options for evaluating the economic benefits of DSM bids include: (1) using the TRC test as a threshold (e.g., m:' be greater than one) and relying solely on the UC test, (2) using a combination price metric wusch includes some explicit weighting of TRC and UC test - 50/50 has been proposed by regulatory staff in California (Division of Ratepayer Advocates 1991), or (3) establishing a ceiling price, which is arbitrarily set lower than the utility's avoided cost, using some other rationale (e.g., consistency with utility rebate levels).

Within non-price categories, NMPC attempted to tailor scoring of attributes to the particular characteristics of supply-side and DSM resources (see Chapter 3 ).$^{16}$ However, in many cases, the relative weights established to score individual components within a category were not appropriate for DSM projects. For example, the experience of the DSM project team was worth only $3 \%$ of the total points ( 35 of 1310 points), which seems low given the relative immaturity of the energy services industry. Ability to measure, verify and guarantee savings of installed measures is an extremely important distinguishing characteristic among DSM bidders. However, DSM bidders could obtain a maximum of 20 points, or $2 \%$ of the total, if payment was based on metered savings, and another 20 points if they guaranteed a specified amount of savings documented through metering. These weights also seem quite low, particularly in light of the fact that NMPC emphasizes measured savings based on impact evaluations in its long-range DSM plan as well as the structure of its shareholder incentive mechanism (NMPC 1990b). Scores on these non-price factors were not particularly informative to the utility on the relative merits of individual DSM projects. Points that DSM bidders earned automatically (e.g., environmental factor) plus their ability to obtain superior price scores, meant that DSM projects were able to compete very effectively against supply-side bids in the first phase ranking of bids. However, the overall framework created by NMPC's decision to offer similar point totals for each factor (i.e., success, operational) proved to be too limiting to adequately value individual attributes that were critical for evaluation of DSM projects.

It is our view that DSM bidders could have been sent clearer signals regarding the company's true preferences (as embodied in its Phase Two evaluation) if the initial DSM scoring criteria were developed separately from supply-side projects. Bid evaluation criteria should be revised to facilitate comparisons between different DSM projects. It makes little sense to use similar weights in the major non-price categories for supply-side and demand-side options. This approach emphasizes form over content, in an attempt to ensure consistent treatment of all resource options. At this early stage of development, we believe that the design of DSM

\footnotetext{
${ }^{16}$ For example, in the longevity factor, the criteria for supply-side projects focused on evidence of fuel supply, provisions for O\&M, and additional operating security. In contrast, for DSM projects, bidders could receive maximum points if they could demonstrate that there would be no customer "snapback" effect that would reduce savings and if the program concept had been demonstrated in another utility's bidding program.
} 
competitive procurements and bid evaluation criteria should emphasize those factors that are critical to the deployment and achievement of long-term demand and energy savings: reasonable bid price, qualifications and experience of firms, technical expertise in installing and maintaining DSM technologies, market research and program design tailored to customer needs, types of financing arrangements offered to customers, and plans for measuring and verifying energy savings.

\subsubsection{Limitations of Ratio Price Scoring}

NMPC used a variant of the ratio scoring approach to evaluate the price offers of supply-side and DSM bidders in Phase One. The ratio score is also known as the "percentage of avoided cost" method for ranking bid prices. In this approach, the present-value of the bid price is compared to the present-value of avoided cost, and their ratio is the figure-of-merit for assigning price points. For all the apparent simplicity of this approach, it potentially neglects the role of dispatchability, and contains inherent bias against baseload bids. We will discuss these two issues, which are in fact linked, in this section. We begin with a description of the NMPC Phase One procedure for calculating price score, and then discuss its limitations.

\section{Treatment of Price in NMPC's Scoring System}

NMPC uses annual estimates of on-peak and off-peak avoided cost as the standard of value. This is expressed in units of $\mathrm{c} / \mathrm{kWh}$. Bidders offer prices (also in $\mathrm{c} / \mathrm{kWh}$ ) for each period in each year and indicate an availability for their project. Using the bidder's estimate of project availability, a total project payment and avoided cost for the same amount of power is computed for each year. Price points are assigned using the following formula (taken from Evaluation Sheet 5, NMPC 1989a).

$$
\text { Project Price Score }=[(\mathrm{AC}-\mathrm{Bid}) / \mathrm{AC}] * 850
$$

where AC is the present value of avoided cost adjusted for the bidder's availability, and Bid is the present value of bidder's payments.

This formula is equivalent to,

where Ratio $=\mathrm{Bid} / \mathrm{AC}$.

$$
\text { Project Price Score }=[1-\text { Ratio }] * 850
$$

Equation (2) simply says that the lower a bidder's ratio of payments to the utility's avoided cost, the more points received, up to a limit of 850 points if power is offered for free (i.e., Bid Price $=0$ ).

The Phase One evaluation system treats dispatchability issues separately from price under the heading of the Operational Factor (Evaluation Sheet 11). This factor is sub-divided into four components: (1) unit commitment, (2) dispatch, (3) automatic generation control (AGC), and 
(4) black start ability. The maximum point score for these components is 14 for unit commitment, 20 for dispatch, 10 for AGC and 6 for black start. NMPC's Phase Two evaluation, which used the PROMOD simulation model, could develop 'economic valuations that reasonably integrate unit commitment and dispatch with price. AGC and black start ability are not easily evaluated using production simulation models. For analytic purposes, it is convenient to refer only to those project features which can be evaluated using simulation models as "dispatchability". By this definition, NMPC assigns 34 points to these features, or about $4 \%$ of avoided cost (i.e., 34 points out of 850 total price points).

\section{Options for Incorporating Dispatchability in Self-Scoring Systems}

The price and dispatchability components of the NMPC Phase One method are inconsistent with one another if bidder's offer any significant operational flexibility. In such a case, the amount of annual production from a project is not determined by its availability alone, but also depends upon its price. In particular, the relevant price is the variable component, corresponding to fuel and variable operating and maintenance cost. In most private power contracts where suppliers provide operational flexibility, the bid price is specified as a fixed capacity component and a variable operating component (Kahn 1991). The NMPC price specification in Phase One recognizes the inconsistency explicitly in Appendix A of the Response Package for Supply Options, Section 2.1.2 (f). In this section, supply-side bidders proposing dispatchable projects are told that they must "explain fully the assumptions used and stipulate peak and off-peak production". It is, of course, difficult or impossible for the bidder to give any reasonable estimate of peak and off-peak production without further information from the utility. No bidder can reasonably estimate how much their project will operate unless they have information on the estimated operation of utility generators which have variable costs near the price they have bid.

One example of a self-scoring bid evaluation system which incorporates dispatchability more coherently than the NMPC Phase One approach is the method used by Jersey Central Power and Light (JCPL) in their 1990 Capacity RFP (JCPL 1990). JCPL's method relies upon marginal cost duration curves to estimate simultaneously the operation and avoided energy cost associated with a variable price bid of any particular level. We will briefly explain their approach.

A marginal cost duration curve can be derived from standard production simulations to characterize the structure of marginal energy costs in a load duration curve framework. Technical definitions are given in Bloom (1984) and illustrations and examples in Kahn (1988). Given such a curve, one can easily estimate the dispatch and avoided cost associated with a variable bid price at any level. Any dispatchable bid will be optimally operated only up to the point where its variable price equals the system marginal energy cost. The marginal cost duration curve can be used to estimate how large a fraction of the simulation period that will be. The avoided cost benefits to the utility associated with the dispatch of such a bid are simply the area under the cost duration curve and above the line representing the bid price. This area, shown in Fig. 4-2 for a hypothetical marginal energy cost duration curve and bid price, $\mathrm{B}_{\mathrm{i}}$, with a variable cost of $5.5 \mathrm{c} / \mathrm{kWh}$, represents the value saved by displacing high cost units with the 
dispatchable bid. This method simultaneously determines both the operation and energy value of dispatchable bids.

The JCPL implementation of this method is not without some controversy. They required bidders to use difficult software supplied by the utility to perform these calculations for a number of scenarios. Details associated with the JCPL estimation of these curves are also questionable. The general approach, however, is reasonable.

\section{Ratio Price Scoring is Biased Against Baseload Projects}

The issue which is of most importance for our purposes, however, is the use of a more accurate measure of value for the overall figure of merit. JCPL, like NMPC, used a ratio of bid price to avoided cost to assign price points in its overall evaluation system. This choice was essentially constrained by the stipulation governing bidding in New Jersey that required ratio scoring (NJBPU 1988). We argue below that ratio scoring is systematically biased against baseload bids. Therefore, the careful effort to improve the estimate of dispatchable operation and the true associated avoided costs is wasted by the introduction of a biased metric at the end of the process. This argument is developed mathematically and illustrated by example in Stoft and Kahn (1991). Here we give the intuitive explanation of these results.

Consider two supply bids, call them A and B, which are both dispatchable but differ considerably in their optimal dispatch. Let us call Bid A peaking bid and Bid B : baseload bid. Further, we normalize all costs and values to a per $\mathrm{kW}$ basis to eliminate effects due to potential size differences. Bid $\mathrm{A}$ has a high variable cost and avoids higher energy cost for a relatively few hours per year. Therefore, its total cost and its avoided cost (per $\mathrm{kW}$ ) are relatively low. Conversely, Bid B has a low variable cost and avoids much higher cost energy for many thousands of hours per year. Therefore, its total cost and its avoided cost (per $\mathrm{kW}$ ) are high. Now suppose that both bids have the same ratio score. For concreteness, suppose that the price score is 0.9, which for Bid A means a bid price of 90 and an avoided cost of 100, and for Bid $B$, a bid price of 450 and an avoided cost of 500, as depicted in Table 4-11. In this case, the baseload bid will actually provide many more dollars per $\mathrm{kW}$ benefits than the peaking bid since the difference between the two large numbers (avoided cost and total bid cost) is greater than the difference between the two corresponding but much smaller numbers for the peaking bid; 
i.e., 50 is greater than 10. Essentially, the ratio scoring method suppresses the differences in optimal operating duration and thereby sacrifices the benefits of long duration, i.e., baseload bids. For example, suppose that our illustration were modified slightly so that Bid A cost only 89. Then the ratio scoring rule would say to accept Bid A whose benefits were 11 and to reject Bid B whose benefits were 50 .

Table 4-11. Comparison of Two Hypothetical Price Bids

\begin{tabular}{lllll} 
& Bid Price $(\$ / \mathrm{kW})$ & $\begin{array}{l}\text { Avoided Cost } \\
(\$ / \mathrm{kW})\end{array}$ & Price Score & Net Benefits \\
\hline Bid A & 90 & 100 & 0.9 & 10 \\
Bid B & 450 & 500 & 0.9 & 50 \\
\hline
\end{tabular}

It is important to note that this argument also carries over to DSM bids which operate at low load factors compared to typical baseload supply projects. For example, a DSM bid targeted to a commercial sector end use saves energy for only 3,000 hours per year, which would be roughly half the operation of a baseload supply hid. Now suppose that both bids score $90 \%$ of avoided cost. Then adapting the Table 4-11 example to this case suggests that the net benefits from the DSM bid would be roughly half that from Bid B (or $\$ 25 / \mathrm{kW}$ rather than $\$ 50 / \mathrm{kW}$ ). This result suggests another reason why there was no effective competition between DSM and supply bids, which were primarily baseload projects.

The methodological question of the correct price metric is not confined to Phase One. The Phase Two evaluation relies to some extent upon benefit/cost (B/C) ratios. B/C ratios are just the inverse of the "percentage of avoided cost" on which Phase One is based. Other metrics are also introduced in Phase Two. The choice of metric is discussed further in Chapter 5. By the argument just given, however, it is clear that where dispatchability is significant, the better metrics involve direct estimates of absolute dollar benefits rather than ratios.

\section{NMPC's Self-Scoring System May Undervalue Dispatchability}

We conclude this discussion by examining how well the points assigned to dispatchability in the Operational Factor Score correct for the limitations of the Price Score. While there is no definitive answer to this question, we can develop an order of magnitude estimate of their effect. As indicated above, the two components of the Operational Factor Score that are most easily represented in production simulation models, commitment and dispatch, account for 34 points maximum. This is $4 \%$ of avoided cost. Comparing this to simulation studies conducted by LBL, we believe that the weight is too low (Kahn et al. 1990).

Using detailed chronological simulation techniques, we examined a sample of private power contracts containing limited dispatch flexibility in detail from various utility bidding solicitations. 
For cases where the supplier provided unlimited unit commitment, but severely constrained dispatch, we found that the constraint corresponded to a cost penalty of 5-12\% of bid price. Since bid price is usually near $90 \%$ or more of avoided cost, these cost penalties would approximate the value of eliminating dispatch constraints. In the NMPC evaluation of dispatch, the full 20 points is awarded for full dispatch and only eight points where bidders impose significant constraints. The value of eliminating dispatch constraints is therefore 12 points or $1.4 \%$ of avoided cost. Compared to the LBL research, this is between four and eight times too low (Kahn et al. 1990).

The value of operating flexibility is typically correlated with operating cost. The higher values correspond to projects with high operating cost, and vice versa. The intuition behind this correlation is clear. High operating costs are only justified if they provide the utility with flexibility. This means that projects which are intermediate load or peaking in their optimal operation are more under-valued by the NMPC Phase One evaluation system than baseload projects. Interestingly, the effect of the under-valuation of dispatchability runs in the opposite direction than the problem due to ratio scoring. The first works against low capacity factor bids, the second works against high capacity-factor bids.

In conclusion, the Phase One evaluation of price is relatively confused. The ratio score neglects any serious consideration of dispatch. Even in a self-scoring system, such as the one used by JCPL, much better information can be conveyed to bidders about the value of operating flexibility. The use of "add-on" points for dispatch and unit commitment corrects the problem only to a very limited degree. We have argued that the ratio score is biased against baseload bids. The low weight given to dispatchability works against peaking or intermediate projects. Just because these two limitations work in opposite directions, however, is no reason to argue that the system is neutral. Rather it is uninformative.

Most of the problems identified in this section are solvable by using production simulation models. This is the basis of NMPC's Phase Two approach. Phase One is designed to identify only the most promising bids, however, it is not reassuring to find such poor approximations at this stage. Even if better methods are used in Phase 'Two, it is possible that errors in Phase One bid evaluation eliminated a project that would look even better with more accurate analysis. There is also an issue in Phase One of providing clear signals to bidders. The philosophy of selfscoring systems is based on the notion that efficiency of procurement improves if the bidders know the evaluation criteria clearly. We have shown that the Phase One system for price does not meet such a test and could be improved.

\subsubsection{Effective Weights of Environmental Factors}

In this section, we examine the actual workings of the environmental scoring system. One area in which New York's overall approach to bidding broke new ground was the explicit incorporation and significant weight assigned to environmental factors. Environmental factors accounted for the majority of non-price points, and thus were an important area of competition among projects, both among supply bids and between supply and DSM bids. The NYPSC intended that 
the maximum differential of 220 points in the environmental category of Niagara Mohawk's bidding system correspond to an environmental credit of $1.4 \mathrm{c} / \mathrm{kWh}$ for a clean, pollution-free technology over the least acceptable technology in terms of environmental impacts (i.e., highest pollution emitting). The PSC defined this latter technology as a coal unit which met Federal New Source Performance Standards (NSPS). In order for this credit to apply, two conditions must be met: (1) price bids must be $90 \%$ of avoided cost, and (2) some supply-side bid must receive zero environmental points. In this section we show that the second condition was not met in practice. This problem was inherent in the design of the scoring system, and thus the effective weight of environmental factors in the implementation of the NMPC scoring system proved to be lower than their nominal weight. In this discussion, DSM in the form of conservation (as opposed to peak-shaving or load-building measures), serves as a proxy for the Commission's clean technology.

The average supply-side price bid in Niagara Mohawk's auction was $86 \%$ of long-range avoided costs (LRACs). Therefore, the PSC estimate that price bids would average $90 \%$ of LRACs proved to be reasonably accurate. Environmental factor scores ranged from 72 to 216 points out of the maximum of 220 points among the 49 supply-side bids. The lowest scoring bid received over $30 \%$ of the available points in the environmental factor category. In the next sections, we explore to what extent this result was inherent in NMPC's design of the scoring of environmerta' factors and/or a byproduct of supply bidder's attempts to develop projects that responded to the utility's preferences as represented by the scoring system.

\section{Environmertal Scores for Hypothetical Plants Meeting NSPS}

To arswer these questions, we first asked how many environmental points hypothetical gas and coal-fired plants which minimally met NSPS would receive in the NMPC scoring system. ${ }^{17}$ The allowable $\mathrm{SO}_{2}$ and $\mathrm{NO}_{\mathrm{x}}$ limits in NSPS are based on fuel type. The standards are given as pounds of allowable emissions per MBtu of input fuel consumption. Applying heat rates for a given technology (EPRI 1986) converts these emissions factors into the lbs/MWh units used in the NMPC scoring system to assign environmental points. $\mathrm{CO}_{2}$ emission levels for conventional plants are calculated in the same manner using data from Koomey (1990).

As shown in Table 4-12, coal-fired powerplants meeting NSPS automatically get $25 \%$ of the possible points for $\mathrm{SO}_{2}, \mathrm{NO}_{\mathrm{x}}$, and $\mathrm{CO}_{2}$ in NMPC's scoring system. The scores for gas-fired powerplants depend on the type of technology because of significant differences in average heat rates. Combined cycle plants automatically receive $71 \%$ of the possible environmental points for $\mathrm{SO}_{2}, \mathrm{NO}_{x}$, and $\mathrm{CO}_{2}$, while lower-efficiency combustion turbines receive $59 \%$. It is worth noting that the scoring system appears not to differentiate well for $\mathrm{CO}_{2}$ emissions between gas and coal-fired plants meeting NSPS, despite the fact that coal-fired plants emit almost twice as much $\mathrm{CO}_{2}$ per unit energy.

\footnotetext{
${ }^{17}$ We focus on gas and coal fired technologies because they represent most bids.
} 
Table 4-12. Environmental Scores for Hypothetical Plants Meeting NSPS

\begin{tabular}{|c|c|c|c|c|c|c|c|c|c|}
\hline \multirow[b]{2}{*}{ Technology } & $\begin{array}{l}\text { NSPS } \\
\text { (lb/M }\end{array}$ & $\begin{array}{l}\text { Stand } \\
\text { tu) }\end{array}$ & & \multirow[t]{2}{*}{$\begin{array}{l}\text { Heat } \\
\text { Rate } \\
\text { (Btu/ } \\
\text { kWh) }\end{array}$} & \multicolumn{3}{|c|}{$\begin{array}{l}\text { Environmental Points } \\
\text { for Meeting NSPS }\end{array}$} & \multirow[t]{2}{*}{$\begin{array}{l}\% \text { of } \mathrm{SO}_{21} \\
\mathrm{NO}_{x} \text { and } \\
\mathrm{CO}_{2} \text { Points }\end{array}$} & \multirow[t]{2}{*}{$\begin{array}{l}\text { \% of } \\
\text { Total } \\
\text { Env. } \\
\text { Points }\end{array}$} \\
\hline & $\mathrm{SO}_{2}$ & $\mathrm{NO}_{x}$ & $\mathrm{CO}_{2}$ & & $\mathrm{SO}_{2}$ & $\mathrm{NO}_{x}$ & $\mathrm{CO}_{2}$ & & \\
\hline Fluidized Bed & 0.6 & 0.6 & 57 & 10000 & 7 & 16 & 9 & 25 & 35 \\
\hline Steam Turbine & 0.6 & 0.6 & 57 & 9660 & 7 & 16 & 9 & 25 & 35 \\
\hline Combined Cycle & 0.0 & 0.2 & 30 & 8390 & 35 & 48 & 9 & 71 & 67 \\
\hline $\begin{array}{l}\text { Combustion } \\
\text { Turbine }\end{array}$ & 0.0 & 0.2 & 30 & 13800 & 35 & 32 & 9 & 59 & 60 \\
\hline
\end{tabular}

To estimate total scores on all environmental factors, we added in the average scores of actual bids in the other categories (i.e., particulates, land impacts, and water impacts) to our hypothetical coal and gas projects. The hypothetical coal project that met NSPS would then receive 76 out of the maximum 220 points (35\%). Using NSPS as the lower bound of permissible pollution characteristics for a supply bid, the maximum net environmental credit for conservation is the difference between the hypothetical NSPS plant(s) score and the full 220 points that conservation is awarded. As compared to coal technologies, the DSM credit is 65$75 \%$ of the $1.405 \mathrm{c} / \mathrm{kWh}$ value, which indicates that the scoring system, as designed, reduced the maximum value of environmental credits to between $0.91-1.05 \mathrm{c} / \mathrm{kWh} .{ }^{18}$

\section{Environmental Scores for Actual Supply Bids}

Our analysis also suggests that bidders responded to the significant number of points for environmental factors by proposing projects that exceeded minimum requirements. In Table 413, we present average environmental scores by component (i.e., air, water, and land) disaggregated by fuel (gas, coal) and technology type. On average, gas-fired projects had higher environmental scores than coal-fired projects (168 vs. 126 points). Environmental scores were quite varied for both coal and gas-fired projects. Scores ranged between 72 and 169 points for the eight coal projects and 129 to 202 for the 28 gas-fired projects.

${ }^{18}$ The lower value includes all environmental factors for the coal projects while the upper value includes only $\mathrm{SO}_{\mathrm{x}}, \mathrm{NO}_{\mathrm{x}}$, and $\mathrm{CO}_{2}$ factors (and assumes that a project could get zero points on the other factors). 
Table 4-13. Average Environmental Scores of Supply-Side Technologies

\begin{tabular}{lcccccccc} 
& Env. & Air & $\mathrm{So}_{x}$ & $\mathrm{No}_{x}$ & $\mathrm{CO}_{2}$ & Part. & Water & Land \\
\hline & $(220)$ & $(135)$ & $(35)$ & $(80)$ & $(15)$ & $(5)$ & $(15)$ & $(60)$ \\
All Supply: & 162 & 106 & 31 & 63 & 8 & 3 & 14 & 37 \\
\hline Coal: & 126 & 81 & 20 & 52 & 6 & 2 & 12 & 31 \\
$\begin{array}{l}\text { Fluidized Bed } \\
\text { Steam Turbine }\end{array}$ & 126 & 88 & 18 & 56 & 12 & 2 & 14 & 23 \\
\hline $\begin{array}{l}\text { Gas: } \\
\text { Combined }\end{array}$ & 168 & 110 & 35 & 65 & 7 & 4 & 14 & 37 \\
$\begin{array}{l}\text { Cycle } \\
\text { Combustion }\end{array}$ & 167 & 110 & 35 & 65 & 7 & 4 & 14 & 37 \\
\begin{tabular}{l} 
Turbine \\
\hline
\end{tabular} & 172 & 112 & 35 & 68 & 5 & 4 & 15 & 41 \\
\hline
\end{tabular}

Table 4-13 shows that coal-fired and gas combined cycle bidders proposed projects that far exceeded minimum requirements. For example, the average coal project received about $57 \%$ of the total environmental points compared to $25 \%$ for a hypothetical NSPS coal plant, and the average gas combined cycle bid received $76 \%$ of the total environmental points. Thus, in practice, conservation bids had only a relatively small advantage over winning supply projects, which were relatively "clean".

In some categories (e.g., water, land, and $\mathrm{CO}_{2}$ ), differences between gas and coal-fired projects were quite small. Some results of the environmental scoring appear anomalous when disaggregated by type of technology. Average environmental scores were comparable for fluidized bed combustion plants and standard steam turbines (see Table 4-13). For gas, combined cycle plants are generally $50 \%$ more efficient than standard combustion turbines. Since less fuel is burned per unit of electricity produced, we would expect combined cycle plants to score higher across all emissions categories, but this was not the case.

In some cases, the points awarded do not seem to match the basic characteristics of the technologies. The most obvious anomaly is that fluidized bed coal plants scored better on $\mathrm{CO}_{2}$ emissions than gas plants and dramatically higher than standard coal-fired steam turbines. No commercially viable technology exists for controlling $\mathrm{CO}_{2}$ emitted at the site. Generally speaking, fluidized bed technology using coal has comparable $\mathrm{CO}_{2}$ emissions to standard coal steam turbines, and produces roughly twice the $\mathrm{CO}_{2}$ per unit of energy as gas-fired technologies. It appears that either the scoring system failed to distinguish the emissions characteristics of plants for $\mathrm{CO}_{2}$, or that errors in using the scoring system were not detected in the bid evaluation process. 
Theoretically, bidders could in principle trade off advantages in environmental points by raising their price bid. We conducted exploratory statistical analysis to see if this hypothesis could be observed in the actual bid data, but found that there was no statistically significant positive correlation between environmental score and price.

\subsubsection{Pitfalls of the Environmental Scoring System}

In this section, we critique the use of a binned range of values to assign points for each environmental factor. We limit our discussion to the scoring of air emission impacts, because these attributes constituted the majority of possible environmental points. We also discuss asymmetric treatment of power plant refurbishments compared to new IPP projects.

\section{Implementation of Intended Approach: Bins vs. Linear Scales}

NMPC established six bins to encompass the range of sulfur oxide, nitrogen oxide, carbon dioxide, and particulate emissions. Each bin represents a range of emissions in $\mathrm{lbs} / \mathrm{MWh}$ unique to that pollutant, and has a point value from zero to five points. In addition, each pollutant is assigned a weight, with particulates receiving the lower weight of one and $\mathrm{NO}_{\mathrm{x}}$ receiving the highest weight of sixteen. To arrive at the score for emissions of a particular pollutant, the bidder multiplies the bin point value by the relative weight. This describes the mechanics of calculating environmental scores. Before explaining the distortions that such an approach introduces, it is necessary to review briefly the basis for environmental scoring instituted by the regulators in New York.

The PSC adopted two guidelines that shaped the development of NMPC's scoring of environmental factors: (1) a base NSPS coal plant should receive zero points, and (2) emissions should be valued according to the cost of pollution abatement (Putta 1990). These two rules plus the formula for establishing the value of points in monetary units are sufficient to determine unambiguously the environmental scoring formula. The first rule is necessary but not critical because some zero-point must always be established in monetizing a non-price factor, but its value is inconsequential. The second rule contains all of the economic content.

By monetizing the points in the scoring system, we can deduce the implied formula for each pollutant. First, we determine the implied value of price points. In the NMPC scoring system, 850 price points are given to a project charging zero $\mathrm{c} / \mathrm{kWh}$ and zero price points are given to a project charging full avoided cost of $6.34 \mathrm{c} / \mathrm{kWh} .^{19}$

By taking the difference between these two projects, the formula for calculating the price score implies,

$$
\begin{gathered}
850 \text { points }=6.34 \mathrm{c} / \mathrm{kWh} \\
1 \text { point }=7.458 \mathrm{c} / \mathrm{MWh}
\end{gathered}
$$

\footnotetext{
19 This is the levelized avoided cost for Niagara Mohawk for the period between 1989 and 2003, and thus represents the best before-the-auction guess at the avoided cost of the average bid.
} 
Second, we use the damage values assumed for each pollutant (see Table 4-14) and express them on a per pound basis. For example, the costs of abatement for $\mathrm{SO}_{2}$ are $\$ 832$ per ton, which is equivalent to saying that 1 pound of $\mathrm{SO}_{2}$ costs $\$ 0.416$. We then divide by $\mathrm{MWh}$ to express the environmental attribute in the same terms as price score formula.

$$
\begin{gathered}
1 \text { pound } \mathrm{SO}_{2} \text { reduction }=\$ 0.416 \\
1 \text { pound } \mathrm{SO}_{2} / \mathrm{MWh}=\$ 0.416 / \mathrm{MWh}
\end{gathered}
$$

We can convert $\$ 0.416 / \mathrm{MWh}$ to points by substituting and combining results from Equations 4 and 6.

Combining Equations (4) and (6):

$$
1 \text { pound } \mathrm{SO}_{2} / \mathrm{MWh}=5.58 \text { points }
$$

The result is that 1 pound of $\mathrm{SO}_{2}$ is worth 5.58 points.

Table 4-14. Emissions Abatement Costs Adopted in New York

$\begin{array}{rr}\mathrm{SO}_{x} & \$ 832.00 / \text { ton } \\ \mathrm{NO}_{x} & \$ 1832.00 / \text { ton } \\ \mathrm{CO}_{2} & \$ 1.10 / \text { ton }\end{array}$

Source: Putta 1990

We now take into account that a base NSPS coal plant with a heat rate of $10,000 \mathrm{Btu} / \mathrm{kWh}$ produces about six pounds of $\mathrm{SO}_{2} / \mathrm{MWh}$. Thus, a power plant with zero $\mathrm{SO}_{2}$ emissions should receive 33.5 points more than the base NSPS coal plant. Formally,

$$
5.58 \text { points } * 6 \text { pounds } \mathrm{SO}_{2} / \mathrm{MWh}=33.5 \text { points }
$$

Using Equations (7) and (8), along with the stipulation that a NSPS coal plant should receive zero points, leads to the following scoring formula for $\mathrm{SO}_{2}$ emissions.

$$
\mathrm{SO}_{2} \text { points }=33.5-5.58 * \mathrm{lbs}-\mathrm{SO}_{2} / \mathrm{MWh}
$$

Figure 4-3 provides a comparison of the $\mathrm{SO}_{2}$ point formula that we derived and the bins used in the NMPC scoring system. As can be seen, the utility's step function does approximate the correct formula fairly closely. The step function was used in order to simplify the self scoring procedure, and this motive also determined the use of relatively large steps.

Next, we can derive point formulae for $\mathrm{NO}_{x}$ and $\mathrm{CO}_{2}$ using the same approach. We need two more pieces of information: the zero point for $\mathrm{NO}_{\mathrm{x}}$ is 6 pounds/MWh and the zero point for $\mathrm{CO}_{2}$ 
Figure 4-3. Scoring of $\mathrm{SO}_{2}$ Emissions

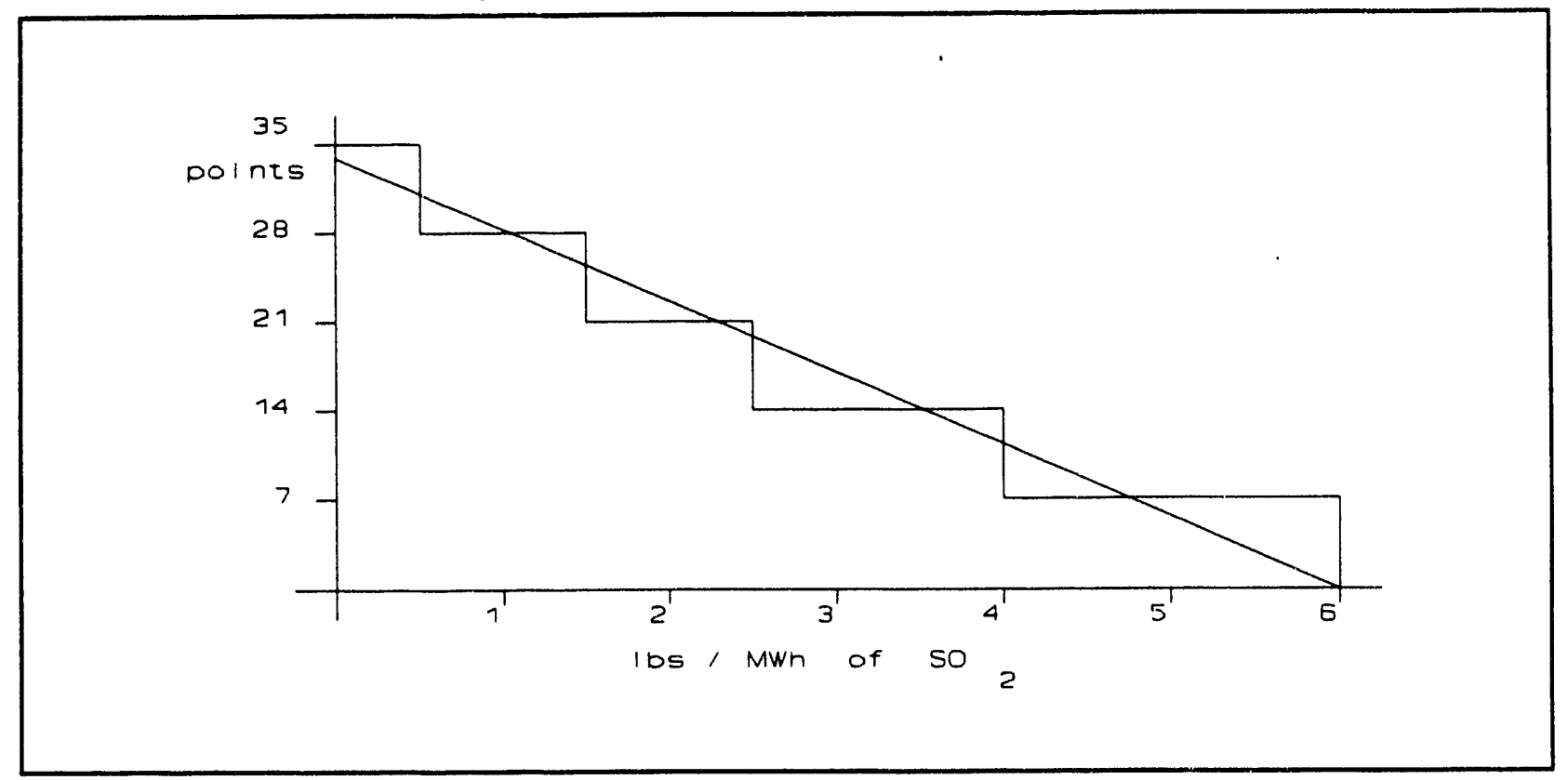

is 1,500 pounds/MWh (0.75 tons/MWh).

$$
\begin{aligned}
& \text { For } \mathrm{NO}_{\mathrm{x}}: \quad 1 \text { pound } \mathrm{NO}_{\mathrm{x}} / \mathrm{MWh}=\$ 0.916 / \mathrm{MWh} \\
& 1 \text { pound } \mathrm{NO}_{\mathrm{x}} / \mathrm{MWh}=12.28 \text { points } \\
& 6 \text { pounds } \mathrm{NO}_{\mathrm{x}} / \mathrm{MWh}=73.69 \text { points } \\
& \mathrm{NO}_{\mathrm{x}} \text { points }=73.7-12.3 * \mathrm{lbs}-\mathrm{NO}_{\mathrm{x}} / \mathrm{MWh} \\
& \text { For } \mathrm{CO}_{2}: \quad 1 \text { ton } \mathrm{CO}_{2} / \mathrm{MWh}=\$ 1.1 / \mathrm{MWh} \\
& 1 \text { ton } \mathrm{CO}_{2} / \mathrm{MWh}=14.75 \text { points } \\
& 0.75 \text { tons } \mathrm{CO}_{2} / \mathrm{MWh}=11.06 \text { points } \\
& \mathrm{CO}_{2} \text { points }=11.1-14.75 * \text { tons }-\mathrm{CO}_{2} / \mathrm{MWh}
\end{aligned}
$$

Equations (13) and (17) are plotted in Fig. 4-4 along with their respective scoring step functions employed in the NMPC scoring system. The step approximation for $\mathrm{CO}_{2}$ is much worse than for $\mathrm{NO}_{\mathrm{x}}$ and $\mathrm{SO}_{2}$ since Equation 17 lies below the bins almost everywhere.

We can now examine the effect of using a step function instead of a linear function in the scoring system. For discussion purposes, we consider the $\mathrm{NO}_{\mathrm{x}}$ formula, but the conclusions are generalizable to all continuously measurable pollutants. In designing a scoring system to account for environmental impacts of various resource options, utilities would like to appropriately motivate developers to reduce emissions in the face of negative externalities, while not paying 
too much for the installation of high pollution technology. Both of these effects must be considered in the context of particular choices that might be faced by potential bidders.

These choices are of the form:

\begin{tabular}{|l|l|}
\begin{tabular}{|l|l|}
\hline p1 pounds $\mathrm{NO}_{\mathrm{x}} / \mathrm{MWh}$ \\
$\mathrm{c} 1 / \mathrm{kWh}$
\end{tabular} & vs. \\
\hline
\end{tabular}

Figure 4-4. Scoring of $\mathrm{NO}_{x}$ and $\mathrm{CO}_{2}$ Emissions

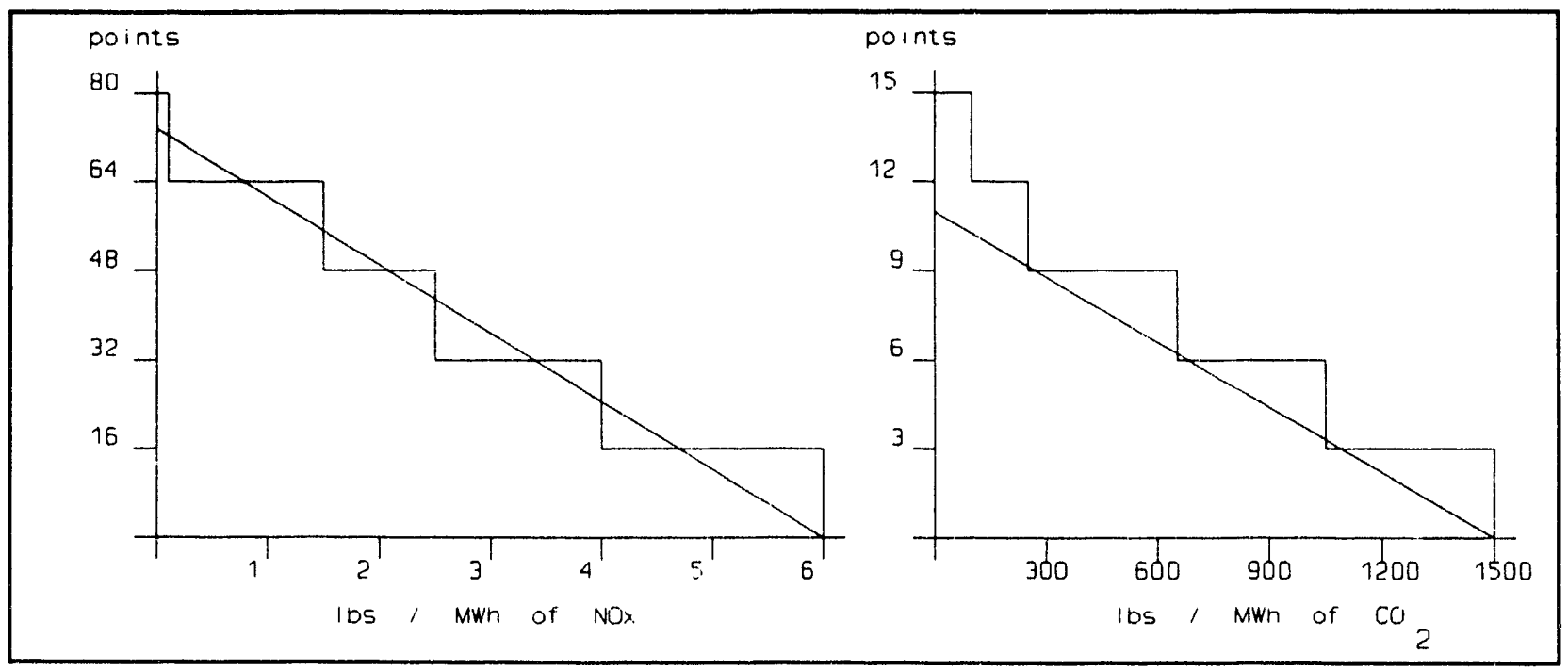

In developing projects, bidders typically must respond to this explicit tradeoff: higher pollution levels with lower cost compared to lower pollution levels obtained by installing higher cost control technology. Bidder's choices will be influenced by the utility's environmental scoring system. Assuming $\mathrm{p} 2>\mathrm{p} 1$, this choice translates into $\mathrm{p} 2-\mathrm{p} 1$ pounds $\mathrm{NO}_{\mathrm{x}} / \mathrm{MWh}$ at a cost of $\mathrm{cl}$ $\mathrm{c} 2 / \mathrm{kWh}$. The bidder will choose the lower level of pollution, $\mathrm{p} 1$, only if they receive additional points worth $\mathrm{cl}-\mathrm{c} 2 / \mathrm{kWh}$ for that choice. With a linear scoring function, whether this happens or not depends only on the difference p2-p1, while with a step function it also depends on the level of $\mathrm{p} 2$. This is not desirable because the value of saving $\mathrm{p} 2-\mathrm{p} 1$ pounds $\mathrm{NO}_{\mathrm{x}}$ depends only on p2-p1 and not on the level of emissions of the plant in question. The consequences of this difference vary depending on the specific values of $\mathrm{p} 1$ and $\mathrm{p} 2$, and the specific step function.

The important point is that the use of the step function amounts to inconsistent incentives for pollution control. Our explicit valuations show the intended incentives are given by the slope co-efficient. With bins, we get very different slopes, i.e., different incentives. In Fig. 4-5, we illustrate three generic possibilities that arise using scoring bins. The lower half of the figure shows hypothetical emissions reductions that bidders might undertake, while the upper half of 
Figure 4-5. Implicit Incentive Payment for $\mathrm{NO}_{\mathrm{x}}$ Reduction

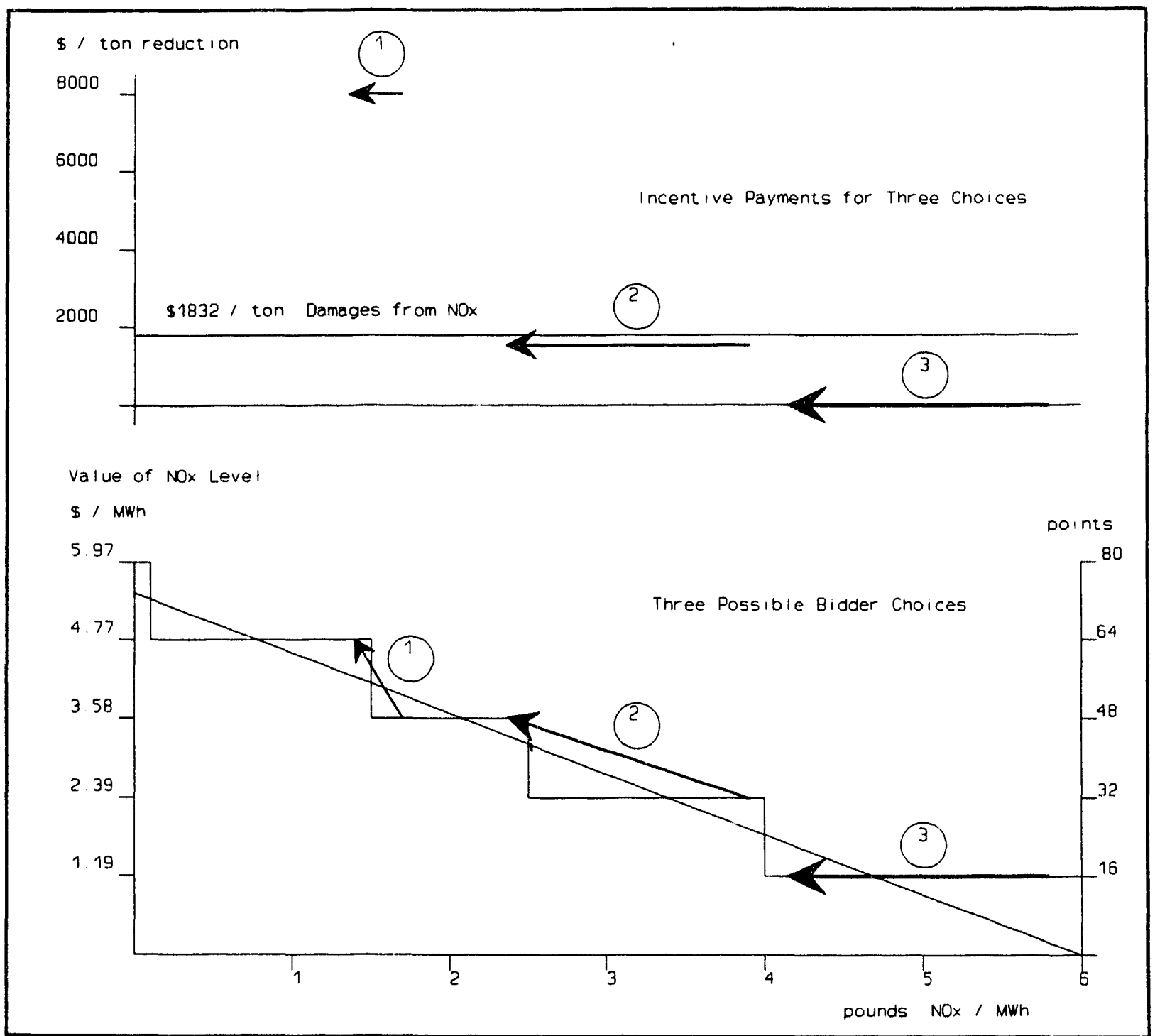

the figure shows the implied payments NMPC would pay to bidders for those emission reductions. The first choice (shown as arrow 1) represents a rather small reduction in $\mathrm{NO}_{\mathbf{x}}$ emissions of only $0.3 \mathrm{lbs} / \mathrm{MWh}$ that just happens to cross from one "point-bin" to the next. Because it crosses this boundary, a relatively large number of points are awarded for a rather small change in emissions. The incentive payment for reducing emissions is the slope of the arrow. There are two consequences of this incorrect incentive. First, an uneconomical emissions control choice may be induced, and second, NMPC will pay four times as much for this reduction in emissions as intended. If this same amount of improvement had been available starting from a different base, say from 3.3 to $3.0 \mathrm{lbs} / \mathrm{MWh}$, the point system would not have offered any incentive at all. Moderately large changes can be rewarded at approximately the correct level, as shown by arrow 2 in Fig. 4-5, or, if they happen to fall in a large bin, they may not be rewarded at all, as shown by arrow 3 . 
Notice that the step approximations always overvalue the minimal compliance with NSPS. This accounts for the results described in Table 4-12. One can only conclude from these examples that using a bin system or step function generates many inappropriate incentives. Using the bin method, it is likely that small changes in emission levels will either be grossly over-rewarded, or rewarded not at all. On average, the implicit incentive payment for reducing emissions will be correct, but the wrong signal could be sent in particular cases. Fortunately, these problems can be eliminated easily by using a linear scoring function. These results could be rounded to the nearest integer if one wants to simplify reporting. In the case of $\mathrm{NO}_{\mathrm{x}}$, this is equivalent to having 80 evenly spaced bins, which means that only the very smallest emission control measures would be significantly affected by the discontinuities.

\section{Control Costs vs. Damage Costs}

A second issue arises through the non-uniformity of the step sizes in NMPC's scoring functions for air emissions. With one exception (the second step for $\mathrm{NO}_{\mathrm{x}}$ ), the width of the step in pounds of pollutant increases as we move from lower to higher levels of emissions (see Fig. 4-4). This was done intentionally in an attempt to mimic the rising unit cost of emission control at low emission levels (Putta 1990). While this effect is indisputable, its application in this situation is conceptually flawed. The reason for this is because the cost of pollution abatement which forms the basis of the environmental scoring system is used as a proxy for damage costs which are quite difficult to quantify. Pollution mitigation costs are more easily quantified, but may bear little or no relationship to actual damage costs. There is a large literature on approaches to environmental costing (NARUC 1990). Here we address one limited aspect which affects how diminishing returns from increased costs of control should be taken into account in scoring systems.

Figure 4-6 shows a hypothetical damage cost curve for a pollutant. The cost curve is non-linear in such a way that the first ton of emission reduction by a power plant reduces damage slightly more than does its last ton of emission reduction. The direction of curvature shown for the damage function is the typical shape for a dose-response function at low levels of toxicity. On the 
benefit side, the value of reduced emissions is the inverse of the damage costs as shown by reductions in emissions from level $\mathrm{A}$ to level $B$ in Fig. 4-6. Over the full range of possible emission reductions, the value function can be translated into a convex curve as shown in Fig. 4-7.

On the cost side, the cost of abatement control function is concave because emissions typically are more expensive to curb at low levels. Proponents of the cost of abatement approach assert that society should be willing to pay more for curbing the last pound of pollutant/MWh. However, as the level of emissions is reduced towards zero, the cost of further reduction becomes exorbitant. The control cost and value of reduced damaged (i.e., benefit) curves are juxtaposed in Fig. 4-8. The difference in slopes of the two curves at a given emissions level shows the discrepancy between using the costs of control as the basis for the scoring system compared to the value of reduced damages. Given that the cost of control function does not reflect the true value of reduced emissions and the damage cost function is unknown, the best approach is a linear approximation (shown as the dashed line in Fig. 4-8).

Another argument for a linear air emissions function is that it is a reasonable approximation at the individual plant level. The damage caused by emissions is generally quite diffuse. Thus, we can fairly safely attribute a single value to a pound of pollutant independent of its source. The appropriate value to use is the marginal damage of one additional ton of pollutant produced. Project developers should be charged this marginal damage value for producing a ton of pollutant, whether it is the first ton produced or the last. This principle should apply even if the true damage function is a non-linear curve, so long as a single power plant generates only a fairly small fraction of the total emissions within its sphere of impact. We illustrate this point in Fig. 4-9 by showing a very non-linear damage curve which might apply to $\mathrm{NO}_{\mathrm{x}}$ in some metropolitan area. A single power plant will produce small quantities of pollution in a particular air basin, which is represented by the right-most section of the curve. By magnifying this section, we see that it is nearly linear and so the damage done by the plants first ton of pollution is nearly the same as that done by the last. ${ }^{20}$ Practically speaking then, a linear scoring function would be an adequate representation of the value of alleviating the damages caused by a single emitter.

\footnotetext{
${ }^{20}$ This effect holds with even more force if the pollutant causes damage on a regional or global scale, because one plant then forms an even smaller section of the curve.
} 
Figure 4-9. Damage Functions for Aggregate and Individual Pollution Sources

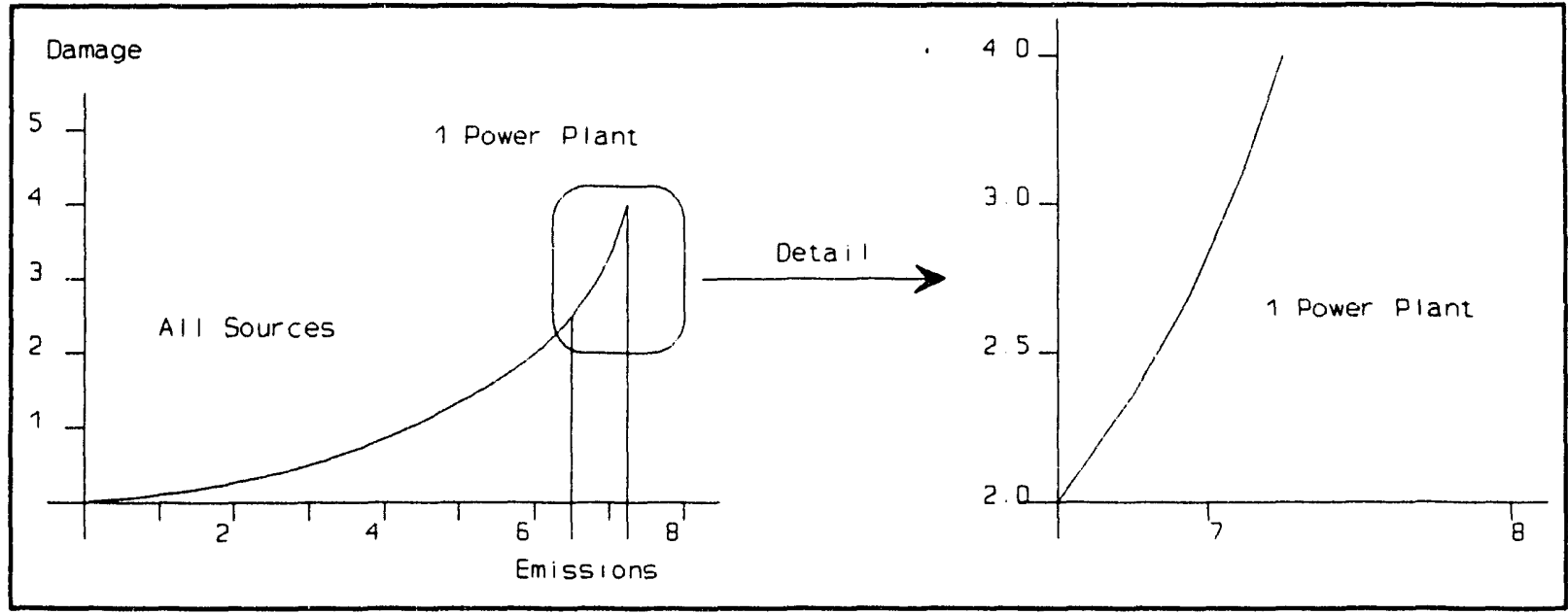

Asymmetric Treatment in Environmental Scoring of Refurbishments vs. New Projects

NMPC's scoring system for air emissions used six bins to represent the range of emissions in $\mathrm{lbs} / \mathrm{MWh}$ for four pollutants. For new projects, scores were based on absolute emission levels (per $\mathrm{MWh}$ ). However, this approach was not used for existing facilities that proposed refurbishment (e.g., Huntley 67). In this case, in the event that a plant refurbishment resulted in increased capacity and less emissions in any of the four categories of air emissions, then the project would be given the maximum score for that category. In effect, scoring of air emission impacts for refurbishment projects was done relative to the existing plant rather than in terms of the absolute level of emissions (NMPC 1990c). ${ }^{21}$ It appears that the Huntley 67 project benefitted from this treatment in that it received the maximum score for reducing impacts of sulfur oxides, $\mathrm{NO}_{\mathrm{x}}$, and particulates (123 points out of 135 maximum in the air emissions category), although Huntley 64 did not. In effect, air emission scores for these types of refurbishments resulted in essentially qualitative, rather than strictly quantitative scoring. This example provides another illustration of the difficulty in comparing life extensions and refurbishments with new projects in bid evaluation.

To summarize, the environmental scoring system employed in the NMPC solicitation was ill conceived on several grounds. First, the use of a limited number of bins introduced distortions in the incentives of bidders to reduce pollutant emissions. Secondly, the bins were designed in a way to approximate the cost of pollution abatement at different levels of emissions which probably differ from their value. Third, the environmental scoring system treated power plant refurbishments asymmetrically compared to new IPP facilities. Linear scoring functions would have been superior on both practical and theoretical grounds.

\footnotetext{
${ }^{21}$ NMPC's document states that this interpretation was pursuant to directive from PSC staff.
} 


\subsubsection{Inconsistency in the Size of the Initial Award Group}

The last topic involves an apparent inconsistency in NMPC's implementation of the bidding RFP, in contrast to previous issues, which relate more to limitations in scoring system design. In the RFP, NMPC clearly laid out the criteria that would be applied by its third-party evaluator in determining the size of the Initial Award Group. Bids would be ranked from highest to lowest score, and the Initial Award Group would include the largest number of projects that qualified based on the following criteria:

(1) total capacity selected would be at least $150 \%$ of the resource block of $350 \mathrm{MW}$;

(2) total capacity selected would be at least $250 \%$ of the largest project included under Criteria 1;

(3) projects with point scores within $5 \%$ of the lowest scoring project as defined by Criteria 1 and 2 will also be included. In addition, projects with point scores within $10 \%$ of the lowest scoring project as defined by Criteria 1 and 2 can also be included provided that the cumulative capacity does not exceed $125 \%$ of the cumulative capacity under Criteria 1 and 2

Table 4-15 lists the bids in the Initial Award Group in rank order, including their revised score, project capacity, and cumulative capacity. In addition, we apply the criteria specified in the RFP and show how many bids would be accepted in the Initial Award Group under that criteria. Criteria 1 specified total capacity of at least $150 \%$ of $350 \mathrm{MW}$ or $525 \mathrm{MW}$, which enlarged the Initial Award Group above the strict resource block capacity to include 34 projects, offering 630 MW total capacity. The "lumpiness" of the last project dictated a total capacity somewhat greater than specified by the criteria. Criteria 2 stipulated that the total capacity be at least $250 \%$ of $189 \mathrm{MW}$ (the largest project included under Criteria 1) which means that NMPC would have accepted projects cumulatively representing only $473 \mathrm{MW}$. Thus, Criteria 1 would still hold. The first part of Criteria 3 specifies that projects scoring $5 \%$ less than the threshold project by the earlier criteria should also be included; so $5 \%$ less than the score of 571 is 542 points. This increases the number of projects to be included in the Initial Award Group to 38, with a cumulative capacity of $896 \mathrm{MW}$. The second part of Criteria 3 does not meet the proviso. Therefore, the Initial Award Group should have contained, by the criteria laid out in the RFP, 38 projects for $896 \mathrm{MW}$.

However, this was not the size of the Initial Award Group provided by Burns and McDonnell to NMPC. One additional project with a lower score was included, which happened to be the largest project of the group $(216 \mathrm{MW}){ }^{22}$ We could find no language in the RFP which indicared that NMPC intended this aspect of the bid evaluation and selection process to be subjective. Indeed, the Phase One process was designed to be entirely objective. The issue is

\footnotetext{
${ }^{22}$ NMPC staff indicated that the $216 \mathrm{MW}$ project was included in the Initial Award Group because the point score for the 38 th ranked project (543.2 points) was only $4.87 \%$ (and not $5 \%$ ) less than the lowest scoring project as defined by Criteria 1. Therefore, Burns and McDonnell decided to be inclusive rather than exclusive. However, we would argue that $4.87 \%$ is "within $5 \%$ " as specified in Criteria 3.
} 
not merely an academic exercise because the additional project which was included in the Initial Award Group was ultimately selected for the Final Award Group. Thus, the project's inclusion in the Initial Award Group had an obvious detrimental impact on other eligible projects that failed to make it into the Final Award Group. 
Table 4-15. Rank Order of Bids by Score

\begin{tabular}{|c|c|c|c|c|}
\hline Rank & $\begin{array}{c}\text { Score } \\
\text { (Points) }\end{array}$ & $\begin{array}{c}\text { Capacity } \\
(\mathrm{MW})\end{array}$ & $\begin{array}{l}\text { Cumulativo } \\
\text { Capacity }\end{array}$ & \\
\hline 1 & 1188.6 & $\theta$ & 6 & \\
\hline 2 & 1158.7 & 8 & 14 & \\
\hline 3 & 1113.7 & 2 & 16 & \\
\hline 4 & 1080 & 1 & 17 & \\
\hline 6 & 1031.6 & 1 & 18 & \\
\hline 6 & 988.2 & 0 & 18 & \\
\hline 7 & 934.2 & 1 & 18 & \\
\hline 8 & 808 & 76 & 84 & \\
\hline$\theta$ & 886.1 & 4 & 88 & \\
\hline 10 & 876 & 6 & 104 & \\
\hline 11 & 868.2 & 6 & 109 & \\
\hline 12 & 848.1 & 8 & 117 & \\
\hline 13 & 838.2 & 2 & 110 & \\
\hline 14 & 829.2 & 2 & 121 & \\
\hline 16 & 826 & 6 & 127 & \\
\hline 16 & 801 & 2 & 128 & \\
\hline 17 & 781 & 8 & 137 & \\
\hline 18 & 781 & 8 & 146 & \\
\hline 18 & 761.4 & 8 & 163 & \\
\hline 20 & 743 & 0 & 163 & \\
\hline 21 & 696 & 6 & 168 & \\
\hline 22 & 686 & 0 & 168 & \\
\hline 23 & 678.8 & 6 & 164 & \\
\hline 24 & 673 & 0 & 184 & \\
\hline 25 & 688 & 8 & 173 & \\
\hline 26 & 654 & 11 & 183 & \\
\hline 27 & 631.81 & 8 & 182 & \\
\hline 28 & 618.8 & 4 & 188 & \\
\hline 28 & 612 & 188 & 386 & Resource 8lock \\
\hline 30 & 611 & 8 & 393 & \\
\hline 31 & 684.3 & 1 & 395 & \\
\hline 32 & 677.4 & 10 & 405 & \\
\hline 33 & 671.1 & 82 & 487 & Criterie 2 (RFP): $189 \mathrm{MW} \cdot 250 \%=472 \mathrm{MW}$ \\
\hline 34 & 671 & 143 & 630 & Criterie 1 (RFP): $360 \mathrm{MW} \cdot 160 \%=625 \mathrm{MW}$ \\
\hline 36 & 660 & 80 & 708 & Criteria $3 b$ (RFP): $<630 \mathrm{MW} \cdot 125 \%=788 \mathrm{MW}$ \\
\hline 36 & 669 & 161 & 871 & \\
\hline 37 & 653 & 8 & 878 & \\
\hline 38 & 643.2 & 17 & 896 & Criterie 3. (RFP): 671 pts $-5 \%=642.6$ pts \\
\hline 39 & 638 & 216 & 1112 & NMPC'E Threanold of Initiel Awerd Group \\
\hline 40 & 528.8 & 47 & 1168 & First Rejected Bid \\
\hline
\end{tabular}




\section{Chapter 5 \\ Phase Two Bid Evaluation Process}

\subsection{Overview}

In this chapter, we focus on the second phase of NMPC's bid evaluation process. Here, the utility exercised its judgment to select the best mix of projects for its Final Award Group from the 39 projects selected in the Initial Award Group. Ultimately, NMPC selected two supply projects and seven DSM projects representing $441 \mathrm{MW}$ for its Final Award Group. By design, there was a subjective element to this phase of the bid evaluation process and the Company's ultimate decision proved to be quite controversial. Thus, one of our objectives is to describe the procedures, modeling tools, and apparent decision rules used by NMPC during Phase Two. We rely principally on publicly available documents, supplemented by interviews with NMPC staff.

We then offer our assessment of major issues and problems that arose during Phase Two. We start with the assumption that it is reasonable for the utility to be allowed substantial discretion in selecting winning bidders and that the bid evaluation process need not be transparent to bidders in the RFP. However, utilities that want to exercise substantial discretion in their resource procurement processes should be held to the following standards: analytic methods and decision criteria should be (1) fairly applied to all parties, (2) reasonable and internally coherent, and (3) consistent with Commission policy and the utility's IRP plan.

Our comments fall into two general areas. The first area involves issues in the DSM bid evaluation process, where we discuss our concerns that NMPC's criteria were unnecessarily stringent and worked against DSM bidders that offered multiple measures in the $\mathrm{C} / \mathrm{I}$ sector. The second area focuses on integration and policy issues. These include the economic analysis and comparison of utility DSM programs with DSM bids, the economic figure of merit used by NMPC to select among individual supply bids and the portfolio of projects, the utility's treatment of uncertainty in bid evaluation and selection, and contingency planning. For several of these issues, we suggest ways in which NMPC's analysis methods could be improved or identify an issue in which the Commission should provide additional policy guidance. Specifically, we argue that expected net present value (NPV) is the most appropriate figure of merit in selecting among comparably-sized portfolios of projects.

\subsection{Description of the Phase Two Evaluation Methodology}

Unless otherwise noted, the information presented in this section is drawn from two documents prepare 1 by Niagara Mohawk: a report to senior management prepared by the Corporate Planning Department which documents the methodology, results and recommendations for the Final Award Group (NMPC 1990a), and testimony given by NMPC staff before the Commission in response to a formal petition filed by two losing bidders (NMPC 1991).

Each of the Initial Award Group bids was evaluated extensively in the second phase by a group of experts within Niagara Mohawk. These experts came from the Business Planning, 
Engineering - Fossil and Hydro, Environmental Affairs, System Planning, Demand-Side and Supply-Side Planning, Transmission Planning, Financial Analysis, Fuel Supply, Legal, Power Contracts, and System Gas departments. Costs and benefits of each project were evaluated both in isolation and in combination with other projects, using criteria that were tailored to DSM and supply-side bids. It is convenient to describe NMPC's methodology used for evaluating DSM and supply-side projects separately because the approaches were distinctive.

All DSM and supply bids were assessed under a common set of three planning scenarios in order to determine the economic merits of individual projects under alternative futures. These scenarios - Base, Low Need, and High Need - differ from one another with respect to future forecast of fuel prices, load growth, and amount of non-utility generation (NUG). Table 5-1 shows qualitatively how the varying assumptions regarding these key variables were used in the three scenarios. In the high fuel price forecast, oil and gas prices were $3 \%$ to $15 \%$ higher than the base case forecast, while coal prices were $1 \%$ to $4 \%$ higher, depending on the year. Similarly, in the low fuel price forecast, oil and gas prices were assumed to be $3 \%$ to $15 \%$ lower than for the base forecast, while coal prices were $1 \%$ to $4 \%$ lower. The NUG forecast for Niagara Mohawk's service territory in the base case anticipates about 2,100 MW of capacity, while the low forecast assumes about $1,100 \mathrm{MW}$. In the absence of this bidding program, load and capacity projections developed by the New York Power Pool show the need for NMPC to acquire new generating capacity in the year 1999 in the Base scenario, in 1996 in the High Need scenario, and in 2003 in the Low Need scenario.

Table 5-1. Planning Scenarios Used in Phase Two Bid Evaluation

\begin{tabular}{llll} 
Planning Scenario & Fuel Price Forecast & Load Growth & NUG Forecast \\
\hline Base & Base & Base & Base \\
Low Need & Low & Low & Base \\
High Need & High & High & Low
\end{tabular}

\subsubsection{Evaluation of DSM Bids}

It is difficult to ascertain the exact sequence or hierarchy of criteria applied by NMPC in evaluating DSM bids solely through publicly available sources. In this section, we describe the decision criteria used by NMPC for evaluating DSM bids based on a synthesis of several sources and our own judgment. ${ }^{23}$ Figure 5-1 represents our interpretation of the process by which DSM bids succeeded or failed in Phase Two.

\footnotetext{
${ }^{2}$ Sources include NMPC Corporate Planning recommendations concerning selection of projects (NMPC 1990a), NMPC testimony to the PSC in regards to the ESCO protest (NMPC 1991), draft report of process evaluation prepared by ERCE (1991) of NMPC's DSM bidding program, summary of lessons learned by NMPC staff (Hamilton and Flaim 1992), and interviews with NMPC staff.
} 
Figure 5-1. Decision Rules Applied to DSM Bids

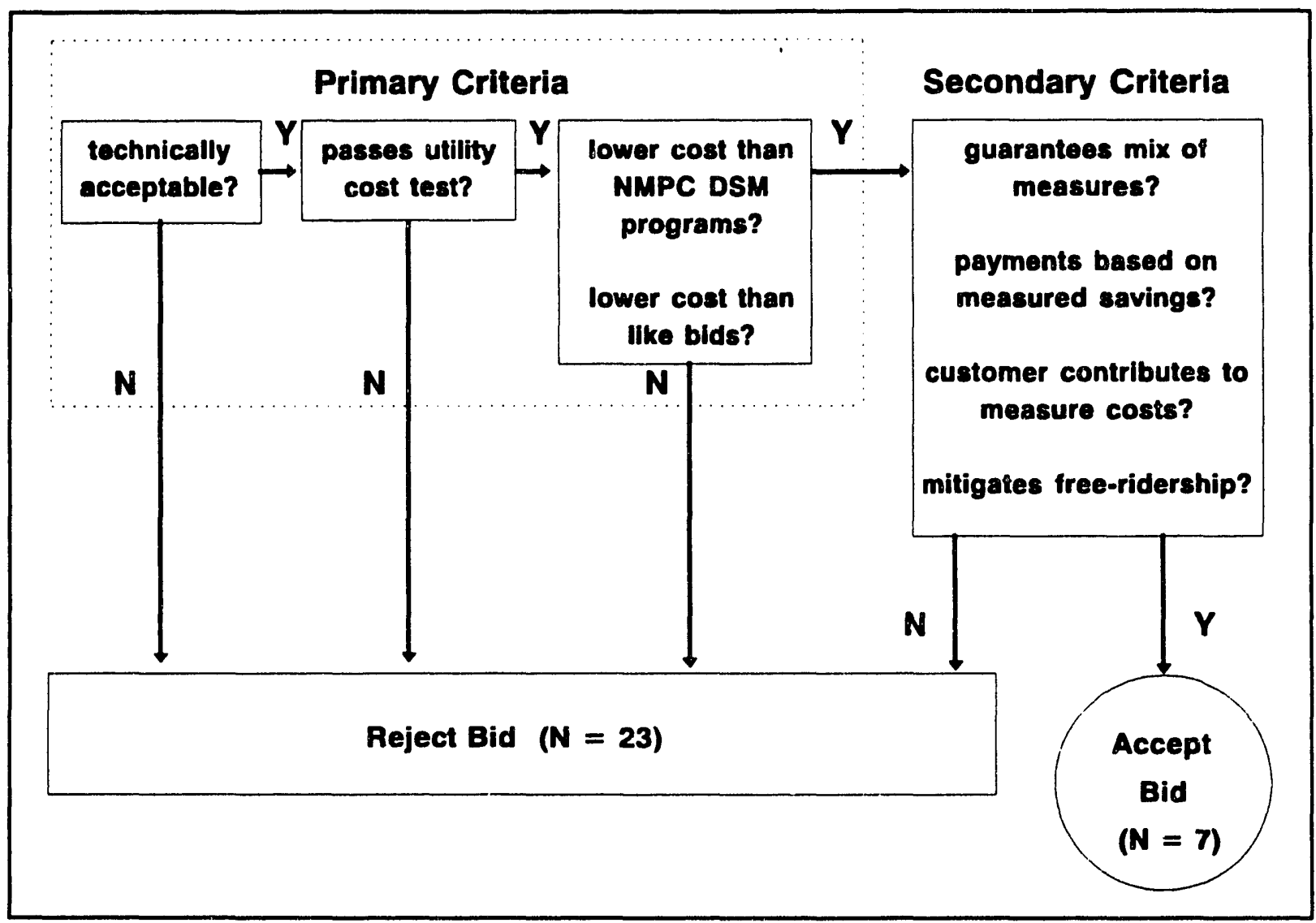

DSM projects were not rejected or accepted until the complete analysis had been performed but it is apparent that NMPC used primary and secondary decision criteria. It also appears that the secondary decision criteria were not binding in the sense that NMPC staff had some concerns about several of the accepted bids. First, NMPC staff evaluated the technical feasibility of each DSM proposal, analyzing the detailed information included in the bids themselves as well as summary information developed in Phase One by the third-party independent contractor. Technical acceptability appears to have been primarily determined by whether the proposal relied upon plausible and substantiated assumptions that were not overly simplistic or optimistic, and whether the sponsor had made a convincing case for being able to carry out the program. We can reasonably assume that any proposal judged to be technically unacceptable could not be accepted. Thus, as the first decision rule in screening DSM bids:

- Any proposal deemed technically unacceptable would be rejected.

Second, NMPC analyzed the economic feasibility of each DSM bid using various cost/benefit tests and perspectives that have become customary in assessing the merits of utility conservation programs. NMPC used four economic tests that reflect the perspectives of various entities affected by the program: Participant Test, Rate Impact Measure (RIM) Test, Utility Cost (UC) 
Test, and Total Resource Cost Test. The benefit and cost components of these tests are summarized in Table 5-2. These four economic tests were performed under each of the three scenarios described above for each DSM bid. Note that the utility program costs include the payments to bidders as well as administration costs, though NMPC purposely neglected to include the latter cost item in performing the economic tests so as to put the DSM bids in a more optimistic light.

Table 5-2. Components of Economic Tests of DSM Bids

\begin{tabular}{|c|c|c|c|c|c|c|}
\hline \multirow[b]{2}{*}{$\begin{array}{l}\text { Economic } \\
\text { Test }\end{array}$} & \multicolumn{3}{|c|}{ Benefit Components } & \multicolumn{3}{|c|}{ Cost Components } \\
\hline & $\begin{array}{l}\text { Utility } \\
\text { Avoided } \\
\text { Costs }\end{array}$ & $\begin{array}{c}\text { Customer } \\
\text { Bill } \\
\text { Savings }\end{array}$ & $\begin{array}{l}\text { Incentive } \\
\text { Payment to } \\
\text { Customer }\end{array}$ & $\begin{array}{c}\text { Utility } \\
\text { Bidding } \\
\text { Program } \\
\text { Costs }\end{array}$ & $\begin{array}{l}\text { Customer } \\
\text { Contri- } \\
\text { bution }\end{array}$ & $\begin{array}{c}\text { Customer } \\
\text { Bill } \\
\text { Savings }\end{array}$ \\
\hline Participant & & $x$ & $x$ & & $x$ & \\
\hline $\begin{array}{l}\text { Rate Impact } \\
\text { Measure }\end{array}$ & $x$ & & & $x$ & & $x$ \\
\hline Utility Cost & $x$ & & & $x$ & & \\
\hline $\begin{array}{l}\text { Total Re- } \\
\text { source Cost }\end{array}$ & $x$ & & & $x$ & $x$ & \\
\hline
\end{tabular}

NMPC typically used bidder's data on savings, load shape impact, bid price, and customer contribution in its economic screening analysis. In addition, NMPC supplied common assumptions on discount rate $(11.7 \%)$, credit for transmission and distribution losses, and electric rate schedules for each customer class to estimate participant bill savings and revenue impacts on the utility. NMPC also decided not to include environmental or other non-market benefits in this phase of the economic evaluation of DSM programs, arguing that "those benefits are not unique to bidder utility-sponsored programs. They can also be obtained through Niagara Mohawk's own DSM programs which target the same technologies and end uses" (NMPC 1990a). It is not clear that this choice was appropriate, given that ultimately the economic benefits of DSM projects were compared with the remaining supply-side projects.

Most importantly, NMPC estimated hour-by-hour marginal costs using its Multi-Company Load Management Strategy Testing Model (LMSTM) which were used for the utility's avoided costs, rather than the long-run avoided costs (LRACs) published in the RFP. ${ }^{24}$ Then, marginal costs plus NMPC's other planning assumptions were input into a screening model, called DSManager, where the four economic tests were performed on each DSM bid. NMPC's decision to use its

\footnotetext{
${ }^{24}$ The multi-area version of LMSTM, a chronological production-cost model, was used in calculating the hourly marginal costs under all three scenarios. The multi-area dispatch algorithm of LMSTM was used to simulate the dispatch of the New York Power Pool and thereby capture the pool dispatch effect in the marginal cost estimates.
} 
internal estimate of marginal costs in calculating the benefits of DSM projects is extremely important because marginal costs for the base case scenario were $29 \%$ lower than the LRACs on a present value basis. For the low need scenario, the NMPC-calculated marginal costs were $38 \%$ lower than the LRACs, while for the high need scenario they were $5 \%$ lower. Niagara Mohawk claims that the LRACs adopted by the Commission were based on obsolete forecasts. Specifically, changes in planning assumptions regarding higher levels of DSM program penetration in New York and increased production from non-utility generators contributed to lower estimates of marginal costs compared to PSC-adopted LRACs. Using lower marginal costs had the obvious effect of significantly raising the cost-effectiveness threshold for the group of DSM bids compared to avoided costs used in Phase One, and resulted in many bids failing the Utility Cost Test under the base need scenario.

NMPC applied the following decision rules in screening out projects on the basis of the economic analysis of individual DSM projects:

- Any proposal failing the Participant test was rejected.

- Any proposal failing the Utility Cost test in the base or high need scenarios was rejected.

- Any proposal failing the Total Resource Cost test in the base or high need scenarios was rejected.

Of the four economic tests, the Utility Cost (UC) Test proved to be the most important. No bids failed the Participant Test, so this test turned out to be a non-binding constraint. In addition, while the RIM Test was performed for each bid, it too was non-binding in the sense that no bids were dropped for failing this test. NMPC does not indicate how many bids had B/C ratios less than one on the RIM test but, based on results from company's other DSM programs, we assume that almost all bids would have failed this test. It appears that NMPC, in effect, used the UC Test as a proxy for potential rate impacts on non-participating customers because the RIM Test could not be used to differentiate among projects. Similarly, NMPC does not indicate how many DSM bids failed the total resource cost test using the lower avoided costs. Thus, NMPC relied very heavily on results from the utility cost test in screening out remaining DSM bids.

After examining the bids in isolation, NMPC considered the potential impact of each bid on other bids and on NMPC's other DSM programs. NMPC focused on bids that were proposing similar measures or targeting similar end-use sectors as NMPC's own core DSM programs. The disaggregation along these lines was facilitated by grouping the projects into five categories: commercial and industrial $(\mathrm{C} / \mathrm{I})$ lighting, $\mathrm{C} / \mathrm{I}$ multiple measures, customer sponsored, miscellaneous, and residential heating and lighting. Bids falling into the first two categories, numbering five and eight bids, respectively, were perceived as direct competitors to current or proposed DSM programs. 
NMPC reasoned that among the bids in a like category, only the lowest cost one should be accepted. ${ }^{25}$ The primary concern was over relative cost. Of the DSM bids that were rejected, 17 were eliminated primarily due to their high cost to NMPC relative to the company's own DSM programs or relative to lower-cost bidder sponsored programs (NMPC 1991). NMPC also expressed concern that DSM bids competing for the same markets would have a direct detrimental impact on their own DSM programs. In particular, NMPC was worried that bidders were intending to exploit the lowest cost DSM resources and charge high premiums for them (NMPC 1991). NMPC was also unfavorably disposed towards some bidder's strategy of offering measures free to customers. While this approach would facilitate bidder's marketing efforts, NMPC perceived that it would undercut their offerings to customers in their core DSM programs, because the utility's rebates typically only covered a fraction of the incremental costs for high-efficiency products.

Further concerns expressed by NMPC centered on "high risk" compensation plans. For instance, some of the bids proposed a mix of conservation measures that had a range of costs. These bids typically proposed payment based on a weighted average cost of those measures, but included no guarantees to the utility in their proposals that the mix of measures actually implemented would match the mix upon which proposed payments were based. Bids that proposed payment based on estimated savings rather than measured savings were also deemed high risk. Free-riders were a related risk factor accompanying bids that proposed payment based on estimated savings. NMPC wanted such bidders to eliminate or mitigate the potential for free-ridership, or at a minimum to account for this potential in their savings estimates and payment schemes.

We can summarize the decision rules that emerge from the record as follows:

- Any proposal that was more expensive (i.e., cost $/ \mathrm{kWh}$ saved) than the competing NMPC DSM program was rejected. ${ }^{26}$

- Any proposal that was more expensive than another, similar bid was rejected.

We classify these bullet decision rules as primary criteria for rejecting bids (also shown in Fig. 5-1). We have listed a number of other factors that NMPC cited as contributing to bid rejection, but perhaps not as decisively as the primary criteria, and these we classify as secondary criteria. While we have presented these decision rules for screening DSM bids as absolute determinants of outcome, in practice they usually worked in combination; seldom was a single reason given for rejecting a given bid. Beyond this fundamental distinction, we can only speculate upon the relative importance attached to any of the individual criteria.

\footnotetext{
${ }^{25}$ It is not clear whether this latter criteria was binding in all instances, but it was the primary reason for rejecting at least one bid in the $\mathrm{C} / \mathrm{I}$ Multiple Measures category.

${ }^{26}$ It appears that this cost comparison includes only those components used in the utility cost, not the total resource cost test but NMPC's document is not explicit on this issue.
} 
Table 5-3 identifies the reasons cited by NMPC for rejecting 23 DSM bids (NMPC 1990a). ${ }^{27}$ The vertical dashed line through the table divides the primary criteria on the left from the secondary criteria on the right. With DSM bids grouped by the five NMPC categories, patterns clearly emerge as to the bid attributes that caused the most concern. For C/I Lighting bids, the sole reason given for rejecting all five bids was their high price relative to NMPC DSM program costs. NMPC stated that ESCO bid prices for C/I lighting programs were substantially more expensive than estimated costs per kWh saved of the Company's C/I lighting program (\$0.058$0.079 / \mathrm{kWh}$ vs. $\$ 0.02-0.03 / \mathrm{kWh}$ ). For C/I Multiple Measures bids, each of the primary criteria was violated by one or several bids. Most strikingly, all but one bid failed two secondary criteria, that of not guaranteeing a mix of measures and not requiring participating customers to pay some portion of the incremental costs of the energy saving measures. For the customer sponsored bids, two were rejected for failing the Utility Cost test, while the secondary criteria included free rider concerns, optimistic savings estimates, and proposed payments based on estimated savings. For the two rejected Miscellaneous bids, they failed primarily for technical unacceptability. Finally, for the five unsuccessful Residential Lighting and Heating proposals, their primary basis for rejection was failure of the Utility Cost test, and secondarily for optimistic savings estimates.

Following this screening of the individual projects, the final step in the DSM bid evaluation process was to combine the bids together into a portfolio of projects in order to ensure their cost-effectiveness as a group. The reason for this step was to avoid exaggerating the benefits of the group of seven DSM bids that would come from summing the individual project benefits a phenomenon of diminishing returns from each additional MW of savings. Cost-effectiveness of the group was tested through LMSTM simulations of the scenarios inclusive of the portfolio of DSM bids in the resource mix. The DSM projects passing the individual bid screening procedure also passed as a group, thus forming the first element of the integrated portfolio analysis following the initial screening of supply bids (see discussion in section 5.2.2).

Table 5-4 shows the DSM bids in the Final Award Group, including targeted end uses and proposed conservation technologies. We next summarize reasons given by NMPC for accepting bids. CES/Way, the lone C/I bid accepted from a national ESCO, proposed a comprehensive package for retrofitting efficient lighting, motors, and chillers in the commercial/industrial sector. CES/Way's bid was successful primarily because their proposal was the lowest cost of those in the same category $(\$ 0.0257 / \mathrm{kWh}$ based on the Utility Cost Test) and involved a substantial cost contribution from customers. The two customer-sponsored bids by Chevrolet, totaling $1.4 \mathrm{MW}$, were accepted because they had $\mathrm{B} / \mathrm{C}$ ratios above 1.0 , even assuming the company would implement the measures without participating in the bidding program by 1995 (i.e., free-riders). Planergy proposed a second refrigerator round-up program and the bid was

27 Table 5-3 summarizes reasons for rejecting bids that were given for each project, based on NMPC's Corporate Planning Department report to senior management. In reviewing our study, NMPC staff indicated that the list was not exhaustive for each project. For example, all $\mathrm{C} / \mathrm{I}$ projects that offered multiple measures were more expensive than other like bids. For consistency, our summary table reflects results as described in the Company's "official" document. 


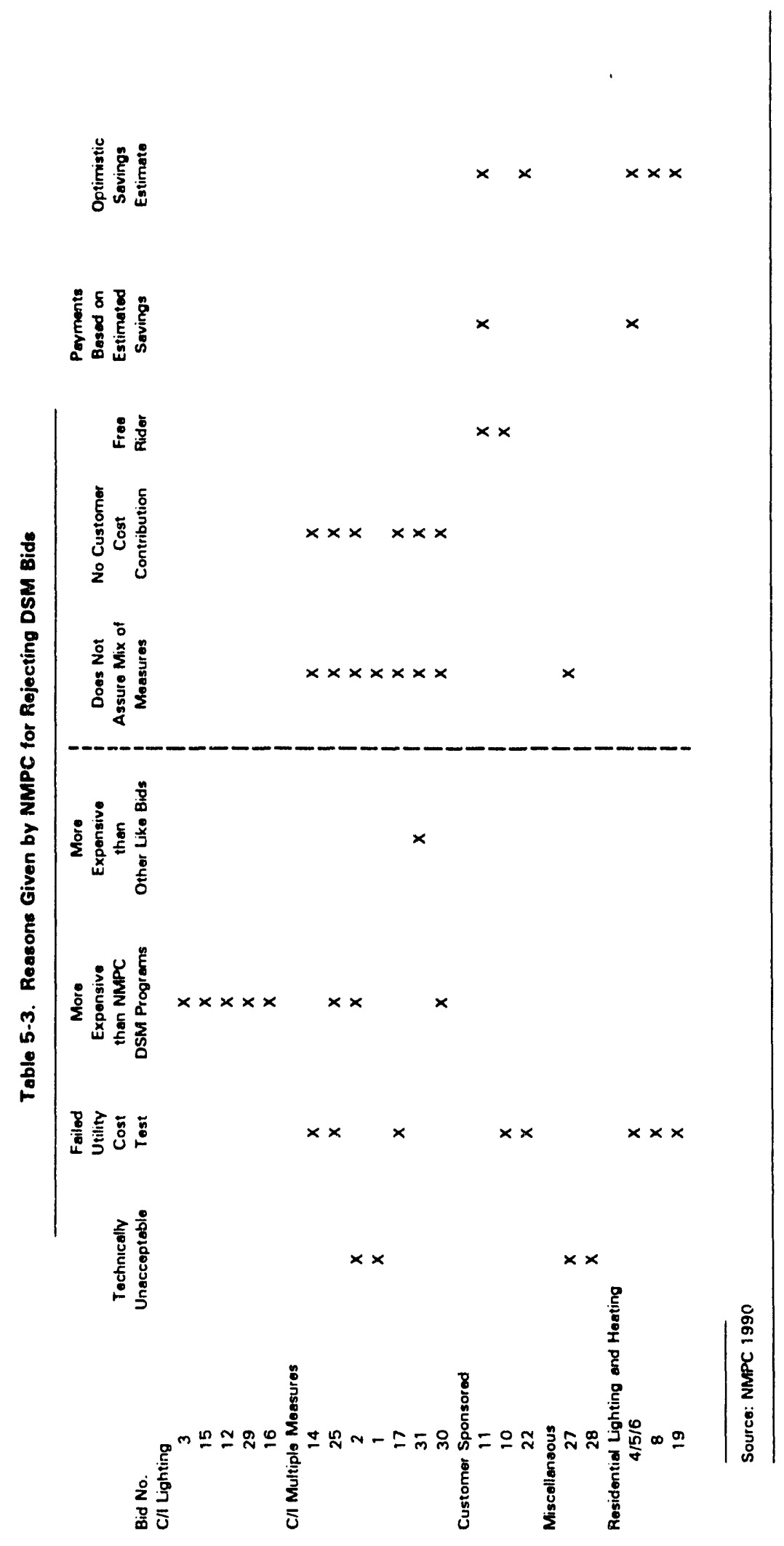


accepted because it was a unique bid in a market that NMPC had no intentions of entering with their own programs, and because the sponsors included controls to minimize the risk of freeriders. SyrESCO, a local non-profit energy services firm, proposed demand reductions of 5.8 MW in multi-family buildings and offered a comprehensive retrofit package, while SESCO had two bids representing about $16 \mathrm{MW}$ of savings which targeted residential customers. The Corporate Planning Department recommended that the SyrESCO and SESCO bids in the Residential Heating and Light categories be accepted subject to working out several contingencies in contract negotiations.

Table 5-4. Final Award Group DSM Bids

\begin{tabular}{|c|c|c|c|c|}
\hline Sponsor & MW & NMPC Category & $\begin{array}{l}\text { End-Use } \\
\text { Sectors }\end{array}$ & Technologies \\
\hline CESMAY & 7.69 & C/I Mult. Measure & $\begin{array}{l}\text { HVAC, Motors, } \\
\text { Lighting }\end{array}$ & Eff. lighting, motors, chillers \\
\hline Chevrolet & 1.108 & Customer Sponsored & Lighting & High-press. sodium lamps \\
\hline Chevrolet & 0.349 & Customer Sponsored & Compressed Air & Automatic elec. controls \\
\hline Planergy & 5.134 & Miscellaneous & Refrigeration & $\begin{array}{l}\text { Removal of secondary refrig- } \\
\text { erator }\end{array}$ \\
\hline SyrESCO & 5.81 & Res. Light \& Heat & Heating, Lighting & $\begin{array}{l}\text { Insulation, air sealing, } \\
\text { eff. lighting }\end{array}$ \\
\hline SESCO & 8.026 & Res. Light \& Heat & Total Facility & $\begin{array}{l}\text { Eff. lighting, envelope \& } \mathrm{w} / \mathrm{h} \\
\text { improvements }\end{array}$ \\
\hline SESCO & 8.026 & Res. Light \& Heat & Total Facility & $\begin{array}{l}\text { Eff. lighting, envelope } \& \mathrm{w} / \mathrm{h} \\
\text { improvements }\end{array}$ \\
\hline
\end{tabular}

\subsubsection{Evaluation of Supply-Side Bids}

The nine supply-side bids in the Initial Award Group included six projects that used natural gas, one coal plant, one hydroelectric project, and one pumped storage unit. Initially, the supply-side projects were screened individually for cost-effectiveness using the multi-area PROMOD III production cost simulation model. Project operating and cost characteristics, such as heat rates, outage rates, price bid, etc. were input into the model and simulated in the overall dispatch of the NYPP system under the Base, Low Need, and High Need scenarios. The production costs from these runs were then compared to those of their counterpart runs without the proposed project in order to estimate the energy benefits of the project.

The total benefits of the project are composed of an energy component, determined as described above, and a capacity component. The capacity benefits associated with a supply bid are based on the avoided carrying (i.e., fixed) costs of a proxy baseloaded generating unit, calculated in the following way (Petrie 1991). First, the company's reserve margins are compared with and 
Table 5-5. B/C Ratios of Supply Bids Screened Individually

\begin{tabular}{|c|c|c|c|}
\hline Project & Base Scenario & $\begin{array}{l}\text { Low Need } \\
\text { Scenario }\end{array}$ & $\begin{array}{l}\text { High Need } \\
\text { Scenario }\end{array}$ \\
\hline Guilderland & 1.14 & 0.93 & 1.62 \\
\hline Huntley 67 & 1.03 & 0.77 & 1.38 \\
\hline E. Syracuse I & 1.02 & 0.83 & 1.39 \\
\hline Minden Cogen & 1.00 & 0.70 & 1.34 \\
\hline Xerox-Webster & 0.92 & 0.79 & 1.23 \\
\hline Oxy Cogen & 0.88 & 0.68 & 1.34 \\
\hline Indeck-Niagara & 0.88 & 0.70 & 1.28 \\
\hline Lyons Falls & 0.36 & 0.25 & 0.53 \\
\hline Fourth Branch & 0.32 & 0.12 & 0.61 \\
\hline
\end{tabular}

Source: NMPC 1990a for base case and high need scenario; NMPC staff sent LBL results for Low Need scenario, based on our request (Petrie 1991).

without the supply bid. The project is then given an annual capacity credit for its contribution to reducing any reserve margin deficiency. No capacity credit was given in years when NMPC had surplus capacity in the Base Need case. The capacity credit (MW) was multiplied by the annual carrying cost ( $\$ / \mathrm{kW} /$ year) of the proxy generating unit to determine the capacity benefit produced by the supply bid.

Thes: estimated benefits of an individual supply project to the utility were compared to the costs incurred by the utility in the form of payments proposed by the bidder. Two indicators were used to assess the economic merits of supply-side projects: the net present value of savings (NPV) and the benefit/cost ratio (B/C) ${ }^{28}$ The NPV, expressed in absolute monetary terms or per unit bid capacity, is really a measure of net savings from the project (i.e., benefits minus costs, or B-C). The NPV was used as a measure of the absolute net benefit of the project, while the $\mathrm{B} / \mathrm{C}$ ratio was used to scale the economic merit of the project to project size and bid contract length.

Table 5-5 shows the ranking of supply bids in terms of B/C ratio. None of the supply bids had a B/C ratio above 1.0 - the minimum for economic worthiness - in the Low Need scenario. All projects except the two hydro bids (Lyons Falls and Fourth Branch) had B/C ratios higher than 1.0 in the High Need scenario. The highest ranking project under all scenarios was Guilderland. Huntley 67, NMPC's life extension project, ranked second in the Base Need scenario, fourth

\footnotetext{
${ }^{28}$ Note that in calculating $\mathrm{B} / \mathrm{C}$, both benefits and costs must be computed as present values in order for this ratio to make sense, thus the difference between NPV and B/C has nothing to do with the present value operation which is common to both.
} 
in the Low Need scenario, and third in the High Need scenario. East Syracuse I ranked third in the Base scenario, and second in the Low and High Need scenarios. Minden Cogen ranked fourth in the Base and High Need scenarios, and fifth in the Low Need scenario. All other supply bids received $B / C$ ratios lower than 1.0 in the Base scenario. Two projects, Lyons Fall and Fourth Branch had $\mathrm{B} / \mathrm{C}$ ratios less than 1.0 under all three scenarios. NMPC's presentation of $\mathrm{B} / \mathrm{C}$ ratios alone among the economic measures calculated for all supply projects suggests that NPV and NPV/kW were not used in the screening of individual supply projects (NMPC 1990a).

\subsubsection{Integrated Bid Evaluation}

Supply bids in the Initial Award Group along with the group of seven remaining DSM bids were eligible to be included in the portfolio analysis, although NMPC had reservations about including any supply project that had a B/C ratio of less than 1.0 in the Base scenario in the individual screening. Supply projects were put together in various combinations with the group of DSM projects to form portfolios in sizes ranging from $450 \mathrm{MW}$ to $550 \mathrm{MW}$. It is important to note that the group of DSM projects was invariant during the integrated bid evaluation process. In all, eleven portfolios were analyzed under the three scenarios, though NMPC only reported on eight of them, shown in Tables 5-6 to 5-8 (NMPC 1990a). ${ }^{29}$ For each portfolio, the NPV of savings, the NPV of savings per $\mathrm{kW}$, and the $\mathrm{B} / \mathrm{C}$ ratio are presented. However, NMPC presents no rationale for how the three economic indicators guided their choices among portfolios.

Portfolio 1 ultimately became the Final Award Group. Inspection ci Table 5-6 shows the results for the three economic indicators for all portfolios under the Base scenario. Portfolio 1 has the second highest NPV of savings after Portfolio 3, the highest NPV/kW, and ties for the highest $\mathrm{B} / \mathrm{C}$ ratio with Portfolio 2. In the High Need scenario, Portfolio 1 fell to sixth in the NPV ranking, largely because of its smaller capacity size compared to the other portfolios (Table 5-7). However, Portfolio 1 still ranked first in NPV/kW and B/C ratio, though only marginally higher than Portfolios 2, 3, and 4 by these latter two measures. In the Low Need scenario, all portfolios have negative net savings, and therefore also $\mathrm{B} / \mathrm{C}$ ratios of less than 1.0 (Table 5-8). Portfolio 1 still ranks the highest in all three economic measures. The relationships that defined the rankings in the High Need scenario apply in the Low Need scenario as well. To wit, Portfolio 1 ranks highest in NPV, precisely for the same reason that it did poorly in the High Need scenario, because of its relatively small size. Likewise, the differences among Portfolios 1 to 4 in NPV/kW and B/C are very slight.

\footnotetext{
${ }^{29}$ Presumably, the remaining undisclosed three portfolios performed more poorly than the ones presented.
} 
Table 5-6. Portfolio Analysis Results: Base Need Scenario

\begin{tabular}{|c|c|c|c|c|c|}
\hline \multirow[b]{2}{*}{ Portfolio } & \multirow[b]{2}{*}{ Project Name } & & \multirow[b]{2}{*}{$\begin{array}{c}\text { Benefit/Cost } \\
\text { Ratio }\end{array}$} \\
\hline & & $\begin{array}{l}\text { Size } \\
\text { (MW) }\end{array}$ & $\begin{array}{l}\text { NPV of } \\
\text { Savings } 1 \\
\text { (Millions of } \\
1990 \$ \text { ) }\end{array}$ & $\begin{array}{c}\text { NPV of } \\
\text { Savings } \\
(1990 \$ / \mathrm{kW}) \\
\end{array}$ & \\
\hline 1 & DSM Guild H 67 & 441 & 127.4 & 289 & 1.11 \\
\hline 2 & $\begin{array}{l}\text { DSM Guild H } 67 \\
\text { E. Syr } 9\end{array}$ & 450 & 126.2 & 280 & 1.11 \\
\hline 3 & $\begin{array}{l}\text { DSM Guild H } 67 \\
\text { Minden }\end{array}$ & 523 & 127.6 & 244 & 1.10 \\
\hline 4 & $\begin{array}{l}\text { DSM Guild H } 67 \\
\text { Minden E. Syr }\end{array}$ & 532 & 126.7 & 238 & 1.10 \\
\hline 5 & $\begin{array}{l}\text { DSM Guild Web- } \\
\text { ster Minden }\end{array}$ & 477 & 53.0 & 111 & 1.04 \\
\hline 6 & $\begin{array}{l}\text { DSM Guild Web- } \\
\text { ster E. Syr }\end{array}$ & 486 & 52.4 & 108 & 1.04 \\
\hline 7 & $\begin{array}{l}\text { DSM H } 67 \text { Xe- } \\
\text { rox } \\
\text { Minden E. Syr }\end{array}$ & 459 & -19.7 & (43) & 1.0 \\
\hline 8 & $\begin{array}{l}\text { DSM H } 67 \\
\text { Xerox Minden }\end{array}$ & 450 & -10.1 & (22) & 1.0 \\
\hline
\end{tabular}

Source: NMPC 1990a 
Table 5-7. Portfolio Analysis Results: High Need Scenario

\begin{tabular}{|c|c|c|c|c|c|}
\hline Portfolio & Project Names & $\begin{array}{l}\text { Size } \\
\text { (MW) }\end{array}$ & $\begin{array}{l}\text { NPV of } \\
\text { Savings } \\
\text { (Millions of } \\
1990 \$ \text { ) }\end{array}$ & $\begin{array}{c}\text { NPV of } \\
\text { Savings } \\
(1990 \$ / \mathrm{kW})\end{array}$ & $\begin{array}{c}\text { Benefit/Cost } \\
\text { Ratio }\end{array}$ \\
\hline 1 & DSM, Guild, H 67 & 441 & 627.2 & 1,422 & 1.54 \\
\hline 2 & $\begin{array}{l}\text { DSM, Guild, H 67, } \\
\text { E. Syr }\end{array}$ & 450 & 632.9 & 1,406 & 1.53 \\
\hline 3 & $\begin{array}{l}\text { DSM, Guild, H 67, } \\
\text { Minden }\end{array}$ & 523 & 681.1 & 1,302 & 1.51 \\
\hline 4 & $\begin{array}{l}\text { DSM, Guild, H } 67 \text {, } \\
\text { Minden, E. Syr }\end{array}$ & 532 & 686.8 & 1,291 & 1.50 \\
\hline 5 & $\begin{array}{l}\text { DSM, Guild, Web- } \\
\text { ster, Minden }\end{array}$ & 477 & 643.6 & 1,349 & 1.42 \\
\hline 6 & $\begin{array}{l}\text { DSM, Guild, Web- } \\
\text { ster, E. Syr }\end{array}$ & 486 & 649.8 & 1,337 & 1.42 \\
\hline 7 & $\begin{array}{l}\text { DSM, H 67, Xerox, } \\
\text { Minden, E. Syr }\end{array}$ & 459 & 421.1 & 917 & 1.32 \\
\hline 8 & $\begin{array}{l}\text { DSM, H 67, } \\
\text { Xerox, Minden }\end{array}$ & 450 & 414.7 & 922 & 1.32 \\
\hline
\end{tabular}


Table 5-8. Portfolio Analysis Results: Low Need Scenario

\begin{tabular}{|c|c|c|c|c|c|}
\hline Portfolio & Project Names & $\begin{array}{l}\text { Size } \\
\text { (MW) }\end{array}$ & $\begin{array}{c}\text { NPV of } \\
\text { Savings } \\
\text { (Millions of } \\
1990 \$ \text { ) } \\
\end{array}$ & $\begin{array}{c}\text { NPV of } \\
\text { Savings } \\
(1990 \$ / \mathrm{kW})\end{array}$ & $\begin{array}{c}\text { Benefit/Cost } \\
\text { Ratio }\end{array}$ \\
\hline 1 & DSM, Guild, H 67 & 441 & -146.7 & -333 & 0.87 \\
\hline 2 & $\begin{array}{l}\text { DSM, Guild, H 67, } \\
\text { E. Syr }\end{array}$ & 450 & -151.2 & -336 & 0.86 \\
\hline 3 & $\begin{array}{l}\text { DSM, Guild, H 67, } \\
\text { Minden }\end{array}$ & 523 & -177.1 & -339 & 0.85 \\
\hline 4 & $\begin{array}{l}\text { DSM, Guild, H 67, } \\
\text { Minden, E. Syr }\end{array}$ & 532 & -182.9 & -334 & 0.85 \\
\hline 5 & $\begin{array}{l}\text { DSM, Guild, Web- } \\
\text { ster, Minden }\end{array}$ & 477 & -205.7 & -431 & 0.83 \\
\hline 6 & $\begin{array}{l}\text { DSM, Guild, Web- } \\
\text { ster, E. Syr }\end{array}$ & 486 & -211.5 & -435 & 0.83 \\
\hline 7 & $\begin{array}{l}\text { DSM, H 67, Xerox, } \\
\text { Minden, E. Syr }\end{array}$ & 459 & -250.6 & -546 & 0.76 \\
\hline 8 & $\begin{array}{l}\text { DSM, H 67, } \\
\text { Xerox, Minden }\end{array}$ & 450 & -244.5 & -543 & 0.76 \\
\hline
\end{tabular}

Source: Petrie 1991 


\subsection{Outcome of Final Screening}

Portfolio 1, which became the Final Award Group, was comprised of two supply projects and seven DSM projects for a combined total of $441 \mathrm{MWs}$. The chosen supply projects were a 216 MW gas-fired combined-cycle generating station to be built in Guilderland N.Y. by a joint venture of Pacific Gas and Electric, Bechtel, and Sycom companies, and Niagara Mohawk's bid for life extension of Huntley unit 67, a pulverized coal steam plant. ${ }^{30}$ The DSM portfolio of seven projects is shown in Table 5-4 and amounts to about $36 \mathrm{MW}$.

\subsubsection{Postscript on NMPC's Self-Scoring System}

In comparing the Phase One ranking and the performance of supply bids in the Phase Two analysis, we observe several anomalous results. ${ }^{31}$ One notable case was the lone pumped storage bid, Fourth Branch. This project had, by a wide margin, the highest Phase One score of the supply bids. The price score of this project was more than two times greater than any other supply project, save one. However, in the analysis of the Phase Two, Fourth Branch did not perform well (see Table 5-5). Production-cost modelling indicated that pumped storage generation was not needed in the NMPC system, because of the existence of another such facility (Gilboa), and because the differential between on-peak and off-peak marginal costs were not great enough to justify it. Similarly, the lowest scoring bid in the first phase, the Guilderland project, happened to win a spot in the Final Award Group.

The fate of these two projects could be viewed as validating NMPC's use of the subjective, closed bid evaluation stage. Conversely, it could as easily be seen as an indictment of the selfscoring system used in Phase One which appeared unable to properly rank projects. This is clearly true for pumped storage. Certain types of supply-side projects are more difficult to rank with objective self-scoring systems because their value is primarily due to interactive effects with the utility system. Similarly, it appears that the Guilderland project offered desirable location and dispatchability features, which were under-valued in Phase One. As discussed in Chapter 4 , given the lack of consistency in the ranking of projects between Phase One and 2 bid evaluation, it is also possible that other marginal supply projects were eliminated in the first phase which could have fared well in the second phase.

\subsection{Culmination of Phase Two: Contract Negotiations}

Following announcement of the Final Award Group, winning bidders entered into contract negotiations with Niagara Mohawk. As of December 1991, four DSM birlders have signed

\footnotetext{
30 Since the announcement of the Final Award Group, the Guilderland project has be in moved to the Albany area (Rotterdam).

31 We would expect significant differences in rankings for DSM bids because NMPC wa s explicit that additional factors would be - znsidered in Phase Two bid evaluation. For supply-side bids, we would xpect some differences because the self-scoring system used in Phase One could not capture interactive effects of individual bids.
} 
contracts with the utility: CES/Way, Planergy, Syresco, and Chevrolet. Negotiations are continuing with two remaining bidders: SESCO and Guilderland. NMPC recently announced that it had cancelled the life extension of Huntley 67 primarily because the project was no longer cost-effective based on NMPC's most recent estimates of avoided costs. We describe winning bidders' and NMPC's views on the principal issues that arose in contract negotiations in Chapter 6 and summarize key features of signed contracts in Chapter 7, based on interviews with the various parties. Our ability to analyze contract terms and conditions is quite limited because we were not able to obtain the signed contracts.

\subsection{Issues in the DSM Evaluation Process}

In this section, we discuss a number of our concerns regarding NMPC's Phase Two bid evaluation and selection process which, in our view, worked against DSM bidders unnecessarily stringently. We believe that NMPC's decision to select only one ESCO that offered multiple measures in the C/I sector was unfortunate. Our intent is not to second guess NMPC's selection decisions but to focus on the appropriateness and application of the decision criteria. ${ }^{32}$

\subsubsection{ESCO vs. ESCO Competition}

Niagara Mohawk's DSM bid evaluation process effectively pitted ESCO bids from the same category against one another. We agree with NMPC's approach to group and compare bids that targeted similar customer classes and end uses. Moreover, we acknowledge the risk to the utility, ratepayers (and even winning bidders) from taking too many DSM bids that offer comprehensive services and target the same market segment (e.g., commercial/industrial customers). However, we would argue that Niagara Mohawk over-reacted by rejecting all but the least cost ESCO bid. This problem arose explicitly among ESCOs that proposed multiple measures in the $\mathrm{C} / \mathrm{I}$ sector. One of the reasons that NMPC gave for eliminating ESCO bids in this category was that the cost to the utility (as measured by the Utility Cost Test) was significantly higher than the low price ESCO bid (see Table 5-3). We have two problems with NMPC's decision criteria. First, in comparing the economic benefits of competing DSM bids, NMPC should have placed some weight on the overall cost to society (as measured by the Total Resource Cost Test), and not just the costs to the utility, because CES/Way's winning bid anticipated a substantial customer cost contribution. Second, the C/I sector is not homogenous and ESCOs offering multiple measures conceivably developed their program designs to target various C/I market segments and ownership patterns (e.g., offices, hospitals, public institutions vs. private sector). The winning bid targeted institutional and public buildings. The program designs of other ESCOs may well have reflected market barriers that exist among different types

\footnotetext{
32 We have not seen the actual bid proposals; our conclusions are based solely on our analysis and interpretation of the Phase One rankings and NMPC's summary of its Phase Two bid evaluation process.
} 
of commercial and industrial customers, which was reflected in their estimates of customer contribution. ${ }^{33}$

\subsubsection{Treatment of Measure Mix Risk on ESCO Bids}

Similarly, NMPC overreacted to the measure mix risk in ESCO bids. In some cases, the project sponsor proposed payment based on an average cost of the bundle of measures but made no guarantee concerning what measures would actually be implemented. The company characterized these proposals as "high risk", and listed it as one of the factors given for rejecting bids. While we acknowledge the legitimacy of NMPC's concern on these type of bids, NMPC could have responded differently. It is not clear why this issue could not have been handled and resolved by additional contractual negotiations among the parties in the event the DSM project was selected for the Final Award Group. Some ESCOs may have been willing to negotiate on this issue: either offering to tie their payments to achievement of an agreed upon mix of DSM measures or some adjustment to the payment mechanism if the actual mix of installed measures differed significantly from that anticipated by the ESCO in their bid price. These projects could have been included in the Final Award Group conditionally pending satisfactory resolution of this issue.

Comprehensive retrofit packages are exactly the kind of projects that ESCOs are suited to deliver and provide an alternative to the conventional utility-sponsored DSM rebate program. It will always be quite difficult for an ESCO to predict in advance the actual mix of installed measures. This issue will always arise unless the utility relies on extremely high threshold requirements, such as requiring ESCOs to obtain signed letters of intent from all potential customers specifying actual measures as in the Consolidated Edison solicitation. However, as evidenced by the poor response to Con Ed's RFP by DSM bidders (i.e., four bids), few bidders will find this approach reasonable. The challenge is to devise contractual mechanisms that will apportion the marketing risk and uncertainty surrounding customer acceptance of various DSM technologies between the ESCO and the utility's ratepayers. This issue is endemic to any scheme that relies on a pre-specified fixed payment for a bundle of measures.

\subsubsection{DSM Bidder vS. NiMPC DSM Program Competition}

We believe that it was appropriate for NMPC to compare bidder's proposals with the company's own DSM programs. This issue was discussed by NMPC in its bidding guidelines describing the Phase Two evaluation process and was mentioned in the PSC's decision approving the company's RFP (NYPSC 1989b; NMPC 1989a). Ultimately, the Commission has to share much of the responsibility for confusions on this issue because it provided insufficient policy guidance to the utilities who were left to grapple with potential conflicts between PSC-mandated core DSM programs and DSM bidders' proposals. With the benefits of hindsight, however, it is also

\footnotetext{
33 For example, customers that own large office buildings may have higher investment hurdle rates than public institutions that may have long-term perspective but much more limited access to capital.
} 
clear that NMPC could have been more explicit in the RFP that this criteria would weigh heavily in the bid evaluation and selection process (NMPC 1991).

The utilities were left to solve this problem and, in effect, asked to develop creative solutions in terms of coordinating program implementation. At the bid evaluation stage, this was clearly a judgment call. For example, NMPC's decision to reject $\mathrm{C} / \mathrm{I}$ lighting bids on the grounds that they were significantly more expensive than the utility's lighting rebate programs appears reasonable. However, it is unclear that it was appropriate for NMPC to reject DSM bids that offered multiple measures in the $\mathrm{C} / \mathrm{I}$ sector on the grounds that they were more expensive than utility rebate programs (see Table 5-3). At the time of bid evaluation, NMPC had some field experience with its lighting program, but virtually no experience implementing its C/I HVAC and motor rebate programs. Moreover, even if NMPC had substantial field experience, NMPC would have had to factor in the more comprehensive services offered by ESCOs and performance risk (in some cases) compared to rebate programs in comparing the costs of ESCO bids with utility rebate programs.

NMPC was in a difficult position, because even though its HVAC and motor rebate programs were not on the street, its long-range DSM plan committed NMPC to achieving aggressive market penetration for its core DSM programs. Accepting many ESCO bids could conceivably make it harder for the utility to achieve these goals. In the future, the PSC could help resolve this dilemma by ensuring that a mechanism exists for adjusting the utility's goals for core DSM programs in affected markets to reflect the outcome and selection of winning bidders. In addition, the PSC should continue its policy of comparable treatment to utility shareholders for successful implementation of company-sponsored and third party DSM programs (i.e., financial incentives). However, given the significant market potential for DSM in the C/I sector, we believe that the Company's approach was too conservative. It is possible that creative solutions could have been developed in contract negotiations with winning bidders (e.g., targeting only portions of service territory) and proposals brought to the Commission regarding adjustment of core DSM goals. Moreover, there was too little evidence to conclude that $\mathrm{C} / \mathrm{I}$ multiple measure bids were more expensive than utility rebate programs, adjusting for performance risk and service differences. As a pilot program, admittedly a large-scale one, we believe that the bidding program provided an excellent opportunity to test this view by accepting more than one ESCO bid in this sector and still not put ratepayers unduly at risk. In evaluating the risks associated with accepting more DSM bids in the C/I sector, we think it appropriate to consider their cost-effectiveness relative to accepted supply bids, and not just their estimated costs vs. current and proposed utility DSM programs.

\subsection{Integration and Policy Issue:}

In this section, we raise several integration and policy issues based on our review of NMPC's Phase Two bid evaluation and selection process. First, we discuss possible inconsistencies in the economic analysis of DSM bids vs. company DSM programs because of the utility's heavy reliance on the Utility Cost Test and use of its internal estimates of marginal costs rather than the PSC-approved LRACs. In our view, NMPC's approach raises larger policy issues that the 
PSC may want to address. Second, we analyze the various economic figure(s) of merit that were used by NMPC in selecting the Final Award Group of projects as well as their treatment of uncertainty in bid evaluation. For these issues, we suggest ways in which the utility's analysis could be improved or at least be made more explicit. Finally, we discuss issues related to contingency planning.

\subsubsection{Comparing Economic Benefits and Costs of DSM Bids vs. PSC-Mandated Core DSM Programs}

NMPC's economic analysis and comparison of DSM bids to PSC-mandated core DSM programs raises two important methodological issues: (1) NMPC's use of internal estimates of marginal costs vs. PSC-approved LRACs, and (2) NMPC's decision rules regarding various economic tests used to evaluate DSM programs.

The PSC has ordered utilities to use PSC-approved LRACs in evaluating benefits of DSM programs. However, NMPC's cost/benefit analysis in Phase Two relied on the company's internal estimates of marginal costs, which were significantly lower than the LRACs published in the RFP. NMPC staff state that although company-sponsored DSM programs are analyzed using the PSC-approved LRACs, the programs also are designed to be cost-effective using NMPC's internal (and lower) estimates of marginal costs. However, NMPC's DSM planners have an inherent advantage compared to DSM bidders because they can iterate on program designs, adjusting rebate levels as necessary, so that their programs pass the various costeffectiveness tests under both sets of avoided costs (PSC-approved LRACs and internal estimates of marginal costs). This option was not available to bidders. Moreover, it is clear that many bidders believed that NMPC would perform its economic analysis of project benefits using the avoided costs published in the RFP. ${ }^{34}$

At a minimum, the utility needs to indicate more clearly how avoided costs published in the RFP will be used for bid evaluation and assure that the process is consistent with the evaluation of its own DSM programs. However, this will not fully solve all problems because there is always the possibility that conditions could change significantly between the time the RFP is issued and the utility evaluates bids such that the avoided costs published in the RFP are outdated. In fact, this is the primary reason NMPC gives for discrepancies between the PSC-r pproved LRACs and the Company's lower estimates of marginal costs. ${ }^{35}$ Thus, if self-scoring systems are utilized in the future, the PSC and utilities may want to adopt clear guidelines regarding procedures that

\footnotetext{
34 It is easy to see how DSM bidder's reading the RFP would conclude that price factor scores for individual project would be determined from avoided costs provided in the RFP; see pgs. 5, 30, 35-36 of NMPC's bidding RFP.

35 Because of long-standing differences between utilities and PSC staff in estimating various avoided cost components (energy, capacity), it would be useful to analyze in more depth the factors that account for differences between PSC-approved LRACs and NMPC's marginal costs: 1) changed load/resource balance (increased DSM, lower load growth, and increased non-utility generation) and 2) possible differences in methodology (e.g., treatment of avoided capacity benefits) and resource characterization (assumptions about future power purchase contracts).
} 
the utility will use (if any) to update avoided cost estimates if conditions change significantly after the RFP is issued. If bid prices can not be altered, then DSM bidders can not respond to new conditions and are therefore place at a disadvantage compared to utility DSM planners who can modify DSM programs proposed in a long-range DSM plan based on updated information available only to the utility. Other alternatives could also be considered if the self-scoring system is not retained. For example, several utilities (e.g., Central Maine Power, Public Service Indiana) prefer not to post avoided costs in the RFP.

In its Phase Two evaluation, NMPC was particulariy concerned about the costs of DSM bids to the utility, and eliminated bids that failed the Utility Cost Test using NMPC's lower internal estimates of marginal costs. It is not obvious that this approach is appropriate in the context of an integrated auction which includes supply-side resources. As indicated in Chapter 4, if the utility intends to rely solely on the Utility Cost Test, then bidders must know this prior to submitting bids so they can design their proposals to maximize customer contribution. It is clear that NMPC's rebate programs will look better than DSM bids if only the Utility Cost Test is utilized because they are structured so as to pay only a fraction of the incremental measure costs. In effect, the economic merits of DSM bids are judged against the uuility's rebate levels and administrative costs. At a minimum, if the utility uses this approach, it must be able to assess and properly value the additional services and performance risks being borne by DSM bidders relative to utility rebate programs.

Given limited experience in making these valuations, we believe that the best course is to gain actual field experience contracting with several ESCOs. During the bid evaluation and selection stage, one way to reflect uncertainties in comparing DSM bids with utility rebate programs is to assign some weight to the Total Resource Cost Test. At least in this way there would be some assurance about the social efficiency of DSM programs, and ESCOs could compete on that basis. In this way, ESCOs that offer comprehensive services and packages of retrofits and are willing to bear substantial performance risk are not unduly penalized in comparisons to utility rebate programs. In our view, issues related to price score and cost/benefit analysis of DSM bids ultimately involve, and are directly linked to, more fundamental DSM and integrated resource planning policy issues. Thus, the NYPSC should clarify its position on the range of acceptable approaches that can be used by utilities to ensure that there is consistency in evaluating the merits of utility DSM programs and DSM bids.

\subsubsection{Figure of Merit in Supply Bid and Portfolio Selection}

NMPC uses three different economic figures of merit in its internal memorandum explaining the portfolio analysis (NMPC 1990a). These are Net Present Value (NPV), NPV/kW and B/C. We will summarize the usefulness of each measure for the portfolio selection problem, and recommend one of them, i.e., NPV, as the best choice. We also show that there is no clear way to actually discern which of these, or what combination NMPC may actually have used to makes its choices. 
Different figures of merit exist because there are normalization problems involved in comparing projects of different capacity and lifetime. Clearly, one project may have greater benefits than another simply by being larger. Without some way of ensuring comparability of the net benefits, size differences can distort the economic choice. Similarly, if projects have different liferimes then there may also be comparability problems. Although NMPC discusses the lifetime problem, we are not clear how this was handled. Consequently, we focus attention primarily on the capacity normalization issues.

We have already raised some of these issues in our discussion of ratio price scoring in Section 4.4.2 where $\mathrm{B} / \mathrm{C}$ ratios were contrasted with the $\mathrm{NPV} / \mathrm{kW}$ criterion. The $\mathrm{B} / \mathrm{C}$ ratio is just the inverse of the "percentage of avoided cost" rule where the benefits are the avoided costs and the costs are the bidder's price. By taking the ratio, effects related to the different capacity of projects are removed. Unfortunately, the ratio also removes any measure of the normalized benefits. In the examples used in Section 4.4.2, a low capacity-factor project is compared to a high capacity-factor project. If both have the same ratio score (or B/C), then the high capacityfactor project will produce greater benefits per $\mathrm{kW}$. For screening, or ranking, purposes $\mathrm{NPV} / \mathrm{kW}$ (which is just $\mathrm{B}$ minus $\mathrm{C}$ per $\mathrm{kW}$ ) is superior to $\mathrm{B} / \mathrm{C}$ (or related measures) because it will order projects in order of the greatest economic benefit.

When we come to analyzing portfolios, the problem of capacity normalization is much smaller, but it still persists. As Tables 5-6, 5-7 and 5-8 indicate, the portfolios analyzed by NMPC differ in size by only about $20 \%$ going from small to large, or vice versa. Therefore, the need for capacity normalization of alternatives is much less severe than in the case of project rankings, where differences may range from a factor of 2 to 10 or more. Therefore, NPV, which is just $B$ minus $C$, is the preferred figure of merit. Clearly, NPV will have the same advantages over $\mathrm{B} / \mathrm{C}$ that $\mathrm{NPV} / \mathrm{kW}$ has in the project ranking case, because it is benefits that are being maximized. NPV is also superior to NPV/kW in the portfolio case because NPV/kW will tend to favor smaller portfolios, at least among the very best alternatives. This last point is easily seen by considering iwo portfolios which have nearly the same NPV. Clearly the smaller of these will have grea:er NPV/kW as long as size differences are greater than NPV differences.

These points can be illustrated by reference to the NMPC analysis summarized in Tables 5-6, 5-7 and 5-8 by comparing results for Portfolio 1 and Portfolio 3. The latter is $523 \mathrm{MW}$; the former is $441 \mathrm{MW}$. In the Base Need Scenario (Table 5-6) Portfolio 3 shows an NPV that is $0.15 \%$ greater than Portfolio 1 ( $\$ 127.6$ million vs. $\$ 127.4$ million). Since the size of Portfolio 3 is $18.6 \%$ greater than Portfolio 1, it is no surprise that Portfolio 1 is superior to Portfolio 3 by $18.4 \%$ on the NPV/kW criterion.

Careful examination of Tables 5-6, 5-7 and 5-8 shows no clear explanation of the actual NMPC choice. Although we argue for the primacy of the NPV criterion, that cannot explain the choice of Portfolio 1. More strongly, we can define two competing decision rules NMPC might have used to arrive at the choice of Portfolio 1, and there is no way to distinguish between them. Let us call Theory $A$ the rule that NPV/kW is determinative and Theory $B$ the rule that $B / C$ is decisive, but NPV is used in case of a tie. Theory A always picks Portfolio 1, including in the 
Low Need Scenario, where this choice minimizes losses to the utility (because NPV is negative). Theory B also chooses Portfolio 1. On the basis of the documentary record we have, there is no way to decide between Theory A or Theory B. In short, we don't know how NMPC made its final choice, and they articulate no clear rationale for it. We speculate that the answer may lie in part when we consider schemes for weighing the three need scenarios.

\subsubsection{Treating Uncertainty Explicitly}

Although NMPC examined the economic impacts of projects and portfolios of projects under three alternative scenarios, the Company was ambiguous about how these results were utilized in deciding among various portfolios. We suggest a more explicit approach to handling uncertainty. Specifically, we argue that expected NPV is the most appropriate metric to use in evaluating comparably-sized portfolios of projects. This requires assigning a probability to each scenario and calculating a weighted average NPV which reflects the expected value.

Based on the results of the portfolio analysis, we can infer the probabilities of the scenarios which NMPC may have used implicitly. We present two alternate weighting schemes in Table 5-9. In both cases, we assume the Base scenario is the most likely and assign it a probability of $60 \%$. Table 5-9a shows the case where the Low Need and High Need scenarios are equally likely, each with a probability weight of $20 \%$. In this instance, Portfolio 3 obtains the highest rank. In fact, as long as Low Need and High Need scenarios are given equal probability, a Base scenario probability ranging from $33 \%$ to $100 \%$ produces the same result, which is that Portfolio 3 has the highest expected NPV. ${ }^{36}$

In Table 5-9b, we assign a greater probability to the Low Need scenario (30\%) than the High Need scenario $(10 \%)$. This might reflect expectations for greater DSM penetration and nonutility generation. With these asymmetric scenario probabilities, Portfolio 1 becomes the superior choice on the basis of expected NPV. We have no reason to believe that NMPC actually chose Portfolio 1 in this manner (and indeed they may not have), but this is one piece of evidence for assuming that NMPC implicitly weighted its three future scenarios differently. While we feel that this particular weighting scheme is not unjustified, given the recent history of downgraded load forecasts in New York, it is far preferable that the utility articulate these expectations explicitly in their analysis, rather than leaving them implicit.

\subsubsection{Contingency Planning}

Contingency planning is the managerial response to uncertainty. There are essentially two kinds of uncertainties that NMPC considered in its evaluation procedures. There are uncertainties associated with the level of future demand, which are principally exogenous to the utility. Second, there are uncertainties related to likelihood of successfil development, which we will call project development risk. These are not explicitly separated in the NMPC evaluation

\footnotetext{
${ }^{36}$ Note that Portfolio 3 is preferable to Portfolio 1, the portfolio that actually won, by only about $3 \%$, and that it differs from Portfolio 1 only by the addition of the Minden supply project.
} 
procedure, but it is useful to separate them. We have discussed the first category in the previous section, where we find evidence that NMPC views the Low Need Scenario as more important than the High Need. This would imply that expected need is less than the Base Need Scenario. However, our analysis suggests that NMPC did not carry over this expectation into its treatment of project development risk.

As a hedge against the chance that some of the projects in the Final Award Group would not ultimately materialize (i.e., project development risk), NMPC stated that they would select projects representing $125 \%$ of the resource block need in the Final Award Group (i.e., 125\% of $350 \mathrm{MW}$ or $438 \mathrm{MW}$ ). Other utilities have used a similar approach to awarding contracts in a competitive bidding situation. For example, Virginia Power included an assumption of $20 \%$ "attrition" from its expected need when it awarded contracts in its 1988 solicitation. NMPC's Phase Two evaluation is somewhat different, however, since they appear to have used the $25 \%$ contingency allowance as a "floor" in the portfolio analysis, and not as a "ceiling". The smallest portfolios analyzed in Phase Two were essentially at a capacity level corresponding to $125 \%$ of the resource block. The only size adjustment made by NMPC was upward, rather than downward (which would have been more consistent with NMPC's judgment of exogenous need).

There are at least two separate sources of the inflexibility in NMPC's choice of portfolios. First, supply-side projects are often "lumpy", that is, they are large relative to the resource block. In NMPC's case, the lumpiness problem appears particularly difficult because of apparent economies of scale. The larger projects are cheaper than the smaller ones. Therefore, if one of the two large supply-side projects is excluded from a portfolio, if it were replaced by a supply project, then that project would probably be inferior. More importantly, however, NMPC has precluded the possibility of expanding the DSM role in the portfolio analysis. The single DSM portfolio of $36 \mathrm{MW}$ is invariant to all the analysis, and there is never any comparison of marginal DSM with marginal supply projects. As discussed in section 5.2.1, NMPC followed a staged approach in Phase Two in screening DSM bids first, then combining the winning DSM bids into a group as a fixed input to the portfolio analysis. What was lost in this approach was any meaningful comparison of marginal DSM bids and supply bids. ${ }^{37}$ Such comparisons could have produced smaller total portfolios. On the basis of calculations such as Tables 5-9a and 5$9 \mathrm{~b}$, it is entirely possible that the expected NPV of smaller portfolios with more DSM would be superior to the performance of Portfolio 1. Since such an exercise was never reported in the NMPC documents that we have examined, it is not possible to determine if this is the case. Presumably, it would result primarily from diminished losses to the utility in the Low Need Scenario, and a high probability assigned to that case.

\footnotetext{
${ }^{37}$ By marginal bids, we mean those bids that were not included in the group of DSM bids that passed the initial Phase Two screening.
} 
Table 5-9a. 20-60-20 Weighting of Scenario Results

\begin{tabular}{|c|c|c|c|c|}
\hline \multirow[b]{2}{*}{ Weights: } & \multicolumn{4}{|c|}{$\begin{array}{l}\text { Net Present Value of Savings } \\
\text { (Millions of } 1990 \$ \text { ) }\end{array}$} \\
\hline & $20 \%$ & $60 \%$ & $20 \%$ & \multirow{2}{*}{$\begin{array}{l}\text { Weighted } \\
\text { Average }\end{array}$} \\
\hline Portfolio & Low Need & Base & High Need & \\
\hline 1 & -146.7 & 127.4 & 627.2 & 172.5 \\
\hline 2 & -151.2 & 126.2 & 632.9 & 172.1 \\
\hline 3 & -177.1 & 127.6 & 681.1 & 177.4 \\
\hline 4 & -182.9 & 126.7 & 686.8 & 176.8 \\
\hline 5 & -205.7 & 53.0 & 643.6 & 119.4 \\
\hline 6 & -221.5 & 52.0 & 649.8 & 116.9 \\
\hline 7 & -250.6 & -19.7 & 421.1 & 22.3 \\
\hline 8 & -244.5 & -10.1 & 414.7 & 28.0 \\
\hline
\end{tabular}

Table 5-9b. 30-60-10 Weighting of Scenario Results

\begin{tabular}{|c|c|c|c|c|}
\hline \multirow[b]{2}{*}{ Weights: } & \multicolumn{4}{|c|}{$\begin{array}{l}\text { Net Present Value of Savings } \\
\text { (Millions of } 1990 \$ \text { ) }\end{array}$} \\
\hline & $30 \%$ & $60 \%$ & $10 \%$ & \multirow{2}{*}{$\begin{array}{l}\text { Weighted } \\
\text { Average }\end{array}$} \\
\hline Portfolio & Low Need & Base & High Need & \\
\hline 1 & -146.7 & 127.4 & 627.2 & 95.2 \\
\hline 2 & -151.2 & 126.2 & 632.9 & 93.7 \\
\hline 3 & -177.1 & 127.6 & 681.1 & 91.5 \\
\hline 4 & -182.9 & 126.7 & 686.8 & 89.8 \\
\hline 5 & -205.7 & 53.0 & 643.6 & 34.5 \\
\hline 6 & -221.5 & 52.0 & 649.8 & 29.7 \\
\hline 7 & -250.6 & -19.7 & 421.1 & -44.9 \\
\hline 8 & -244.5 & -10.1 & 414.7 & -37.9 \\
\hline
\end{tabular}




\section{Chapter 6 \\ Reactions to Niagara Mohawk's DSM Bidding Program}

\subsection{Overview}

In this chapter, we discuss reactions to the demand-side component of Niagara Mohawk's (NMPC) bidding program. We draw upon several sources including our own survey of prospective and actual DSM bidders, an evaluation prepared for the company by ERCE Environmental and Energy Services (ERCE 1991), formal protests submitted by losing bidders to the New York Public Service Commission, and interviews with Niagara Mohawk staff.

Many of the subjects explored in this section are typically discussed in the context of a formal process evaluation, such as that conducted by ERCE for Niagara Mohawk. The prototypical process evaluation is oriented toward providing feedback on ways to improve program design: how was the program implemented, discussion of the logistics of program operation and barriers to implementation, and perceptions of managers, participants, and regulatory agencies. However, with DSM bidding programs, the perspectives of participants must be interpreted critically because we must account explicitly for the relative number of winning and losing bidders in making comparisons across nrograms. In addition, the financial stakes for winning and losing bidders are typically far higher than the decision of a customer whether or not to participate in a utility-sponsored DSM program. Bidders incur substantial expenses in bid preparation and we would expect that the opinions and views of losing bidders on certain questions (e.g., overall fairness of bid evaluation and selection process) may be influenced by the outcome. Moreover, the arms-length relationship between utility and bidders (e.g., buyer and sellers) established by a procurement framework creates a different dynamic than the typical utility-sponsored DSM program which is available to all qualified customers. Because of these factors, the analytic framework used in process evaluations of utility DSM programs must be adapted somewhat to the bidding context because of the differing interests and objectives of various parties. Despite these caveats, potential and actual bidders can provide valuable insights into aspects of program design and implementation that worked well, identify problem areas that need improvement, and discuss factors that affected their decisions to participate.

\subsection{Survey of Prospective and Actual DSM Bidders}

LBL conducted a telephone survey of a sample of prospective and actual DSM bidders in the Niagara Mohawk and Consolidated Edison bidding programs during May-June 1991. The objectives and scope of the LBL survey were rather limited, in part because of the activities of other organizations. The Bidding Working Group, led by the Department of Public Service, plans to survey supply-side and DSM bidders, and both utilities are conducting evaluations of their bidding programs. We wanted to minimize overlap with their efforts. We developed separate surveys for bidders and non-bidders, which relied heavily on open-ended questions and 
covered selected topics (see Appendices A and B for bidder and non-bidder survey). Major issues explored with bidders in NMPC's program included: ${ }^{38}$

(1) factors that influenced prospective DSM bidders in their decision about whether to participate in the NMPC bidding program and assessment of program design features;

(2) assessment of the utility bid evaluation and selection process. This became a very contentious issue in the Phase Two evaluation of bids;

(3) coordination and relationship between DSM bidding and the utility's other DSM programs. ESCOs confront this issue in bid preparation (developing their target market and marketing plan), as well as in bid evaluation. We sought bidders perceptions about how this issue should be handled, their views on the approaches adopted by NMPC, and suggestions about how to handle this issue in the future;

(4) suggestions for improving future DSM bidding programs. ESCOs and customers are a prime source for input about how to improve the next round of DSM bidding programs (should they be continued);

(5) summary of key issues that arose in contract negotiations with winning DSM bidders.

Another objective of the surveys was to obtain some insights into the way that different entities in the energy services market respond to DSM bidding programs. We think it useful to segment potential bidders into three broad categories: energy service companies that have participated in other utility DSM bidding or performance contracting programs ("national" ESCOs), local firms that provide various types of energy services, and ultimate customers. ${ }^{39}$ We believe that there are some important distinctions among these groups both in terms of their frame of reference with which they evaluate DSM bidding programs (relative to other opportunities) as well as for the utility that has to judge the relative merits of their bids. ${ }^{40}$ Distinctions between local and "national" energy service firms are not static because barriers to entry in other locations are not high. Local energy service firms can expand relatively easily into other markets, but at this stage we believe the distinction can be illuminating. One underlying hypothesis is that DSM bidding programs may need to be tailored more selectively to potential respondents (ESCOs vs. customers). Other evaluations of bidding programs have noted that customers differ from ESC.Os in their reasons for participation, financial constraints, technical expertise, and project size (ERCE 1989; ERCE 1990).

Niagara Mohawk received 33 DSM bids from 20 different companies in response to its solicitation. Using our classification scheme, 14 companies were "national" ESCOs, one firm

38 Responses of prospective and actual bidders in Consolidated Edison's program will be discussed in the final report in the context of an overall review of that utility's program.

${ }^{39}$ ESCOs that have participated in other utility DSM bidding programs bring a somewhat different experience and perspective thar local firms.

${ }^{40}$ For example, the point of reference for a customer in deciding to bid is other utility DSM programs. For a "national" ESCO, it is the relative merits of submitting a bid in one program compared to other DSM bidding programs. 
was a local energy services company, and five bids were submitted by large industrial customers. We interviewed 18 of the 20 companies that submitted DSM bids. In addition, we identified and attempted to contact a selected sample of 'DSM non-bidders, which were drawn from lists of entities that were sent or requested NMPC's (and Consolidated Edison's) RFP. Given that virtually every "national" ESCO responded to NMPC's solicitation, we attempted to identify local energy service firms and customers that had received NMPC's RFP but chose not to respond. We identified 17 firms that were non-bidders and which, based on very limited information, could potentially be either a local energy service firm or large customer. ${ }^{41}$

Responses of bidders are discussed first, followed by those of non-bidders.

\subsubsection{Profile of ESCO bidders}

Based on information collected by ERCE in their telephone survey, 8 of 13 of the ESCOs are headquartered in the Northeastern United States. ${ }^{42}$ The firms surveyed indicated that they are active in 25 different states, and have been in business for an average of 13 years. About $70 \%$ of the ESCOs indicated that they also operate programs that are not affiliated with DSM bidding solicitations. Almost half of the ESCOs have conducted programs or signed contracts with other New York utilities.

Table 6-1 summarizes the services provided to customers by the 13 ESCOs surveyed by ERCE and suggests that most ESCOs offer comprehensive energy services to customers including audits, management of facility energy use, installation of measures, financing, and monitoring of savings. ESCOs that responded to the NMPC RFP also tend to target their activities to specific customer segments. Eleven of 13 ESCOs focus on commercial and industrial customers, while six of 13 ESCOs indicated that they do work in the residential sector, but only one firm concentrates exclusively on residential customers.

In addition to asking bidders about their reasons for participating, the LBL survey probed specifically about the effect, if any, of the fact that the bidding program was integrated and included all-sources, both supply and demand-side resource options. Six of the 18 bidders surveyed were initially encouraged by the fact that the bid was integrated to include supply and demand. Several bidders remarked that NMPC's apparent intent to create "a level playing field" in evaluating resource options was a positive feature. The other 12 bidders indicated that the

\footnotetext{
4) Given the relatively low priority of this task, we used a simple, somewhat crude approach. We eliminated companies with out-of-state addresses as well as companies that appeared to be independent power producers.

42 Bidder profile information reported by ERCE accurately reflects the characteristics of ESCOs surveyed by LBL because the sample is virtually identical (13 of the 14 ESCOs that LBL surveyed are included in the ERCE evaluation).
} 
Table 6-1. Services Provided by Bidding ESCOs

\begin{tabular}{lc}
\hline Service & $\begin{array}{c}\text { Number of ESCOs } \\
\text { Providing Service }\end{array}$ \\
\hline Energy Management & 12 \\
Whole Building Analysis & 12 \\
Energy Use Monitoring & 12 \\
Financing Arrangement & 11 \\
End-Use and Load Shape Analysis & 11 \\
Measure Installation & 10 \\
Assisting Customers with Utility Programs & 5 \\
Third Party Turn Key Operations & 1
\end{tabular}

Source: ERCE 1991.

integration of supply and demand had no impact on their decision to bid. Many of the "national" ESCOs indicated that they would bid in either separate DSM or integrated auctions.

After the announcement of the Final Award Group, a number of bidders commented that the auction had not been truly integrated. For example, a comment by one ESCO echoes concerns voiced by others: "The auction includes supply and demand only on paper."

We also asked bidders to describe the focus and scope of their proposal in terms of measures offered, targeted market segments, end uses, and specific energy-efficient technologies. About half of the ESCOs indicated that they were proposing comprehensive retrofits of all cost-effective measures in each customer facility, and targeted at industrial, commercial, or institutional buildings. About one-third of the ESCOs were proposing only measures covered by rebates offered by NMPC (e.g., commercial lighting). Some customers and other ESCOs bid a limited list of measures, but chose technologies not covered by Niagara Mohawk's core DSM programs.

\subsubsection{Assessment of Program Design Features}

The LBL surve $j_{j}$ asked bidders to comment on individual elements of the solicitation that they thought were particularly well conceived or needed improvement and, then depending upon responses, probed specific areas (e.g., various threshold and self-scoring criteria, time for response to RFP). Overall, NMiPC's RFP received high marks among bidders for being welldesigned and conceived. In general, most bidders felt that the threshold criteria and self-scoring criteria used in the Phase One bid evaluation were reasonable. There were some exceptions to this prevailing view, which are worth mentioning. 
In terms of threshold criteria, one or two ESCOs indicated that they would have preferred a shorter minimum contract length because they thought it would be difficult to persuade host customers to sign a 15-year contract. Several customers and smaller local energy service firms stated that the $100 \mathrm{~kW}$ minimum bid and the $\$ 15 / \mathrm{kW}$ deposit represented a barrier. However, the most significant barrier for these customers was the perceived complexity and up front costs of bid preparation. One customer that submitted a bid felt that it was "impossible for customers to fill out themselves." All customers indicated that they hired outside experts to prepare their bid.

There were relatively few complaints regarding the self-scoring criteria. One ESCO indicated that the self-scoring system was too rigid to properly evaluate bids and would have preferred more negotiation among the parties. Two ESCOs felt that price was too dominant a factor and that qualifications and experience should be given additional weight in the RFP. Several ESCOs commented that payment and measurement/verification issues should be detailed more explicitly in the RFP, particularly if price is non-negotiable, because of their potential impact on performance risk assumed by the bidder. Resolution of these measurement and verification issues later delayed the contract negotiation process.

\subsubsection{Bid Evaluation and Selection Process}

We asked DSM bidders if they were satisfied with the way that NMPC's two-stage bid evaluation and selection process worked in practice and whether the company provided an explanation for their decision in selecting the Final Award Group. All bidders indicated that the first phase of the selection process followed the intent of the RFP and that verification of bid scores by an independent third party and selection of an Initial Award Group worked well. Several bidders commented that the third party firm that evaluated and verified bids in the first phase did "a workmanlike job", was "very professional" and that this approach "increased the credibility of the process". A number of bidders did however point out that the scoring software provided in the RFP package could be improved as it had some apparent bugs and was difficult to use.

In contrast, many bidders, particularly those that were not selected to the Final Award Group, were quite critical of the Phase Two evaluation process. Comments from losing bidders included:

- "Niagara Mohawk changed the rules in midstream, which was not fair."

- "Niagara Mohawk did not award based on their published RFP methodology."

- "The second stage was a black box; the effect of Niagara Mohawk's other DSM programs was not specified beforehand."

Most losing bidders thought the phase two bid evaluation process was not fair principally because criteria were not explained adequately in advance (i.e., in the RFP) and because they were not told that their bids would compete with NMPC's other DSM programs (ERCE 1991). Winning bidders were less critical of the process, though some indicated that they would have 
had radically different attitudes if they had lost. Nearly all bidders indicated that increased communication between the utility and bidders was needed during various stages of the bid evaluation and selection process. This sentiment encompassed bidders' preference for the utility to be more explicit in the RFP regarding its evaluation criteria, particularly the way that bids will be assessed in relation to other utility DSM programs. Several bidders also thought that the Phase Two selection process should explicitly allow for negotiation between the utilities and bidders.

\subsubsection{Coordination and Relationship to Utility DSM Programs}

It became clear after the results of the Phase Two evaluation were announced that NMPC explicitly compared bids to the company's other core DSM programs. We asked bidders for their views on the appropriate relationship between a utility's other DSM programs and DSM bids. ESCOs articulated similar opinions on this topic and suggested several different approaches. All bidders stated that it was important for the utility in its RFP to articulate clearly how bids would be evaluated against the utility's own DSM programs. Most ESCOs stated that it was acceptable to compare utility DSM programs against third party bids if similar standards are applied. However, virtually all ESCOs believe that utility rebate programs are not comparable to typical DSM bids because certain costs are not accounted for (e.g., operations and maintenance), while savings are not typically monitored and verified over the expected lifetime of the measure.

Several ESCOs suggested that utility DSM programs should be put out to bid or that the utility should bid its own DSM programs in an auction in a similar fashion to utility generation projects. Other ESCOs acknowledged that the problem of evaluating utility DSM programs vs. third party DSM bids was structurally quite difficult, given the utility's ongoing relationship with customers, and thought that segmenting markets between utility-operated DSM programs and ESCOs was the best solution.

\subsubsection{Contract Negotiation Process}

Four of the twenty bidders had proposals that were selected for the Final Award Group. Contract negotiations were still underway in May-June 1991 during our initial survey. At that time, winning bidders expressed some frustration and indicated that measurement and evaluation protocols to be used in verifying energy savings were among the most controversial and difficult issues to negotiate.

We interviewed several winning bidders again on key issues that arose during contract negotiations after the process was completed (see Appendix A for survey questionnaire). Overall impressions of the interaction with Niagara Mohawk were much more favorable after contracts were signed. Bidders indicated that the primary issues which had to be resolved were the savings measurement and evaluation protocol as well as situations in which the ESCO had no control over savings not being realized over the expected lifetime (e.g., termination issues such as customer closing facility). Topics that had to be resolved included acceptable methods of 
defining baseline energy consumption from which energy savings would be calculated, appropriateness of including and techniques to estimate the effect of "free riders", and specification of acceptable monitoring protocols for individual measures. Initially, NMPC and ESCOs held fairly divergent views on several of these topics, and we will examine the compromises negotiated in the contracts in more detail to illustrate these risk allocation issues. If price is non-negotiable, it is clear that utility expectations regarding appropriate measurement and verification activities must be better understood by and communicated so that potential bidders can factor these costs and risks into their bid prices.

\subsubsection{Overall Impressions of Bidding Program}

Bidders overall assessment of the program was greatly influenced by relative outcome (i.e., winners or losers). But this simple explanation does not adequately capture the depth of feelings expressed by many participants. Virtually all DSM participants had extremely high initial expectations for the NMPC program and many were disappointed and surprised at the outcome that emerged from NMPC's Phase Two bid evaluation process. In contrast, most prospective bidders implicitly had very low expectations for Consolidated Edison's DSM bidding program. ${ }^{43}$

The intensity of feelings of losing bidders comes through in their comments:

- "NMPC's bidding program was anti-competitive; there was no level playing field."

- "The program was a waste of participants time and money."

- "It stunk."

- "Niagara Mohawk lost tremendous credibility; it set the industry back a year or two."

- "Niagara Mohawk violated the clear provi sions of the RFP that the PSC had approved by failing to conduct an 'all-source' bid."

In our view, losing bidder's reacted so negatively to the Final Award Group selection process in part because expectations were so high for NMPC's bidding program. From NMPC's perspective, the negative views expressed by several customers should be particularly troubling because they may adversely affect the utility's ongoing relationship with large electricity consumers. Winning bidders were less critical of the process, and thought that NMPC did a reasonable job in implementing a complex, experimental program.

\subsubsection{Bidder's Suggestions for Improvement}

Bidders had four major suggestions for improving the bidding program. First, customers stressed that the bidding process needed to be simplified in order to reduce transaction costs. Second, criteria that will be used in a second stage evaluation process that involves utility

43 Con Ed received few bids and many respondents indicated that the utility appeared to be hostile to DSM bidding, had established onerous threshold requirements, and that it was difficult for ESCOs to compete with Con Ed's rebate programs. Bidder responses to Con Ed's program will be discussed in more detail in the final report. 
judgments should be more explicit and articulated in advance in the RFP. Implicitly, there must be an explicit linkage berween the first and second phase evaluation stages so that utility preferences are consistently communicated to bidders. Third, the utility's RFP should specify how bid proposals will be evaluated relative to the utility's other DSM programs. Fourth, some bidders recommended that the Phase Two evaluation process should include direct negotiations between utilities and possible winners to refine and clarify proposals.

\subsection{Responses from Non-bidders}

The focus of the non-bidders survey was on identifying barriers to participation. As mentioned previously, we attempted to contact 17 companies that received NMPC's RFP. Attrition was quite high as shown in Table 6-2. Eight firms were not eligible to submit their own DSM bids because they were either lawyers, consultants, or supply-side energy firms. We were unable to contact six companies. For three of these six companies, we ascertained that they wert large Niagara Mohawk customers and hence possible bidders, but we did not succeed in reaching the person who received the RFP. Of the three remaining firms, two companies were iocal energy service firms, while the other was a large customer. Neither of the two locai ESCOs had participated in previous utility DSM programs. Both work directly for clients and indicated that the RFP would have to be simplified before they would be interested in submitting a bid of their own. The potential customer bidder felt that the RFP needed better publicity and that the company should use personal contact to recruit large customer bids. The customer also indicated that the bidding process was too complicated.

Table 6-2. Attrition Among Non-bidder Sample

\begin{tabular}{lc}
\hline Original Sample & 17 \\
Unable to Contact & -6 \\
Supply-side Firms & -8 \\
Final Interview Sample & 3
\end{tabular}

Given the small sample size of non-bidders, we are quite limited in our ability to draw definitive conclusions from these few interviews, although comments made by customers and local energy service firms tend to reinforce views stated by bidders with similar characteristics.

\subsection{Reactions of Utility Staff}

After interviewing prospective and actual bidders, LBL surveyed Niagara Mohawk's DSM planning staff that were involved in bid evaluation. We focused on several topics including the utility's assessment of program design features and the bid evaluation process, major issues in contract negotiation, overall impressions, and suggested improvements (see Appendix C). 
Several of our questions were designed to elicit the utility's perspective on concerns and criticisms that had been raised by bidders.

\subsubsection{DSM Bid Evaluation and Selection Process}

NMPC staff indicated that the self-scoring system used in the first stage did not work particularly well for DSM projects because it did not discriminate among projects. In addition, NMPC staff believe that some bidders misinterpreted the price factor scoring and assumed that the iong-run avoided costs (LRACs) represented NMPC's ceiling price when in fact the utility intended them to be used only to provide an index reference for the price score. NMPC staff also pointed out that, to some extent, the scoring system was a negotiated process involving input from various parties. Many parties pushed for minimal threshold and eligibility requirements and a points and weight system, which influenced the scoring system ultimately approved by the Commission.

Because a self-scoring system was not sufficient, some NMPC staff viewed the step two process as "a safety net". NMPC staff generally defended phase two of the bid evaluation process and argued that it was consistent with the approved bidding guidelines. The RFP specifically indicated that in step two, NMPC would exercise its considered judgment reflecting a variety of factors in selecting winners from the Initial Award Group. They stated that an extensive assessment and thorough review was conducted for individual DSM projects. With the benefit of hindsight, NMPC staff did acknowledge that the utility could have been clearer about the criteria that would be used in the second stage evaluation. In particular, the utility should have stressed more that there would be a direct comparison of utility-sponsored DSM programs with ESCO bids and that the LRACs should not be interpreted as a ceiling price.

\subsubsection{Contract Negotiation Issues}

Utility staff indicated that there were initially strongly divergent views between the utility and winning bidders on what constituted an acceptable measurement and verification plan for energy savings. NMPC argued that it was important to account explicitly for "free riders" in measurement and verification plans and that it was unacceptable to base ESCO payments solely on metered savings at host facilities (i.e., "gross savings"). NMPC favored having strong termination or buyout clauses in the contract if net savings from projects turned out to be lower than expected. In general, ESCOs were unwilling to tie their payments to impact evaluations which would calculate "free riders".

\subsubsection{Lessons Learned}

Utility staff involved in evaluation of DSM bids offered insights on their preferences regarding the design and implementation of any future bidding program. First, NMPC staff believe that the self-scoring system did not adequately discriminate among DSM bids and that it would be preferable to develop separate scoring system and criteria for supply-and DSM bids. Second, a two-stage bid evaluation process could still work if threshold and eligibility requirements were 
articulated more clearly and in more detail. Future DSM procurements should also be targeted specifically to appropriate market segments/end uses or desired technologies. In addition, threshold requirements should include a more detailed discussion of the utility's expectations regarding the type of measurement and evaluation plans and protocols that would be considered adequate. Third, given the confusion and ambiguity regarding price scoring, NMPC staff indicated that passing the total resource cost test should be a threshold requirement for bidders and that the utility cost test should be the primary criteria used to evaluate the price factor. Fourth, NMPC staff do not think it necessary to include avoided costs as a reference price. Fifth, given the high transaction costs associated with preparing bids, few customers are likely to particifate in bidding programs as currently structured. Options include developing a separate, simplified bidding process tailored to customers or encouraging customers to participate in the utility's other DSM programs. 


\section{Chapter 7 \\ Relationship Between DSM Bidders and NMPC's Other DSM Programs}

\subsection{Overview}

In this chapter, we discuss the relationship between the activities of winning DSM bidders that have signed contracts and NMPC's other DSM programs. First, we review the company's recent long-range and annual DSM prograin plans to provide the overall context. We then describe the implementation and marketing plans of bidders with signed contracts as well as NMPC's evaluation plans for these projects. Our discussion of contract terms and provisions is based solely on interviews with NMPC staff and ESCOs, because we were not able to obtain actual signed contracts. The analysis could undoubtedly be improved if the contracts were available. Finally, we discuss the potential for overlap between sectors and end uses being targeted by winning bidders and the Company's other DSM programs. ${ }^{44}$

\subsection{Niagara Mohawk's DSM Plan and Programs}

We reviewed Niagara Mohawk's annual DSM program plans for the last several years to develop a sense of overall trends in the company's DSM programs and expenditures. We grouped company programs and activities into three broad categories: information and pricing programs, programs that involved financial incentives to customers, and development and support activities. ${ }^{45}$ It appears that NMPC assigns most evaluation costs to specific piogram budgets if activities are directly related to that program (e.g., impact evaluation). Development and support projects tend to be activities that are not directly linked to a program. Table 7-1 shows projected expenditures based on the previous year's annual DSM plan. Niagara Mohawk has steadily ramped up its DSM activities during the last 3-4 years, with projected expenditures expected to exceed $\$ 53$ million by 1992 , up from $\$ 11$ million in 1989 . $^{46}$ Programs that involve financial incentives to customers (mainly rebates) have accounted for most of the growth in DSM spending and now account for the majority of the budget. A cursory review of data on artual DSM expenditures suggests that NMPC has had some difficulty in actually ramping up its

\footnotetext{
44 In our final report on integrated resource bidding at both Niagara Mohawk and Consolidated Edison, we will review the actual impacts of the DSM bidding program in more detail, including a discussion of customer acceptance, participation levels, savings, and costs (information permitting). However, because of the limited number of bids accepted by NMPC that actually overlap with the company's other DSM programs, it is unlikely that we will be able to compare alternative delivery approaches in a meaningful way.

${ }^{45}$ We included residential time-of-use rates, voluntary interruptible pricing, and the hourly integrated pricing program under the pricing category. The primary objective of the pricing programs is load management. Energy Management Information Services, Commercial/Industrial Energy Audits, and Residential Bill Disaggregation were grouped under information programs.

46 This data comes from NMPC's long-range DSM plans submitted to PSC; actual expenditures approved by the Commission for annual program plans could differ significantly, although the overall upward trend is accurate. For example, NMPC's approved budget for 1989 was $\$ 10.26$ million compared to the $\$ 11.2$ million in initial filing.
} 
Table 7-1. NMPC's Projected DSM Expenditures (Million \$)

\begin{tabular}{lcccc}
\cline { 2 - 4 } & 1989 & 1990 & 1991 & 1992 \\
\hline Information/Pricing & 0.27 & 9.29 & 7.76 & 11.10 \\
Financial Incentives & 8.22 & 17.30 & 27.08 & 31.64 \\
$\begin{array}{l}\text { Development \& } \\
\text { Support }\end{array}$ & 2.72 & 5.53 & 8.16 & 10.98 \\
Total & $\$ 11.2$ & $\$ 32.1$ & $\$ 43.0$ & $\$ 53.7$ \\
Source: NMPC 1988b (Table 3): NMPC 1990b (Table 2). & & & \\
\hline
\end{tabular}

programs and making the transition from mostly pilot R\&D activities to implementation of largescale, system-wide programs. For example, in 1989, the Company's actual DSM expenditures were only about $\$ 3.6$ million compared to an approved budget of $\$ 10.2$ million (NMPC 1990b).

Until recently, NMPC's DSM programs have consisted principally of small-scale, pilot programs. The Company's low-cost measures, interruptible pricing, and commercial lighting programs represent larger-scale efforts and are projected to account for the majority of Niagara Mohawk's anticipated winter capacity and energy savings (see Fig. 7-1). However, by 1992, energy savings from Other programs, which include a customized rebate program for large $\mathrm{C} / \mathrm{I}$ customers, rebate programs for motors, drives, and HVAC equipment, and an integrated residential program, are expected to provide an important contribution to the overall DSM goals.

The interruptible pricing program is designed to allow the utility to adjust to quick fluctuations in the market. Initially, Niagara Mohawk planned to capture more than $100 \mathrm{MW}$ of capacity in 1990 from interruptible pricing schemes. Given personnel limitations, Niagara Mohawk was unable to sign up and meter the necessary number of customers, causing the program goals to be scaled back for 1991. However, in the first quarter of 1991, Niagara Mohawk exceeded the revised goals for this program.

NMPC's low-cost measures program provides eligible residential customers with a low-flow showerhead, hot water pipe insulation, electric hot water heater wrap, and faucet aerators at no charge. The program is targeted at customers with electric water heating. In its 1989 plan, NMPC projected that its low-cost measures program would account for almost $90 \%$ of the total estimated DSM savings (see Fig. 7-1). Capacity and energy savings are expected to decline relative to 1990 levels as the program begins to saturate the target market. NMPC's 1991-92 DSM plan includes a proposal for an Integrated Residential Program, which represents a major expansion to include other end uses (lighting) and target markets in the residential class (e.g., electric heating). It is useful to describe this new program briefly because some of the components include markets and end uses that may be targeted by SESCO, one of the winning bidders. As described in the 1991-92 Long-Range DSM Plan, the Integrated Residential Program draws together many of NMPC's new initiatives in the residential sector under a single 
Figure 7-1. Niagara Mohawk DSM Saving Estimates

\section{Capacity}

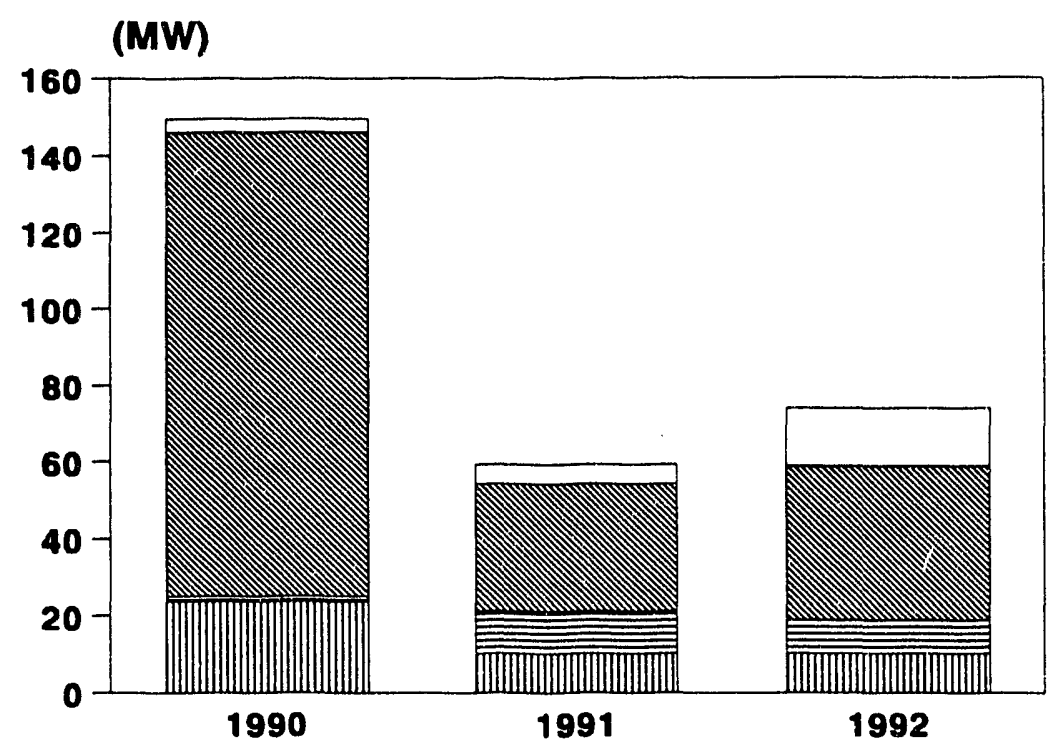

\section{Energy}

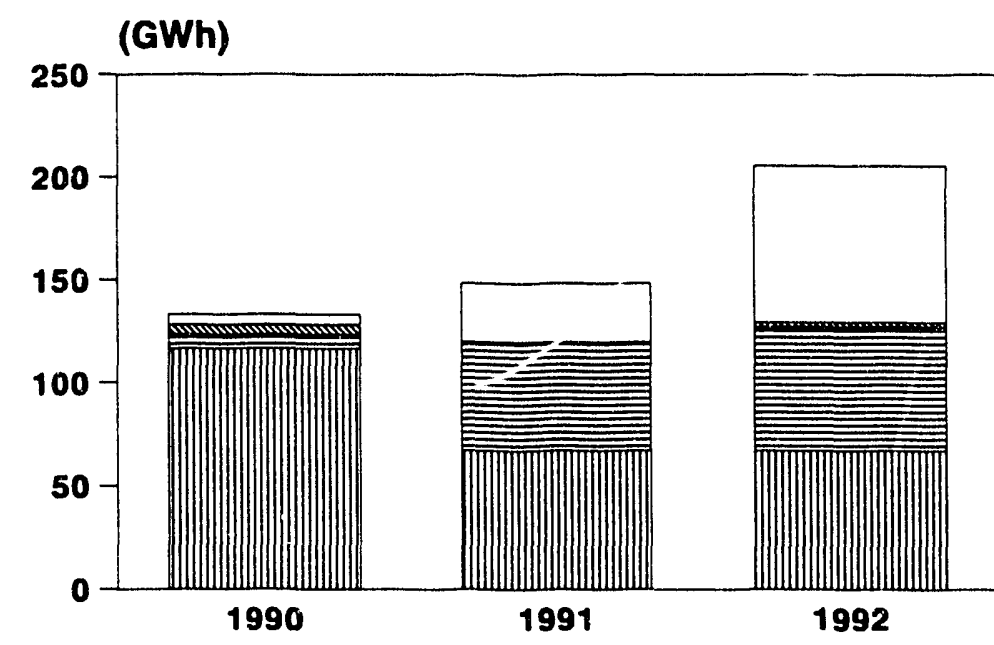

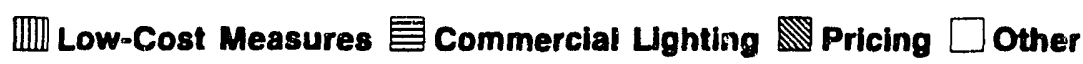
Source: AMPC DSM Plans $(1980,90,01)$ 
Table 7-2. Rebates Offered in NMPC's C/I Lighting DSM Programs

Product

Rebate

Screw-in fluorescent lamps:

compacr unit $\ldots \ldots \ldots \ldots \ldots \ldots \ldots \ldots \ldots \ldots \ldots \ldots$ $\$ 4$

compact twin tube w/screw-in adaptor

$\$ 8$

hard-wire permanent replacement kit

$\$ 10$

Fluorescent reflectors

$\$ 30 /$ fixture

Occupancy sensors:

wall sensor $\ldots \ldots \ldots \ldots \ldots \ldots \ldots \ldots \ldots \ldots \ldots \ldots \ldots$

$\$ 15 /$ unit

ceiling sensor

$\$ 20 /$ unit

High pressure sodium/metal halide fixtures:

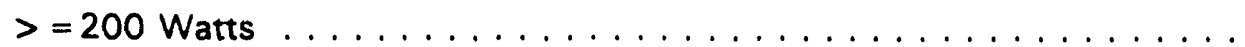

$\$ 60$

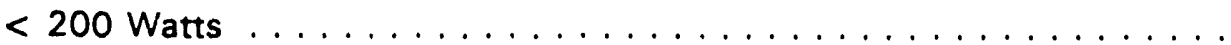

$\$ 50$

High-efficiency fluorescent lamps

$\$ 0.40$

Electronic fluorescent ballasts

$\$ 20$

Hybrid fluorescent ballasts . . . . . . . . . . . . . . . . . . . . . . . . .

$\$ 7.50$

T8 fluorescent fixtures/electronic ballasts

$\$ 30$

Fluorescent exit sign

same as CFLs

Source: NMPC 1990b

banner: rebates for load-shifting and energy-efficiency options for electric heat customers (e.g., supplemental electric thermal storage equipment, heat pumps), energy-efficient security lighting (e.g., high-pressure sodium), installation of 110,000 compact fluorescent lamps sold by local service organizations for $\$ 10$ for four compact fluorescent lights (CFLs), and energy-efficient options for electric-heated new construciion (NMPC 1990b).

NMPC expects that its commercial/industrial lighting program will continue to grow steadily over the next several years. The program provides rebates for customers that install eligible high-efficiency lighting products. Based on results from a pilot program, NMPC has set rebate levels at about $50 \%$ of the incremental price difference between standard and high-efficiency lighting products. Planned rebate levels for various components are shown in Table 7-2. NMPC 
will market the program through multiple direct mailings to eligible customers and through participation of trade allies. NMPC is concerned that rebates be targeted only to those customers that are replacing less efficient lighting products. Thus, NMPC proposes to minimize "free riders" by preapproving customer requests that exceed $\$ 5,000$, which will involve an assessment of the customer's current lighting system, and conducting a post-installation verification for customers whose rebate levels exceed $\$ 1,000$. NMPC planned to start the program in 1990, with estimated savings of 50-60 GWh per year projected for 1991 and 1992 (see Fig. 7-1).
Figure 7-2. NMPC's Projected Expenditures on DSM

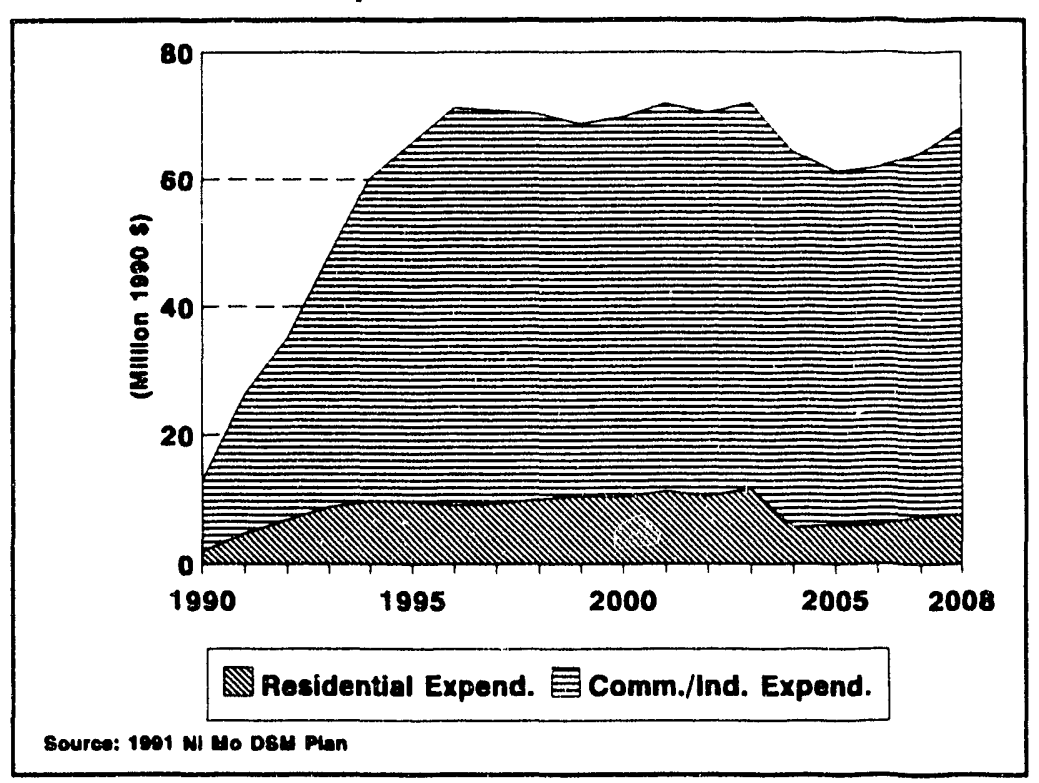

We provide these sletails about NMPC's lighting program because the utility has proposed similar program designs for other major end uses in the C/I sector (e.g., high-efinciency HVAC and motors). NMPC's program designs for these new programs feature rebates in which incentive levels are typically set at about $50 \%$ of the incremental cost difference between highefficiency and standard products or 50\% of NMPC's avoided cost for each measure, whichever is lower. NMPC relies on informational brochures, direct marketing of large customers, and promotional activities of trade allies. While NMPC does not currently offer a comprehensive retrofit program to $\mathrm{C} / \mathrm{I}$ customers, the utility viewed proposals by ESCOs that offered multiple measures to large commercial/industrial customers as potentially overlapping with NMPC's current and proposed rebate programs (NMPC 1990a).

Over the long-term, Niagara Mohawk has developed very ambitious goals for its DSM activities, which are described in detail in the company's 1991-92 Integrated DSM Plan (NMPC 1990h). As Fig. 7-2 shows, NMPC's spending on DSM, expressed in constant 1990 dollars, is projected to increase at a fairly rapid rate until about 1996 and then level off at approximately $\$ 65-70$ million/year (in constant dollars). In nominal dollar terms, NMPC's DSM budget is projected to be almost $\$ 150$ million by the year 2008 . About $60-70 \%$ of total DSM expenditures will be directed at customers in the commercial/industrial sector. By 2008, Niagara Mohawk estimates that proposed DSM programs will save over $2,700 \mathrm{GWh}$, while reducing winter peak capacity by over $700 \mathrm{MW}$ (see Fig. 7-3). 
Figure 7-3. NMPC's Projected Savings From DSM
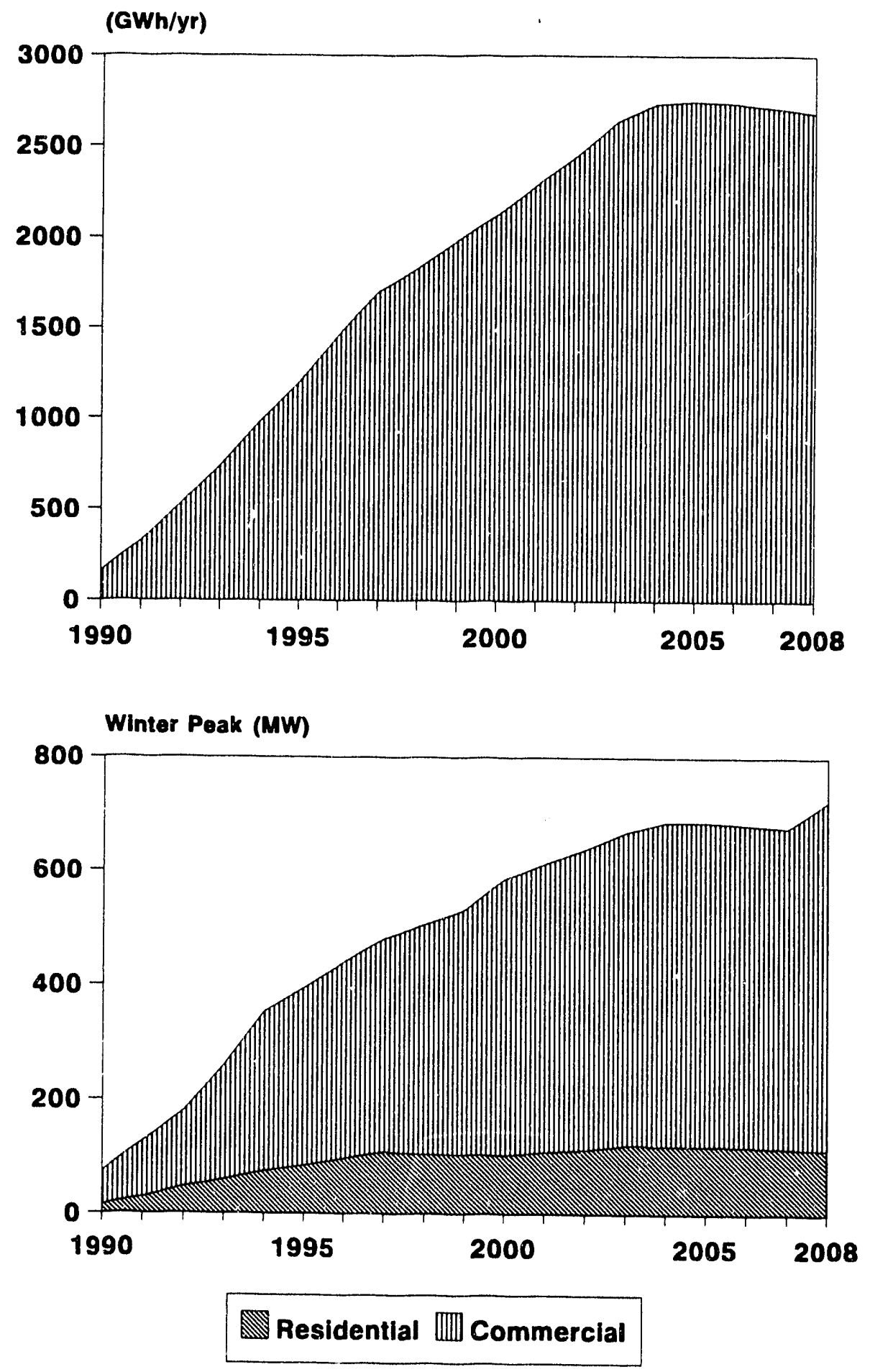

Source: 1991 NMPC DSM PIan 


\subsection{Marketing Plans and Implementation Activities of DSM Bidders}

Information on the current activities of DSM bidders with signed contracts as well as NMPC's evaluation plans are based on interviews with bidders and NMPC staff (as of December 1991). All three ESCOs report that NMPC staff has been very cooperative in working out issues and unanticipated problems that inevitably arise in this type of pilot program. Moreover, where appropriate, ESCOs indicated that NMPC field staff have provided customer referrals and marketing assistance. Overall, the ESCOs gave NMPC staff high marks during the initial implementation phase of the program.

\section{CES/Way International, Inc. (CES/Way) $)^{47}$}

CES/Way is targeting public sector entities (hospitals, schools, government facilities), offering multiple measures as part oi a comprehensive package, to meet its contractual goal of $7.7 \mathrm{MW}$ of demand reduction. DSM measures often include new lighting systems, high efficiency chillers, motors, and energy management control systems. CES/Way has been marketing their program since mid-1991 and will sign their first contract with a customer in January 1992 for demand reductions of $2.5 \mathrm{MW}$. Initially, CES/Way conducts a detailed energy analysis of a customer's facility, often including short-term monitoring of major equipment. The energy analysis includes descriptions of proposed actions, estimated savings and costs for the retrofit, and specification of a measurement protocol for each energy conservation measure (E:CM). After the customer approves the retrofit package, CES/Way brings the detailed study to NMPC. According to the contract, the utility then has ten days to analyze the proposal. During this period, NMPC reviews technical merit and must approve the engineering estimates of savings, conducts an initial cost/benefit analysis, and examines the proposed measurement/verification strategy. In essence, this 10-day review period is NMPC's principal mechanism to ensure that CES/Way is in fact installing an appropriate, and comprehensive, mix of measures. It appears that the contract does not contain explicit language which specifies mix of measures or otherwise ensures that CES/Way will install comprehensive retrofit packages. Thus, NMPC.'s de facto veto power over any proposed measurement plan effectively serves this function.

After installation of the measures, CES/Way gets a one-time payment from NMPC based on demand savings during winter and summer periods which are based on short-term monitoring of actual demand reductions of specific loads affected by the retrofit. NMPC staff plan to conduct post-installation inspection and verify actual demand reductions during short-term monitoring. NMPC will also conduct its own impact evaluation of this contract. In this evaluation, NMPC's primary objective is to estimate energy savings attributable to the program. NMPC plans to analyze pre-and post-retrofit billing data from customers that have signed contracts with CES/Way plus a control group, relying principally on statistical techniques (i.e., conditional demand analysis).

\footnotetext{
"7 CES/Way is a wholly-owned subsidiary of Way Engineering Holding Company.
} 
Planergy, Inc.

Planergy is operating a program that removes second refrigerators from customers' homes which will reduce winter demand by about 5.1 MW. This translates into about 35,000 refrigerators in NMPC's service territory. Planergy has been marketing the program since August 1991 and has picked up approximately 4,000-5,000 refrigerators. It appears that Planergy and NMPC staff have developed a solid working relationship during implementation. For example, Planergy provides press releases and marketing materials to NMPC for input and approval. NMPC has assisted in marketing the program by including "bill stuffers" in customer utility bills announcing the program in selected areas of the service territory. Wherever possible, Planergy clearly associates the utility with the program in its marketing materials.

Planergy provides each participating customer with a $\$ 50$ check and removes the refrigerator at no charge to the customer. Second refrigerators must be operational and currently connected to NMPC's systern. Planergy receives a fixed payment from NMPC for each refrigerator removed. However, NMPC has an option to cancel or renegotiate the contract if the program is no longer cost-effective because of significant changes in actual savings. The figir 2 of merit that is used is the Total Energy Savings (TES), which is defined as:

TES $=($ Number of units * annual $\mathrm{kWh}$ consumption * remaining lifetime $) *$ free rider fraction

Basically, the TES provides an estimate of the lifetime energy savings from the program, adjusted for "free riders". Initially, refrigerators are assumed to have an expected engineering life of 18 years, a remaining life of about 7 years, and annual consumption of about $1,300 \mathrm{kWh}$. Planergy will then true up these estimates based on the actual characteristics of removed refrigerators (i.e., based on model number, age, and estimated annual consumption). Not surprisingly, the method used to determine the extent of free ridership was a major point of contention during contract negotiations. Ultimately, it was decided that NMPC would develop an evaluation methodology which would involve surveys of participants and non-participants in an attempt to determine when customers would have gotten rid of their second refrigerators in the absence of the program. Results from these surveys will be used to determine if the program is still cost-effective. Thus, the contract provides that the program can be cancelled or payment terms renegotiated if the remaining lifetime is much lower than originally estimated or because free riders were higher than expected.

\section{Syracuse Energy Service Company (SyrESCO)}

SyrESCO is a local, not-for-profit energy consulting firm. Their proposal to NMPC targeted low- and moderate-income customers that reside in all-electric, resistance-heated multifamily buildings. SyrESCO is planning to install multiple measures in these buildings at no cost to the customer. Depending on results of an energy audit, measures include high pressure sodium exterior lights, installation of wall-mounted thermostats (to replace thermostats located on strip heaters), air sealing, interior storm windows, additional insulation as necessary (if cost-justified). SyrESCO's approach also features work with building operators and tenants on operation and 
maintenance and energy education, respectively. SyrESCO is providing marketing, specification, bidding, and project management services to implement these conservation measures and received payment from NMPC for these services. Thus far, SyrESCO reports that NMPC field staff have been very good about providing referrals of building owners and tenants that are interested in receiving audits or DSM options.

SyrESCO initially proposed about $5.8 \mathrm{MW}$ of demand savings, although the contractual savings goals are expressed in terms of $\mathrm{kWh} / \mathrm{ft} 2$ reduction. SyrESCO has agreed to achieve a specified $\mathrm{kWh} / \mathrm{ft} 2$ savings in 4.8 million square feet of buildings. By January 1992, SyrESCO claims that it will have completed installations in multi-family buildings with about $100,000 \mathrm{ft} 2$ and is actively marketing and completing audits in many other buildings. SyrESCO's contract, particularly the terms under which it receives payments from NMPC, are structured rather differently from the other ESCOs. These differences are attributable largely to SyrESCO's nonprofit status, smaller size and financial resources, and to the unique characteristics of the target market (i.e., low-income multifamily). SyrESCO's payment stream from NMPC consists of fixed monthly payments for providing comprehensive energy services to the target market as well as a variable component, which is ultimately linked to actual electricity savings. Initially, variable payments are based on engineering estimates of savings. However, SyrESCO is obligated to put a portion of these payments in an escrow account. After one year, NMPC will then estimate actual savings in buildings by analyzing pre- and post-retrofit billing data using the Princeton Scorekeeping Method (PRISM). SyrESCO's variable payments will then be adjusted according to a pre-specified formula in the contract which apportions the performance risk between NMPC and SyrESCO, depending on the results of the PRISM analysis. This type of analysis will then be repeated each year by NMPC for new buildings that enter the program.

To summarize, NMPC will manage the evaluation of savings. SyrESCO is getting reimbursed for the costs of the services that it initially provides to building owners and tenants, and assumes some of the performance risk. SyrESCO is at risk only for actual savings that occur in the first year after installation, while NMPC, in effect, has agreed to bear the long-term performance risk. This type of innovative arrangement is probably necessary to stimulate involvement of smaller, local energy service firms that are serving end user markets characterized by significant market barriers.

\section{Chevrolet, Pontiac, Canada Group (CPC)}

C.PC is a Niagara Mohawk industrial customer operating the Tonawanda Engine Plant. They bid two winning DSM projects at their facility. One, a project to replace the manual control of eleven air compressors with an automated electronic system. The other is an efficient lighting conservation project, replacing mercury vapor fixtures with high pressure sodium fixtures covering an area of 120,000 square feet. 


\subsection{Overlap Between DSM Bidding and Other Company-sponsored DSM Programs}

Assessing the potential for market overlap between bidder's projects and other company DSM programs, particularly program designs or delivery approaches that were perceived to undercut existing programs, was an important element of NMPC's Phase Two bid evaluation process. NMPC was most concerned about programs proposed by ESCOs. Given NMPC's position on this issue, it is not surprising that there is relatively little overlap between bids selected for the Final Award Group and other company DSM programs. For several of the projects, such as Planergy's refrigerator roundup program and the retrofits proposed by General Motors, there is no overlap in terms of end uses and sectors targeted (see Table 7-3). In other cases, winning ESCO bids occupy market niches, such as SyrESCO's project for low-income multifamily, in which NMPC has not been particularly active.

Table 7-3. Overlap Between Winning Bids and Other NMPC DSM Programs

\begin{tabular}{llll} 
Bidder & End-Use & Sector & $\begin{array}{l}\text { Competing } \\
\text { Rebate Program }\end{array}$ \\
\hline CESMay & Multiple measures & Comm,Ind. & Light,HVAC \\
Planergy & Refrigerators & Resid. & None \\
SESCO & Multiple & Resid. (SF) & Low-cost \\
SyrESCO & Multiple & Resid. (MF) & None \\
General Motors & Compressed air & Ind. & None \\
\hline
\end{tabular}

SESCO and CES/Way's proposals each target sectors in which NMPC rebate programs are currently available for certain measures. For example, SESCO proposes to install efficient lighting, insulation, air sealing, and water-heating measures in electric-heated homes at no cost to the participant. Many residential customers targeted by SESCO would be eligible for NMPC's low-cost water heating measures program. However, SESCO's program design, which focuses primarily on electric conservation options marketed by auditors canvassing neighborhoods, differed from new initiatives proposed by NMPC in its Integrated Residential Program (see section 7.2). Thus, NMPC accepted SESCO into the Final Award Group with contingencies. Similarly, customers targeted by CES/Way could potentially participate in NMPC's existing lighting rebate program as well as new rebate programs being proposed for high-efficiency HVAC and motor options. But, NMPC decided that CES/Way's program design, which required substantial customer contribution to the cost of the retrofit, would not undercut the company's C/I rebate programs. NMPC was also attracted to other aspects of CES/Way's program design and marketing plan: comprehensive services (audit, financing, installation), target market (institutional customers in $\mathrm{C} / \mathrm{I}$ sector), and overall incentive structure.

To summarize, faced with lack of clear guidance frnm the PSC on how to manage the relationship between bidding and other PSC-mandated DSM programs, NMPC adopted a 
conservative and rather defensive posture in the selection of winning DSM bids. In our opinion, NMPC's rejection in Phase Two of other ESCO bids that offered to install muitiple measures in the commercial/industrial sector is the prime example where NMPC failed to creatively manage this dilemma. In the C/I sector, NMPC has ambitious plans, but little actual experience in implementing large-scale programs. Moreover, the market potential for DSM is quite significant and many of the other ESCOs were quite experienced in this sector. At a minimum, NMPC could have accepted several other proposals with contingencies and then addressed their concerns during contract negotiations. Ironically, NMPC's stance during the Phase Two bid evaluation process contrasts markedly with the utility's flexibility and responsiveness in working with winning bidders as they attempt to implement their projects. 


\section{Chapter 8 \\ Policy Issues and Recommendations}

\subsection{Overview}

In this section, we focus on key policy issues that emerged during inplementation of the firstgeneration of bidding programs in New York. Our comments address several of the bidding guidelines adopted by the NYPSC in Opinion 88-15, including treatment of utility life extension and repowering projects as well as DSM projects and participation of utility subsidiaries in auctions. We then offer recommendations on several program design and implementation issues, drawing on the experiences of utilities in New York and other states. Given the focus of this study, most of our suggestions relate to structuring DSM bidding processes.

\subsection{Balancing Regulation with Competition: What Role for the Utility and the Regulator?}

Competitive bidding represents an attempt to introduce the benefits of competition into a largely regulated framework. Many of the strains and conflicts that have been identified in this analysis result from the failure to recognize that there are potential conflicts of interest, or even destructive effects from introducing competitive processes into settings for which they are not appropriate. In this section we summarize these issues and identify policy options for the regulator. The goal of this discussion is to focus on future choices in light of past experience.

Most of the real or potential conflicts of interest present in the NMPC integrated resource bidding process involve placing the utility, in one way or another, on both sides of the transaction. While there was some appreciation of the potential self-dealing problems that could arise among various participants (see comments by New York Department of Public Service staff 1988), the PSC's bidding decision assumed that these issues were not intractable. We will argue that this optimism was not warranted. The form of the problem varies between the supply-side and the demand-side. On the demand-side, the NYPSC bears a significant burden of responsibility for mandating both utility-run conservation programs and competitive bidding from ESCOs. The NYPSC guidelines on bidding did not provide the utilities with sufficient guidance about how to structure their DSM bidding processes in light of PSC-mandated core programs. Thus, while we are critical of NMPC's DSM bid evaluation and selection process and, in some cases, would have made different choices, we acknowledge that the company was placed in an extremely difficult position.

On the supply-side, NMPC's use of a third-party evaluator in Phase One was not sufficient protection against the appearance of self-dealing, particularly in light of the subjective evaluation methodology proposed and implemented in Phase Two. The main issue here is the inclusion of NMPC's Huntley 67 in the Final Award Group. As our analysis in Chapter 5 indicates, there is a clear case for a smaller final portfolio, which could have consisted of more DSM projects and fewer supply resources. Such a portfolio would have eliminated Huntley, since it is the marginal project. While there is no evidence that NMPC deliberately biased the process in favor of Huntley, the limited exploration of alternatives and the final outcome give the appearance of 
self-dealing. There is also a Phase One problem with the environmental scoring of Huntley 67 (see section 4.4 of Chapter 4). The asymmetric treatment of refurbishment projects compared to new capacity bids applies a more lenient standard to refurbishment. This also creates the appearance of bias in the selection process. Even such appearances, absent ary clear bias, are destructive to the competitive process. Experience in other states with similar problems was not available at the time when many of these decisions were made, and therefore could not have provided sufficient guidance. It is useful to review briefly some of this experience as a way of both clarifying where conflicts arise and identifying policy options to avoid them in the future.

\subsubsection{Related Cases}

There are a number of cases involving self-dealing between utilities and their unregulated affiliates that own private power projects. One case, which has received considerable attention, involves the Kern River Cogeneration Company (KRCC). KRCC is a joint venture between Getty Oil (now Texaco) and Mission Energy, an affiliate of the Southern California Edison Company (SCE). KRCC sells electricity to SCE under a variation on the famous Interim Star:dard Offer No.4 contracts. The reasonableness of these arrangements was investigated by the California Public Utilities Commission (CPUC). The CPUC Division of Ratepayer Advocates (DRA) issued a report arguing that the capacity payments made by SCE to KRCC were inappropriately high, and resulted from self-dealing between SCE and its affiliate (CPUCDRA 1988). The DRA argued that the contract between KRCC and SCE allowed for operating procedures that were appropriate for non-firm capacity, but the prices were set on a firm capacity basis. In particular, KRCC was allowed to conduct unlimited maintenance during the 600 hour annual on-peak time period. During actual operation, KRCC was allowed to re-classify a forced outage as scheduled maintenance and thereby receive a capacity bonus payment. KRCC was also allowed an unusually liberal set of termination penalties compared to standard CPUC requirements for similar contracts. After reviewing this case for nearly two years, the CPUC upheld the DRA position and disallowed $\$ 48$ million in payments made to KRCC (CPUC 1990).

The KRCC case illustrates that the potential for abusive self dealing goes substantially beyond the project selection stage and involves the details of contract language and administration. It is not even necessary to argue that all of these problems arise from a conspiracy to defraud the ratepayer. In cases where administrative judgments are involved, an attitude of tolerance and forbearance toward an affiliated supplier can be determinative. SCE has argued generally that during the time when KRCC was being negotiated, the CPUC was encouraging joint ventures (Jurewitz 1990). While this may be literally correct, it does not account for the particular terms at issue. It does, however, indicate the important role of the regulator in defining the boundaries of competitive behavior. The need for clarity in these definitions is high.

There is an interesting case of explicit, structured competition between utility DSM and ESCOs which illustrates what is required in the way of regulatory oversight when competitors have very different degrees of power. In 1988, the Wisconsin Public Service Commission (WPSC) ordered Madison Gas and Electric (MGE) to conduct a cumpetitive experiment with ESCOs to determine which was the better approach to delivering DSM services. The WPSC had a number of goals 
it was pursuing with this experiment, including attempting to motivate both MGE and other Wisconsin utilities to promote DSM more aggressively. Policy and implementation issues were decided by a three-person panel, which included representatives of the utility, the PSC staff, and an independent third-party representative. This type of bidding program required PSC staff to spend significant time and resources in the details of DSM program implementation. Not surprisingly, a number of unanticipated problems arose in administering the competition (Vine et al. 1990). In particular, MGE was able to undercut ESCO arrangements with customers by changing the incentive levels of their own programs during the course of the competition. Moreover, some of the local trade allies were reluctant to participate or support the ESCOs because of concern over alienating the local utility. Finally, when customers can participate in DSM programs from multiple vendors or sources, the already difficult job of evaluating and attributing savings to the action of the utility (or ESCO) is further complicated.

\subsubsection{Implications}

The demand-side competition between utilities and ESCOs reveals the need to define the boundaries between the players in a very explicit fashion to avoid "destructive competition". Because these two entities are so different in their obligations, financing and regulatory relationships, it may be best to separate their activities and find ways to allocate market share between them rather than face the problems of administering competition. It is also possible that regulators should consider this solution on the supply-side as well.

NMPC's proposed life extension of the Huntley projects illustrates a generic issue in competitive bidding for supply-side options. The utility has an important resource that is generally unavailable to other suppliers, namely depreciated power plants. These units are typically sited at favorable locations in the transmission network, have a developed fuel supply infrastructure, and considerable useful equipment on site. Such sites can be developed in a number of ways from life-extension to repowering, to replacement of all equipment with new capital. It would be potentially wasteful to exclude these opportunities on the ground of self-dealing. It is also naive to believe that they can be allowed to compete without controls.

There are several ways that the re-powering resource could be developed. The utilities could sell the sites competitively to private developers. This is unlikely to occur unless some of the profits from such transactions were retained for shareholders (Taylor and Kahn 1991). Alternatively, the regulators could reserve some fraction of new resource need to be filled through utility investment in re-powering. As our analysis of the Huntley case indicates, there is too much potential for self-dealing to rely upon competitive bidding as the mechanism to determine when, how much and at what cost re-powering should occur. Therefore, an essentially administrative determination is the only substitute. This may be less efficient than the ideal market al.location, but such ideals are not achievable in practice. If a regulatory agency chooses to adopt an explicit market share allocation mechanism that included utility re-powering, then some form of cost cap procedure might be an appropriate way to limit ratepayer exposure and provide incentives for efficiency. One useful way to integrate such a mechanism with competitive mechanisms is to use 
information from non-utility supply bidding to develop a cost cap for utility re-powering or lifeextension projects.

The basic implication of this discussion is that competitive mechanisms do not represent a panacea for all regulatory issues in electricity. These processes work best when applied to a set of competitors that have relatively equal market power. Because of its franchise obligations, the regulated utility has an ongoing relationship with the regulatory agency that differs qualitatively from the status of private producers or ESCOs. This relationship confers a certain amount of market power that makes competition less workable if the utility is directly involved. The argument in favor of "all-sources bidding" that would include the utility neglects this market power, or assumes that regulators have sufficient information, resources and power to completely control it (see, for example, FERC 1988). We believe that achieving such control is exiremely difficult and/or costly. However, proponents of "all-sources" bidding correctly observe that excluding the utility from the resource development process is inefficient. The regulatory challenge is to develop resource acquisition processes that do not involve such exclusion, without self-dealing.

\subsection{Program Design and Implementation Issues}

Drawing on our overall assessment of the tensions between planning and competition, in this section, we present our recommendations on the design and implementation of competitive resource acquisition processes. Our suggestions are structured so as to follow the actual sequence of choices that utilities and PUCs face with respect to program design: type of auction approach, overall objectives, bid evaluation and selection criteria, specific recommendations on ways to improve self-scoring systems, and eligibility to participate.

1) An alternative model of the relationship between planning and bidding should be examined, where utility preferred resources are given priority in the acquisition process.

The motivations for considering an alternative model are largely strategic. Integrated resource planning involves the proliferation of alternatives and stakeholders seeking market share. To facilitate the entry of new participants such as QFs, IPPs and ESCOs, the regulator may create a set of rules that will de facto reduce the incremental market share of the regulated firm to zero. Sensing such a threat, the regulated firm then has an incentive to manipulate the implementation of "all-sources" bidding in its own favor. In the extreme, this incentive becomes abusive self-dealing; even in less extreme cases the appearance of self-dealing may be created. We would argue that strategic concerns cannot be eliminated from the planning process, but rather that they must be managed with some sense of the trade-off posed by different market share allocation outcomes (Kahn 1992). If the vertically integrated regulated firm were truly felt to be obsolete, then these problems could be controlled by simply barring all further utility investment or participation in all-source bidding. We feel that such a view is unwarranted. There are substantial co-ordination economies of vertical integration as well as costs associated with drastic reductions in the utility's asset base. Downgrading of utility bonds because the company 
purchases very large quantities of non-utility power is one such cost which has recently received considerable attention (Moulton 1991).

As discussed in section 8.2, given the utility's market power and potential for conflicts of interest, we believe that it is desirable for the PUC to make an initial determination of resource and supplier mix issues as part of their review of a utility's IRP plan. The effort to determine market share in advance would allow participation of the utility and their resources on a priority basis, reserving the competitive process for residual needs. Such a process would certainly be contentious, and would require a judicious balancing of competing objectives. It should also not be construed to be an entitlement for uncontrolled investment costs. The competitive bidding process for non-utility supply could provide a basis for designing cost recovery limits on utility projects.

Implementation of such an approach would require an active role for the Public Service Commission, including strong staff support, so that no external participants dominate the process. An example of this model is the Wisconsin Advance Plan process. A transition to such an approach would be complicated in New York by the current existence of potential excess capacity problems. The alternative model basically assume equilibrium conditions and is designed to maintain such equilibria.

However, as a practical matter, we believe that New York's state law (i.e., Section 66-C), which currently provides "energy-only" QFs with a minimum purchase price of six c/kWh levelized for their power, has pre-empted explicit market share determination to a large degree. Section 66-C precludes the possibility of doing systematic planning because it has created an entitlement for a set of private power producers. ${ }^{48}$ While New York state's law was initially instrumental in stimulating the development of a viable private power market and fostering an "infant industry", it is unclear that it is still needed today given the maturity of the independent power sector. By contrast, in California, the PUC approved standard offer contracts for QFs and initially placed no quantity limits on QF development. However, the PUC decided to suspend the standard offers in 1985, because of the unexpectedly high response from QFs and perceived resource glut. The CPUC was able to terminate the state's policy of unlimited QF contracting, in part because there was no explicit pricing legislation. Although the PSC is trying to limit QF development administratively, ultimately it may be up to the New York legislature to address this problem. We believe that recommendations for prospective repeal of Section 66-C make the most sense.

Figure 8-1 contrasts the "preferred resources" approach to planning and bidding with the approach implied in an integrated auction such as that conducted by NMPC. In an integrated auction, the utility defines the total resource need, which can be filled either by independent power producers, ESCOs, or utility-sponsored generation projects. In contrast, in our view, one

\footnotetext{
${ }^{48}$ There are still significant uncertainties regarding the ultimate level of development or timing of "energy only" $\mathrm{QFs}$, many of which are related to future gas prices.
} 
Figure 8-1. Alternative Models for the Relationship Between Planning and Competition

New York Planning/Acquisition Framework

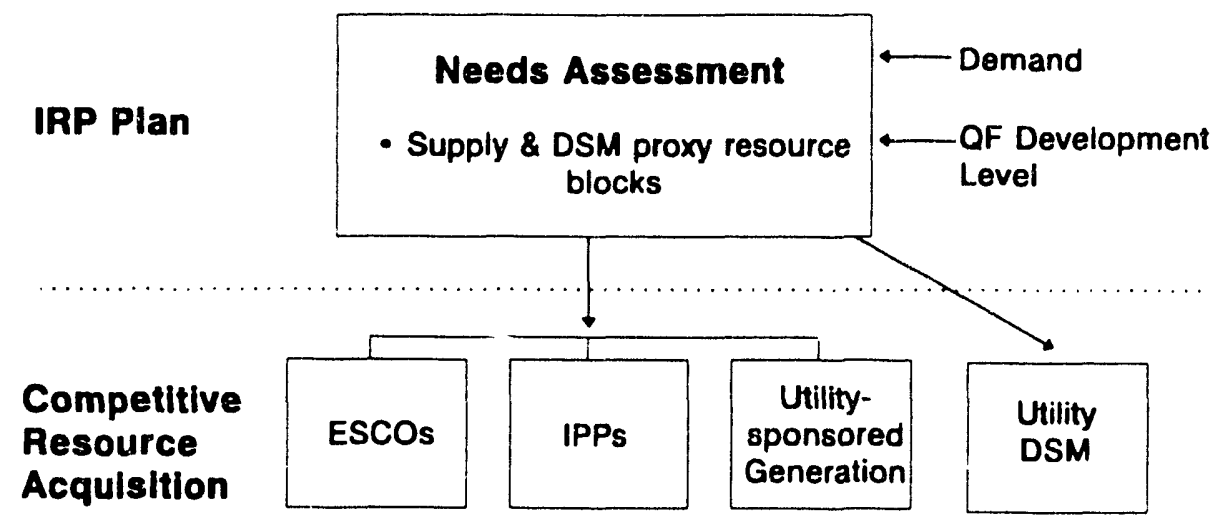

\section{Alternative Planning/Acquisition Framework}

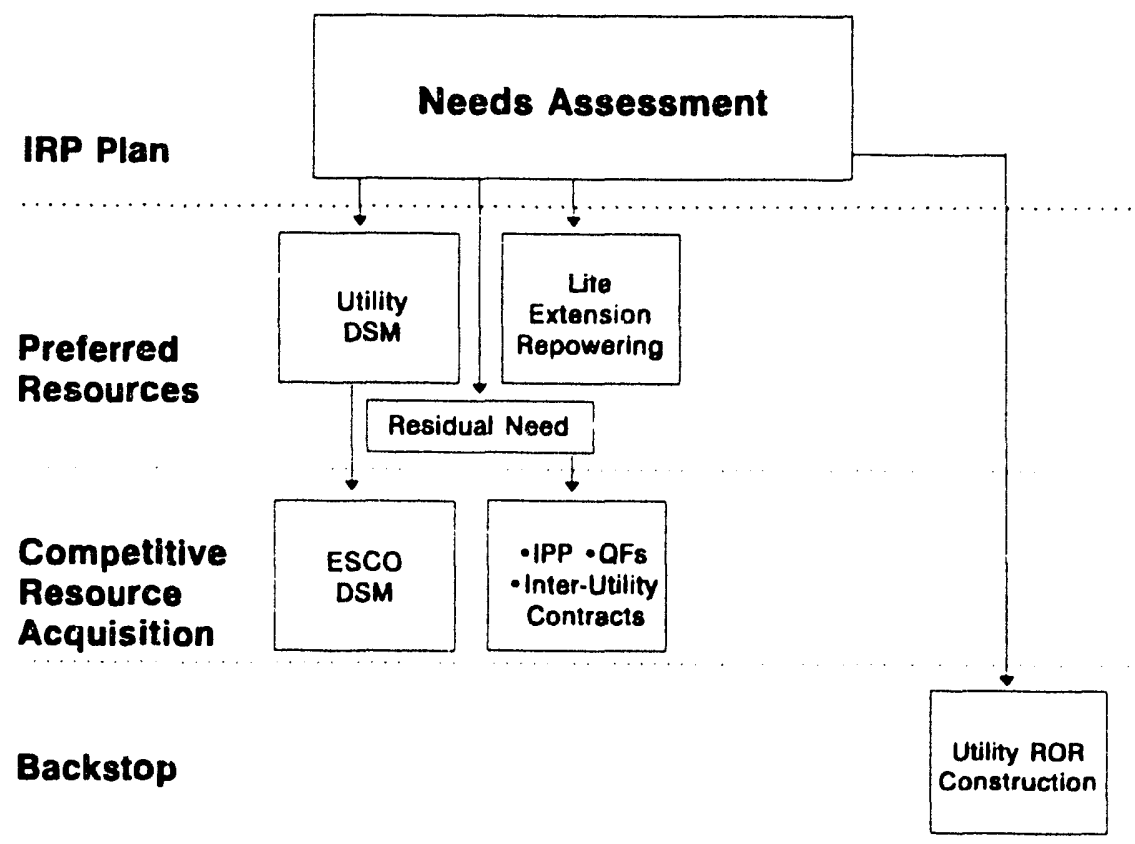


outcome of the IRP plan review process would be an initial determination of the DSM and supply-side quantity targets. ${ }^{49}$ Among supply-side resource options, the utility's IRP plan would define "preferred resources" that are to be developed by the utility, such as repowering projects. On the demand-side, the utility would offer a combination of its own programs and ESCO-delivered programs. Much more experimentation is needed to determine the appropriate level of ESCO involvement and which types of program designs are best to make use of their capabilities. However, initial experience with DSM bidding suggests that the utility will continue to play the key role in developing certain types of DSM programs where the utility is uniquely positioned (e.g., direct load control or informational programs). Ironically, ultimate roles for ESCOs will be shaped by the utility's strategic vision of their longer-term objectives, the capabilities of utilities to effectively deliver DSM resources, and regulatory preferences regarding the utility's roie and degree of involvement on the customer side of the meter. We will discuss various options below.

This administrative approach is admittedly "second-best" but it would then allow the competitive bidding processes among independent power producers to function more efficiently and fairly. There are clearly risks to allocating market share through a preferred resources approach. The main one is that the administrative process becomes excessive, and indistinguishable from micromanagement by the regulator. Barring such unfortunate outcomes, these more structured and targeted competitive processes would provide useful feedback and information on the costs, risks, and reliability of various resource options to the utility and its regulators. This will preserve the "yardstick" function of competition in regulated industries, is well as a potential "second-sourcing" capability in the event of poor utility performance.

\section{2) Separate solicitations for DSM and supply-side resources are preferable given inherent} differences in resource characteristics and market structure.

A distinguishing feature of integrated resource planning is that all resource options are evaluated in a consistent framework. Integrated, "all-sources" bidding is theoretically appealing because it appears to provide an acquisition framework which is consistent with IRP objectives. Proponents of integrated bidding argue that for the purposes of meeting new system demand, a $\mathrm{kWh}$ saved is indistinguishable from a $\mathrm{kWh}$ delivered to customers by a new plant (Cavanagh 1988). At one extreme, all demand-side entities (utility and non-utility) compete against all supply-side providers (utility and non-utility). The utility would evaluate all bids against its proposed resource additions and then select the best mix of these options. In practice, bidding experiments conducted by utilities typically involve a more limited set of players and do not necessarily seek to meet al.1 resource needs through the bidding process. For example, in New Jersey, unregulated utility affiliates (both supply-side and conservation) were prohibited from submitting bids for three years (NJBPU 1988). The Colorado PUC decided that about $20 \%$ of the utility's future capacity needs would be filled through supply-side bidding processes and restricted eligibility to QFs (Colorado PUC 1988). In all states that have embraced "all-sources"

\footnotetext{
${ }^{49}$ We should note that NMPC's bidding solicitation did mention supply-side and DSM quantity goals, which were based on their IRP plan.
} 
bidding (e.g., New Jersey, Maine, Massachusetts, New York), existing utility DSM programs are treated as a non-deferred resource. ${ }^{50}$

However, while many DSM programs have "resource value" to the utility (e.g., defer or avoid the need for new generation capacity ard/or lower future costs of operating the existing utility system), we believe it is not useful to structure competitive bidding processes under the assumption that "negawatts" = Megawatts. Practically speaking, there is a strong tendency in "all-source" bidding RFPs to view ESCOs as "QF-equivalents" and structure scoring systems and contracts so that demand-side resources are evaluated and treated like mini-power plants. We believe this approach is counter-productive and generally leads to bidding systems that are sub-optimal for both type of resources, and particularly DSM resources because it fails to recognize differences in market structure, innate characteristics, and level of development between these resource options.

First, the market for energy efficiency is ultimately a retail market, while the competition for private power contracts is a wholesale market (Kahn and Goldman 1991). Second, on the supplyside, there is a well-developed infrastructure of private power developers that has led to project offerings that greatly exceed requested needs of utilities. The individual contracts are typically for single projects and locations, providing a product that can be directly measured and is well understood by utilities because they have decades of experience operating similar projects. Utility managers are relatively confident that a supply-side project's interaction with the utility system can be predicted and managed (PG\&E 1991). In contrast, compared to the private power industry, the energy services industry is relatively immature (although growing rapidly). ESCOs essentially perform an aggregation function that transforms demand-side opportunities at individual sites into a product of "saved energy."

Third, provision of "saved energy" typically involves a complex relationship among customers, the ESCO, and utility. Within a particular demand-side market and/or end use, individual bidders and the utility's own programs are all "mining" the same resource. Individual DSM bids could impact on other DSM bidders' ability to deliver their projected savings as well as utility's ability to obtain savings goals through its own programs. Thus, DSM bidding must be coordinated explicitly with other utility DSM programs. If utilities are unable to work out creative solutions, then administrative determinations will be required to address and define the most appropriate entities in various market segments to deliver utility DSM program offerings. Fourth, the output of demand-side resources can never be measured with the same degree of

\footnotetext{
${ }^{50}$ In California, the resource planning and acquisition process explicitly designates some types of resource additions as non-deferrable. Utility-sponsored resource additions that are designated as non-deferrable are assessed as cost-effective in the planning process, but can not be deferred by bidding processes. In other states (e.g., New Jersey, Maine, New York), this designation for certain types of resources is usually implicit.
} 
certainty as supply-side resources. ${ }^{51}$ Differences between supply-side and DSM resources argue for procurement processes that are specifically tailored to evaluate the attributes and distinctive features of each resource. In practice, this can be accomplished most easily by designing separate procurement processes for DSM and supply-side resources which could be carried out in parallel with distinctive scoring systems.

\section{3) Structuring demand-side procurement processes: "Partnership" vs. "Replacement" Bidding}

In deciding how to structure demand-side procurement processes, the role(s) of ESCOs need to be more explicitly discussed with respect to policy goals and then reflected in program design. Utilities have traditionally contracted out some elements of their DSM programs and solicited bids to private sector firms using conventional competitive procurement processes to buy "energy services." As currently structured, most DSM bidding programs stretch the boundaries of third-party involvement from procuring energy services to provision of "saved energy" through long-term contracts. The obvious competition occurs among energy service companies in DSM bidding programs, although it is clear that ESCOs are also competing in a less explicit fashion against other utility-sponsored DSM programs (Kahn and Goldman 1991).

Policy and program objectives often mentioned by proponents of DSM bidding (and sometimes embraced by regulators) include: (1) experiment with alternative delivery mechanisms compared to conventional ulility-run DSM, (2) promote the development of an "infant" energy services industry, (3) encourage performance-based DSM programs in which DSM savings are guaranteed and maintained over the long-term, and (4) provide a competitive benchmark to help assess utility DSM performance in terms of program cost, cost-effectiveness, and development of DSM market potential.

Conceptually, "partnership" and "replacement" bidding represent alternative approaches, which helps link policy choices regarding the role of ESCOs to the four overall program objectives listed previously. "Partnership" bidding represents opportunities for ESCOs to extend and expand on the type of activities offered, including provision of "saved energy" or comprehensive delivery of energy services under performance contracting arrangements. In "partnership" bidding programs, there is an explicit recognition that utility and ESCO activities are complementary, that a high degree of coordination is required, and that the ESCO in effect acts as an agent of the utility in its DSM programs. "Partnership bidding" programs are more likely to emphasize qualifications, experience, performance guarantees for savings, customer relations, comprehensiveness and value of services rather than price. The principal aspect of competition is among ESCOs during the selection phase. ESCO activities might best be thought of as

\footnotetext{
${ }^{\text {SI }}$ From a planning perspective, while the output of generation resources is easily measured, there are significant uncertainties associated with the future cost and impacts of these resources (e.g., variability in fuel prices, impacts on environment).
} 
replacing "unplanned utility programs. "52 Ironically, it may be easier to develop "partnership" bidding in situations where utilities conduct few DSM programs or their offerings are not comprehensive across all customer classes or market segments. For example, DSM bidding programs conducted by Public Service of Colorado and Public Service of Indiana have these characteristics. Table 8-1 illustrates who the possible competitors would be under alternate competitive resource acquisition frameworks.

Table 8-1. Competitors in Alternate Bidding Approaches

\begin{tabular}{|c|c|c|c|c|}
\hline Bidding Approach & ESCOs & $\begin{array}{l}\text { Planned } \\
\text { Utility } \\
\text { DSM } \\
\text { Program }\end{array}$ & $\begin{array}{l}\text { Planned Utility } \\
\text { Supply Project }\end{array}$ & IPPs \\
\hline "Partnership Bidding" & $x$ & & & \\
\hline "Replacement Bidding" & & & & \\
\hline $\begin{array}{ll}\text { - } & \text { Demand-side only } \\
\text { - Integrated (supply-side } \\
\text { vs. ESCO) } \\
\text {-All-source" bidding }\end{array}$ & $\begin{array}{l}x \\
x \\
x\end{array}$ & $x$ & $\begin{array}{l}x \\
x\end{array}$ & $\begin{array}{l}x \\
x\end{array}$ \\
\hline
\end{tabular}

Source: Adepted froin Schultz 1992.

In demand-side only "replacement bidding", ESCOs are given an opportunity to compete against and possibly replace a planned utility DSM program or set of programs. In this type of solicitation, a primary objective is to have ESCO bids provide a "price check" on the utility's estimated or actual DSM program costs. In effect, ESCOs serve the functional role that independent power producers perform on the supply-side (Schultz 1992).

Competition between ESCOs and the planned utility program could occur at several possible stages: (1) resource acquisition and selection - using an auction to compare ESCO bicis to a planned utility program and selecting the lowest cost alternative, or (2) implementation - explicit competition in the field between utility DSM staff and designated ESCOs in common markets and end uses (Schultz. 1992). In the first approach, the utility would not offer its planned program if it determined that the ESCO could deliver comparable services more cost-effectively. This approach is being tested by at least one utility in California at the insistence of the Public Utilities Commission (San Diego Gas \& Electric 1992). Some proponents envision that this type of DSM-only replacement bidding would be formalized with planned utility DSM programs

\footnotetext{
$\$ 2$ In point of fact, ESCO activities in "partnership bidding" programs should have resource value (i.e., offset future costs of operating utility system)
} 
being put out for bid on a regular basis. However, this scheme is untested and because of its emphasis on minimizing costs, would require careful specification of all features and desired services. This approach might be appropriate for certain mature DSM programs or technologies but fails to appreciate the dynamics and iterative evolution of many DSM programs.

Madison Gas \& Electric's (MGE's) Competition Pilot Program is an example of the second approach which features head-to-head competition in targeted market segments. ${ }^{53}$ The Wisconsin regulators viewed the MGE pilot as a contest between the utility and ESCOs and was a regulatory policy option (or "stick") to motivate utilities that were performing poorly in the DSM area. We are skeptical that short-term competitions between utilities and ESCOs are a viable long-term approach.

Integrated bidding is another form of replacement bidding in which ESCOs compete alongside independent power producers (IPPs) to displace some or all of a planned utility supply-side project (see Table 8-1). One goal is to determine if ESCOs can provide DSM resources at a lower cost than independent power producers or planned utility supply-side additions. Utilities in New York, Maine, and New Jersey have conducted this type of bidding program. As noted previously, planned utility DSM programs are not explicitly considered as resources that can be replaced in this type of bidding program. ${ }^{54}$ The utility is typically placed in the position of deciding if ESCO bids would adversely affect planned utility DSM programs. Integrated auctions can be made to work if substantial negotiations and flexibility are built into the process.

Finally, as discussed in section 8.2 , it is also possible to conduct an "all-sources" bidding process in which all options, supply- and demand-side, and providers (utility and non-utility) would compete explicitly. In this theoretical construct, the resource acquisition process largely obviates the need for identifying the avoidable plant or potential utility DSM programs in the planning stage (Schultz 1992).

In most situations, we believe that "partnership bidding" types of programs are the preferred approach given the relative immaturity of the ESCO industry and the difficulties of structuring effective competitions among ESCOs and utilities. It is still unclear if the most effective way to utilize ESCO capabilities is to have them offer "saved energy," bid costs for specified services with selection based primarily on qualifications and price, or bid a "value-added" fee for marketing utility rebate programs augmented with additional financial and technical services. Most parties involved with DSM bidding would agree that much more experimentation is needed to determine the most effective way to utilize ESCO capabilities. However, the viability of ESCO/utility partnership arrangements hinges on the utility's ability to satisfactorily resolve potentially thorny "market share" conflicts at the planning and/or implementation stages. State

\footnotetext{
${ }^{53}$ MGE's program was a slight variant in that budgets were fixed, and the objective was to determine which parties, ESCO or utility, could deliver the maximum quantity of cost-effective savings.

\$4 Presumably, quantity targets in this type of replacement bidding program have been determined by a resource plan which already accounts for other utility-sponsored DSM programs.
} 
regulators have significant responsibilities in this area, and, at a minimum, must ensure (as they have in New York) that utility management does not have a financial incentive to pursue utilitysponsored DSM programs at the expense of third-party delivered DSM programs.

4) Few customers are likely to participate in DSM bidding programs as currently structured. Customers should either be encouraged to participate directly in other DSM programs offered by utilities or separate, simplified bidding processes need to be developed which are tailored specifically to customers. However, we are not convinced that bidding type programs are best suited for customers.

Compared to the ESCO's bid and marketing plan, bids submitted by customers directly typically specify proposed site-specific DSM options, and thus the level of resource development is more advanced with fewer uncertainties. However, based on interviews with customers, NMPC staff, and the experience of other utilities, it is clear that few customers are likely to participate in DSM bidding programs given the high transaction costs associated with preparing bids and relative risks compared to other DSM programs. It is possible that simplified bidding processes can be developed which will increase participation of large customers, but we are not convinced that this is likely or, more importantly, even desirable.

The "arms-length" business relationship embodied in signing long-term contracts for "saved energy" places utilities in a difficult position vis a vis their customers. No utility wants to have an adversarial relationship with its customers, and it is clear that during "arms-length" contract negotiations, parties are obligated to bargain hard. In negotiating with customers directly, the utility presumably has multiple objectives, among which cost-effective resource procurement and enhancing customer service are quite important. Unfortunately, these two objectives can conflict and it may be difficult for the regulator to discern if the utility has in fact negotiated effectively to drive a hard bargain that protects ratepayers. ${ }^{55}$ Ironically, contract terms and conditions with ESCOs may be the only yardstick that regulators have to ensure that no "sweetheart deals" with customers have been consummated. Available evidence suggests that utilities have much less trouble entering into and conducting "arms-length" contractual relationships with ESCOs.

Ultimately, given limited customer participation and potential headaches for the utility (in terms of customer relations) and the PUC (in terms of determining prudence), it may turn out that bidding-type programs are most suitable for third-party entities and that customers should be directed to other utility DSM programs. Customized rebate programs offered by some utilities may represent a "hybrid" approach because customers can bring forth site-specific proposals for more complex retrofits and receive pre-specified financial incentives. These programs are easier to participate in than bidding programs, and typically have much lower transaction costs and performance risks compared to most DSM bidding programs (PG\&E 1990).

\footnotetext{
ss Because bid price is fixed, we would expect these conflicts to be fairly subtle and arise principally in negotiations over terms and conditions (e.g., measurement and verification, performance risk, actions that will be taken if circumstances at the customer's facility change significantly).
} 
5) Bid evaluation criteria need to reflect the buyer's preferences explicitly, but this can be accomplished without relying on self-scoring systems.

Most utilities evaluate supply or DSM projects as part of a multi-stage process. Initially, projects are screened to ensure that they satisfy specified threshold and eligibility requirements. Utilities then rank projects to select an award group of winning bidders. ${ }^{56}$ A major difference among utilities is the extent to which the utility discloses evaluation criteria prior to bid preparation as well as the relative weight assigned to each feature. Utilities have utilized two basic approaches, which we classify as either "open" or "closed".

In "open" systems, the utility develops an explicit scoring system and bidders self-score their projects based on evaluation criteria that are stated in the RFP. The utility verifies point scores and then ranks and selects the winning projects. The process is relatively transparent and "open" to bidders. In contrast, "closed" bid evaluation systems encompass a diversity of approaches, but all share the common feature that bidders do not self-score their project. Typically, the utility reveals project selection criteria in qualitative terms only, although some utilities will provide some indication of the relative importance of various attributes. The utility retains substantial discretion to select the optimal mix of projects and often, the flexibility to negotiate with bidders in light of all offers received. We characterize this bid evaluation process as "closed" because the utility possesses information about the evaluation process that is not available to bidders at the time they prepare their bid (Kahn et al. 1989).

NMPC's two-stage approach is a hybrid with Phase One consisting of an objective ranking of projects while in Phase Two the utility exercised substantial judgment in selecting the best mix of projects. The weighting factors in most self-scoring systems were designed primarily with supply-side procurement in mind. Our analysis suggests that NMPC's scoring system does not represent a breakthrough in this area, although the utility made some attempt to adapt evaluativ.1 criteria to the specific features of DSM resources in various non-price categories (see section 4.1 of Chapter 4 ).

Because of the dominance of Phase Two in determining the ultimate outcome, we would argue that NMPC's approach as implemented is closer to a "closed" bid evaluation system. In the future, we believe that it is easier for an utility to develop more useful scoring systems (e.g., relative weights assigned to various criteria) if separate procurement processes are utilized for DSM and supply.

Most utilities prefer the "closed" approach because it recognizes that the attributes of value are not independent, that it is better equipped to handle the complexities of project evaluation, and interactive effects between non-utility projects and the existing system (EPRI 1990). We make no a priori judgment about which approach is preferable, although our previous studies suggest

\footnotetext{
${ }^{56}$ Utilities conduct screening in either one or two phases. Most utilities select a "short list" of projects drawn from initial bids and then designate a Final Award Group, based on more detailed evaluation. However, other utilities commence contract negotiations with all projects selected in the Award Group (e.g., New Jersey).
} 
that self-scoring systems do have some inherent limitations (Kahn et al. 1989). ${ }^{57}$ The most important element of a scoring system is that the buyer's preferences and relative valuations of major criteria are explicitly communicated in the RFP; however, this can be accomplished without relying on self-scoring.

For us, the preferred approach to a bid evaluation system is strongly influenced by the utility's decision regarding its own participation as a seller in the bidding process. If utility lifeextension projects are included or if utility affiliates are allowed to participate, then PUCs should insist that the bid selection process be "transparent," as one safeguard against the potential for self-dealing. ${ }^{58}$ In these situations, objective self-scoring systems, where the selection process is easily verifiable and auditable by the PUC, are probably the most appropriate bid evaluation process. One implicit rationale for relying on self-scoring systems is that the buyer can not be trusted. However, because of our concerns regarding self-dealing and because of the inherent limitations in self-scoring systems, we believe that it would be preferable to restrict participation of utility affiliates and utility generation projects. If these conditions are met, then the promise and theoretical advantages of a "closed" bid evaluation system can potentially be realized.

We think that PG\&E's proposed pilot DSM bidding program incorporates many of the positive features that should be included in "closed" bid evaluation systems. The company's overall objectives are clearly stated. ${ }^{59}$ In addition to specified eligibility requirements and minimum thresholds, PG\&E's RFP includes a list of weighted attributes which give bidders a feel for the relative importance of various attributes. However, the weights are not meant to imply that bidders will self-score their projects. (PG\&E 1991). Bid evaluation criteria include economics $(45 \%)$, location $(3 \%)$, bidder qualifications (10\%), measurement and verification plan (15\%), marketing plan (10\%), compatibility with PG\&E DSM programs (10\%), and proposed comprehensiveness of the package (7\%). Attributes are described in detail in the RFP, giving examples of more and less desirable proposals in each area as well as the inter-relationship among various attributes. For example, PG\&E views their economic attribute as value-based rather than a strict price attribute. Bids will be compared to other bids which address the same market sector as well as PG\&E's costs of program delivery (where relevant). ${ }^{60}$ Finally, PG\&E retains significant discretion to choose an optimal mix of projects that complement existing utility

\footnotetext{
${ }^{57}$ However, it is also obvious that it is easier for an independent analyst to discover limitations in self-scoring systems compared to a "closed" bid evaluation system because much more information is revealed.

${ }^{58}$ Self-scoring systems should be required if the utility has previously been found guilty of unfair practices.

s9 PG\&E wants to: 1) form positive partnerships with ESCOs and utilize them to enhance rather than replace utility DSM programs, 2) encourage bidders to provide services and measure effectiveness over the life of the contract, 3) ensure that services selected are competitively-priced and lower PG\&E's total revenue requirement, re and result in net benefits to society.

${ }^{60}$ PG\&E will also compare bid price relative to bundle of services offered and acknowledges explicitly that it may be more costly to serve some market sectors than others (e.g., residential vs. commercial). The utility proposes to rely principally on the Utility Cost Test, with the Total Resource Cost Test as a threshold requirement.
} 
programs, with heavy emphasis on rlexibility in the negotiations stage with a short list of bidders to resolve implementation issues (e.g., down-sizing of projects if too many bids overlap in one market sector). Thus, the RFP attempts to strike a balance between flexibility for the utility in resource evaluation and selection and openness to bidders regarding utility preferences and marketing assistance. Clearly, the attractiveness of this type of DSM bidding approach can only be determined once the program is actually implemented.

As discussed in Chapter 4, we believe that criteria used in evaluating DSM bids should emphasize projects that offer demand and energy savings with long-term resource value. DSM bidding programs should attempt to overcome some of the limitations of current utility DSM programs for existing buildings which rely principally on informational audits and direct rebates to customers for installation of energy efficiency equipment. Thus, important program objectives include "firming" up DSM savings over the long-term by emphasizing performancebased approaches and provision of comprehensive services and retrofit packages by firms with specialized expertise. It should also be noted that these objectives can be achieved by other types of DSM program designs and delivery mechanisms, and thus are not unique to bidding. ${ }^{61}$ Secondary objectives include using third parties to provide a "price check" on the estimated utility costs of implementing their DSM programs.

Thus, bid evaluation criteria should emphasize: (1) reasonable bid price (relative to costs of measures, and value-provided in terms of services offered), (2) qualifications, experience, and technical competence of firms, (3) measurement and verification of savings with payments linked to performance, (4) encourage comprehensive retrofits at host facilities, and (5) market research and program design that demonstrates knowledge of targeted customers and strategy to facilitate customer acceptance (e.g., types of financing, letters of intent or signed commitments).

\section{6) NMPC's approach to scoring and valuing price, dispatchability, and environmental factors in Phase One could be improved.}

As discussed in Chapter 4, we believe that the technique used by NMPC (and other utilities) to develop bidder's price score, which assigned points based on the ratio of bid price to utility's avoided cost, is not discriminating. The ratio scoring neglects any serious consideration of differing operating profiles and is biased against baseload bids. The use of "add-on" points for dispatch and unit commitment corrects the problem only to a very limited degree. The weight assigned to these features is significantly lower (by a factor of four to eight) compared to simulation studies conducted by LBL. Finally, the scoring of environmental factors could be improved by eliminating the asymmetric treatment of refurbishment and using a iinear scoring function instead of a limited number of bins. The use of bins introduces distortions in the incentives of bidders to reduce pollutant emissions. In addition, the bin size for projects that

\footnotetext{
${ }^{61}$ For example, performance contracting programs or attempts by utilities such as PEPCO to have third party contractors market their existing utility rebate programs, provide additional technical and financial services to customers, and supplement existing programs with additional retrofit options where appropriate. Compensation for these services is based on a "value-added" fee bid by the ESCO.
} 
minimally comply with NSPS over-values that effort compared to the PSC's intention. This problem, which was inherent in the design of NMPC's scoring system, reduces the environmental advantage or credit for conservation projects by about $25-35 \%$. 


\section{Acknowledgements}

The authors acknowledge the support, guidance, and insights offered by the project manager, David Wolcott, of the New York State Energy Research and Development Authority (NYSERDA).

We thank Sam Swanson, Jim Gallagher, Fred Haag, Andrew Harvey, Bill Mills, Sury Putta, Mark Reeder, Gerry Weber, and Bob Whitaker of the New York Department of Public Service and Mike Kelleher. Theresa Flaim, and Bill Hamilton of Niagara Mohawk Power Corporation for their helpful comments on a draft of this report. We also thank Aaron Breidenbaugh, Cary Bullock, Eric Hirst, and Jane Peters for their review comments. Finally, we thank Ellen Hodges for technical editing and report preparation.

The work described in this report was funded by the Assistant Secretary for Conservation and Renewable Energy, Office of Utility Technologies, Office of Energy Management of the U.S. Department of Energy under Contract No. DE-AC03-76SF00098 and by New York State Energy Research and Development Authority under Contract No. 1515-EEED-BES-91. 


\section{References}

J. Bloom 1984, "Generation Cost Curves Including Energy Storage," IEEE Transactions on Power Apparatus and Systems, v.PAS-103, no.7, 1725-1731.

Burns \& McDonnell 1990, "Report on the Independent Evaluation of Bids in Response to RFP No. 1 for Supply and Demand-side Management Resources," Kansas City MO, July.

California Public Utilities Commission (CPUC) 1987, Standard Practice Manual, "Economic Analysis of Demand-Side Management Programs," Report P400-87-006, December.

California Public Utilities Commission Division of Ratepayer Advocates (CPUC-DRA) 1988, "Report on the Reasonableness of Southern California Edison Non-Standard Power Purchase Contracts with Qualifying Facilities," Appl. No.88-02-016.

California Public Utilities Commission (CPUC) 1990, Decision 90-09-088.

R. Cavanagh 1988, "The Role of Conservation Resources in Competitive Bidding Systems for Electricity Supply," House Energy and Commerce Committee's Subcommittee on Energy and Power, March 31.

ERCE Environmental and Energy Services Co. (ERCE) 1990, "Evaluation of the Orange and Rockland Utilities Competitive Bidding Program for Demand-side Resources," ERCE/DSM-66, December.

ERCE Environmental and Energy Services Co. (ERCE) 1991, "Evaluation of NMPC's Demandside Management Competitive Bidding Program: Interim Report (Draft)," September 13.

Federal Energy Regulatory Commission (FERC) 1988, Notice of Proposed Rulemaking, Regulations Governing Bidding Programs, Docket No. RM88-5-000.

C. Goldman and D. Wolcott 1990, "Demand-side Bidding: Assessing Current Experience", Proceedings of the ACEEE Summer Study on Energy Efficiency in Buildings, Pacific Grove, CA, August.

W.E. Hamilton and T.A. Flaim 1992, "Acquiring DSM Resources through All-source Bidding: Lessons Learned", Proc. of DSM Bidding: Status and Results, Synergic Resources Corporation, Albany NY, April.

Jersey Central Power and Light (JCPL) 1989, "Request for Proposal for Generating Capacity: 1989 Solicitation." 
J. Jurewitz 1990, "Prepared Rebuttal Testimony on Behalf of Southern California Edison Company and San Diego Gas and Electric Company," Federal Energy Regulatory Commission Docket No. EC89-5-000.

E. Kahn 1988, Electric Utility Planning and Regulation, American Council for an Energy Efficient Economy.

E. Kahn 1991, "Risk Allocation in Independent Power Contracts," LBL-30065, Lawrence Berkeley Laboratory, Berkeley CA, April.

E. Kahn, C. Goldman, D. Berman and S. Stoft, 1989 "Competitive Bidding for Electric Power, " LBL-26924, Lawrence Berkeley Laboratory, Berkeley, CA, June.

E. Kahn, C. Marnay and D.Berman, "Evaluating Dispatchability Features in Competitive Bidding," IEEE Transactions on Power Systems, (to appear).

E. Kahn 1992, "Integrating Market Processes into Utility Resource Planning," Proc. of 1992 ACEEE Summer Study on Energy Efficiency in Buildings, ACEEE, Washington DC, August.

J. Koomey 1990, "Comparative Analysis of Monetary Estimates of External Environmental Costs Associated with Combustion of Fossil Fuels," LBL-28313, Lawrence Berkeley Laboratory, Berkeley CA, July.

C. Moulton 1991, "Credit Issues for Utility Purchasers, " Standard and Poor's, New York NY.

National Association of Regulatory Utility Commissioners (NARUC) 1990, "Proceedings of National Conference on Environmental Externalities," Washington DC, October.

New Jersey Board of Public Utilities (NJBPU) 1988, Stipulation of Settlement in Docket No. 8010-687B, Trenton NJ, July 1.

New York Department of Public Service 1988 "Staff Comments to Niagara Mohawk's Bidding Proposal," Case 29409, December 5.

New York Power Pool (NYPP) 1988, "Load and Capacity Data 1988-2004," April.

New York Power Pool (NYPP) 1991a, "Report of the Member Electric Corporations of the New York Power Pool Concerning 1991 Long-run Avoided Cost Estimates, " Case 91-E0237, August 30.

New York Public Service Commission (NYPSC) 1986, "Order Instituting Proceeding: Case 29409 - Proceeding on Motion of the Commission to Examine the Plans for Meeting Future Electricity Needs in New York State", August 15. 
New York Public Service Commission (NYPSC) 1988a, "Case 29409 - Proceeding on Motion of the Commission to Examine the Plans for Meeting Future Electricity Needs in New York State", Opinion and Order Concerning Bidding, Avoided-Cost Pricing, and Wheeling Issues, Opinion 88-15, Albany NY, June 3.

New York Public Service Commission (NYPSC) 1988b, “Case 28223, Order Concerning Long Range Demand-side Management Plans," Albany NY, October 13.

New York Public Service Commission (NYPSC) 1989a, "Case 28962 - Long-Run Avoided Costs", Opinion 88-13, Albany NY, May 10.

New York Public Service Commission (NYPSC) 1989b, "Case 88-E-242 - Proceeding on Motion of the Commission (established in Opinion 88-15) as to the guidelines for bidding to meet future electric capacity needs of Niagara Mohawk Power Corporation", Opinion and Order Establishing Guidelines for Bidding Program, Opinion 89-20, Albany NY, June 19.

New York Public Service Commission (NYPSC) 1989c, "Opinion and Order Approving Demand-side Management Incentives and Establishing Further Proceedings," Opinion 8929, Albany NY, September 12.

New York Public Service Commission (NYPSC) 1989d, "Case 88-E-241 -Opinion and Order Establishing Guidelines for Bidding Program” Opinion 89-7, April 13.

New York Public Service Commission (NYPSC) 1990, "Case E-242 - Proceeding on the Motion of the Commission (established in Opinion 88-15) as to the Guidelines for Biditing to Meet Future Electric Capacity Needs of Niagara Mohawk Power Corporation", Albany NY, December 28.

New York Public Service Commission (NYPSC) 1991a, "NYPSC Bidding Group Working Group (Supply-Side) Preparation Materials for January 11, 1991 Meeting,” Albany NY, January 11.

New York Public Service Commission (NYPSC) 1991b, "Case 90-E-1189 - Proceeding on Motion of the Commission as to Petition of Enersave, Inc. and EUA Cogenex Corp. for a Declatory Ruling with Regard to the Commission's Guidelines for Bidding to Meet the Future Electric Capacity Needs of the Niagara Mohawk Power Corporation," Albany NY, March 6.

New York State Energy Office (NYSEO) and New York Departments of Environmental Conservation and Public Service 1989, "New York State Energy Plan," Albany NY, September. 
New York State Energy Office (NYSEO) and New York Departments of Environmental Conservation and Public Service 1991, "Draft New York State Energy Plan 1991 Biennial Update, (Volumes I-IV)," Albany NY, July.

Niagara Mohawk Power Corporation (NMPC) 1988a, "Demand-Side Management Program 1988," Syracuse NY, April 13.

Niagara Mohawk Power Corporation (NMPC) 1988b, "Demand-Side Management Program 1989," Syracuse NY, October 14.

Niagara Mohawk Power Corporation (NMPC) 1988c, "Competitive Bidding Guidelines and Request for Proposals," Syracuse NY, October 17.

Niagara Mohawk Power Corporation (NMPC) 1989a, "Competitive Bidding Guidelines and Request for Proposals RFP No. 1," Syracuse NY, November 20.

Niagara Mohawk Power Corporation (NMPC) 1989c, "Demand-Side Management Program 1990," Syracuse NY, September 18.

Niagara Mohawk Power Corporation (NMPC) 1989b, "Integrated Electric Resource Plan 1989," Syracuse NY, February.

Niagara Mohawk Power Corporation (NMPC) 1990a, "Recommendations Concerning the Selection of Projects in Niagara Mohawk's First Competitive Bidding Request for Proposals," Syracuse NY.

Niagara Mohawk Power Corporation (NMPC) 1990b, “1991 Integrated Demand-Side Management Plan," Syracuse, NY, Volumes I-III, July 23.

Niagara Mohawk Power Corporation (NMPC) 1990c, "Tne most frequently asked questions concerning Niagara Mohawk's Competitive Bidding Guidelines and RFP No. 1," April 4.

Niagara Mohawk Power Corporation (NMPC) 1991, "Response of Niagara Mohawk Power Corporation to Petition of Enersave, Inc. and EUA Cogenex Corporation for a Declaratory Ruling," Syracuse NY, January 29.

Pacific Gas \& Electric (PG\&E) 1990, "Annual Summary Report on Demand-side Management Programs in 1989 and 1990", March.

Pacific Gas \& Electric (PG\&E) 1991, "DSM Pilot Bidding Project: DSM Bidding Policy, Objectives and Incentives", Testimony of Chris Choteau, OII 91-08-002, September 13.

B. Petrie 1991, personal communication, Niagara Mohawk Power Corporation. 
Public Utilities Commission of Colorado (Colorado PUC) 1988, "Application of the Public Service Company of Colorado regarding cogeneration and small power production projects”, Decision No. C88-726, June 9.

S. Putta 1990, "Weighing Environmental Externalities in New York State," Electricity Journal, $3: 6$.

San Diego Gas \& Electric 1992 "SDG\&E Request for Proposals: Energy Efficiency and Customer Service Program for Existing Residential Customers (Draft) ${ }^{4}$ OII.91-08-002, April 3.

D. Schultz 1992, "Report on the Demand-side Bidding Proposals of Southern California Edison, Southern California Gas, and San Diego Gas \& Electric," OII.91-08-002, CPUC Division of Ratepayer Advocates, April 6.

S. Stoft and E.Kahn 1991, "Auction Markets for Dispatchable Power: How to Score the Bids," Journal of Regulatory Economics, 3:3, 275-286.

A. Taylor and E.Kahn 1991, "Re-powering and Site Re-cycling in a Competitive Environment," LBL-30108, Lawrence Berkeley Laboratory, Berkeley CA, March.

E. Vine, O.DeBuen and C.Goldman 1990, "Stimulating Utilities to Promote Energy Efficiency: Process Evaluation of Madison Gas and Electric's Competition Pilot Program," LBL29642, Lawrence Berkeley Laboratory, Berkeley CA, December. 


\section{Appendix A \\ Survey of DSM Bidders}

Firm

Respondent

Title

Date

Interviewer
NMPC $1^{\text {st }}$ Stage Winner $(\mathrm{Y} / \mathrm{N})$

NMPC $2^{\text {nd }}$ Stage Winner $(\mathrm{Y} / \mathrm{N})$

Con Ed Winner $(\mathrm{Y} / \mathrm{N})$

Customer (C), Nat'l (N) or Local (L) E

My name is and I am calling from the Lawrence Berkeley Laboratory in California. We are conducting a study of the integrated resource bidding programs of Niagara Mohawk and Consolidated Edison companies under the sponsorship of NYSERDA, NYPSC, and DOE and as part of that study we are surveying the views of prospective and actual bidders in these programs.

We appreciate your taking the time to answer a few prepared questions. The interview should take approximately 30 to 45 minutes and all responses will be kept in strict confidence.

\section{NIAGARA MOHAWK BIDDING PROGRAM}

1. Did you submit a DSM bid in Niagara Mohawk's competitive bidding solicitation? yes no

(If no, skip to question 18)

2. What in particular motivated you to participate in this bidding program?

3. What market sectors (commercial, industrial, residential) did you intend to approach?

4. What types of measures did you bid (lighting, HVAC etc.)? Was the choice of measures a reflection of your specialty, dictated by the list of eligible measures in the RFP, determined by the posted ceiling price, or due to other factors? 


\section{Potential Impact of "Integrated" Bidding Program}

5. What affect, if any, did the fact that the bidding program was integrated and included "all-sources", both supply and demand-side resource options, have on your decision to bid or the content of your bid?

\section{Assessment of Program Design Features}

6. Were there any elements of the RFP that you found to be particularly well thought out?

\section{(PROBE: specific areas in table below)}

7. Were there any elements of the RFP that you found to be particularly problematic or generally in need of improvement?

(PROBE: specific areas in table below)

Threshold criteria

- 15 year minimum contract length

- $100 \mathrm{~kW}$ minimum capacity bid

- contract deposit of $\$ 15 / \mathrm{kW}$

Self-scoring criteria

- price score

- front-loaded payments \& security

- technical and market feasibility

- impact of customer behavior

- project viability (level of development, financing)

- qualifications \& experience

- performance monitoring and verification of savings

- basis for payment (estimated vs. measured savings)

- project location

- environmental score

Time for response to RFP

Other 


\section{Bid Evaluation and Selection Process}

8. Did the RFP adequately explain the bid evaluation and contractor selection process for Phase One?

9. Did the company provide an explanation for their decision in selecting the Final Award Group (Phase Two)?

10. Were you satisfied with the way Niagara Mohawk's two-stage bid evaluation and contractor selection process worked in practice?

11. Do you have any comments on your interactions with the independent third party firm that conducted the evaluation and verification of bids in Phase One?

\section{Coordination and Relationship to Other Utility DSM Programs}

12. Niagara Mohawk has indicated that DSM bids were evaluated in relation to the company's own core DSM programs. Do you have an opinion about whether, or how, this consideration should be treated in a bidding program?

\section{Comparison of Bidding to Other Utility DSM Programs}

13. Are you now, or have you in the past, participated in other Niagara Mohawk DSM programs? If so, what advantages or disadvantages does the bidding program have in comparison to those other programs?

\section{Conclusions}

14. What is your overall assessment of the bidding program?

15. How could the bidding program be improved?

\section{(Final Award Group Only)}

16. What were the major issues in the contract negotiation process? 
17. Have you begun to install measures in field? What is your timetable?

\section{CONSOLIDATED EDISON BIDDING PROGRAM}

18. Did you submit a DSM bid in Consolidated Edison's bidding program? yes no

(If yes, skip to question 21; if no, go to questions 19-20)

19. Were there any aspects in particular of Con Ed's program that led you to decide against participation?

20. Were there reasons other than those directly related to the program that led to your decision not to participate (e.g., not enough time, too much of a hassle doing business in New York state or city, etc.)?

(If 18 = no and national ESCO, skip to 34 ; if customer, skip to 36; if local ESCO terminate interview)

21. What motivated you to participate in this bidding program?

22. What market sectors (commercial, industrial, residential) do you intend to approach?

23. What types of measures did you bid (lighting, HVAC etc.)? Was the choice of measures a reflection of your specialty, dictated by the list of eligible measures in the RFP, determined by the posted ceiling price, or due to other factors?

\section{Potential Impact of "Integrated" Bidding Program}

24. What affect, if any, did the fact that the bidding program was integrated and included "all-sources", both supply and demand-side resource options, have on your decision to bid or the content of your bid? 


\section{Assessment of Program Design Features}

25. Were there any elements of the program that you found to be particularly well thought out?

(PROBE: specific areas in table below)

26. Were there any elements of the program that you found to be particularly in need of improvement?

(PROBE: specific areas in table below)

Threshold criteria

- list of eligible measures

- $100 \mathrm{~kW}$ minimum capacity bid

- ceiling price for measures

- letter proving that bid is financeable

- verification of installation

- signed letter of intent with DSM client

- security arrangements ( $\$ 15 / \mathrm{kW}$ deposit)

- front loading security

- ten year minimum contract

Self-scoring criteria

- make-up energy for hours not operating

- term adjustment (penalties for short lifetimes)

- availability adjustment

- front loading adjustment

Time for response to RFP

Other

Bid Evaluation and Selection Process

27. Did the RFP adequately explain the bid evaluation and contractor selection process?

28. Were you satisfied with Consolidate Edison's implementation of the bid evaluation and contractor selection process? 
29. Do you feel the company gave an adequate explanation for their final selections?

\section{Comparison of Bidding to Other Utility DSM Programs}

30. Are you now, or have you in the past, participated in other Consolidated Edison DSM programs? If so, what advantages or disadvantages does the bidding program have in comparison to those other programs?

\section{Conclusions}

31. What is your overall assessment of the bidding program?

32. How could the bidding program be improved?

\section{(Con Ed Winners Only)}

33. What were the major issues in the contract negotiation process?

(If customer, skip to 37; if local ESCO, terminate interview)

Comparison of NMPC and Con Ed Bidding Programs (National ESCOs only)

34. How would you compare the bidding programs of Consolidated Edison and Niagara Mohawk?

35. Have you had experience with other DSM bidding programs besides Niagara Mohawk or Consolidated Edison? If so, how would you characterize that experience vis a vis the NMPC and Con Ed programs?

[terminate interview]

\section{(Customers Only)}

36. Have you been aware of, or participated in, other utility DSM programs? (PROBE: Which ones, and how?) 
37. Were you approached by any ESCOs as a possible client during this bidding program?

38. Do you feel that the bidding program is adequately geared to the needs of customers?

[terminate interview] 

. 


\section{Appendix B \\ Survey of DSM Non-bidders}

Firm

Respondent

Title

Phone

Date

Customer (C), Nat'l (N) or Local (L) ESCO

Interviewer

Con Ed Non-respondent

NMPC non-respondent

This survey will be used for those firms/customers that received RFPs from either NMPC or Con Ed and chose not to respónd.

My name is and I am calling from the Lawrence Berkeley Laboratory in California. We are conducting a study of the integrated resource bidding programs of Niagara Mohawk and Consolidated Edison companies under the sponsorship of NYSERDA, NYPSC, and DOE. As part of that study we are surveying views of firms/customers that received a copy of the Request for Proposals.

In 1989, [choose 1 Niagara Mohawk, Consolidated Edison] requested demand and supply bids in their Competitive Bidding Program.

It is our understanding that you received a copy of the RFP. We appreciate your taking the time to answer a few prepared questions. The interview should take approximately 20 minutes and all responses will be kept in strict confidence.

The first questions I have are about your firm.

Non-respondents

1. Were you the person responsible for reviewing the RFP?

Yes

No 
2. Which of the following best describes your firms' major type of business? [check box]

a. Industrial Manufacturing firm

b. Commercial business

c. Government/Health Care/Education

d. Energy Service Company

e. Architecture/Engineering firm

f. Other Describe:

\section{Customer Perspective on Bidding Programs}

(Customers only; If $2=a$ or $b$ or $c$ )

3. Have you been aware of, or participated in, other utility DSM programs?

(PROBE: Which ones, and how?)

4. Were you approached by any ESCOs as a possible client during this solicitation?

5. Do you feel that the bidding program is adequately geared to the needs of customers?

\section{[Skip to 9]}

Perspectives of Non-participating Energy Service Firm

6. (For Energy service firms; $2=e$ or $f$ ) Which of the following DSM energy services does your firm provide?
a. Energy auditing
b. Design of ECMs
c. Installation of ECMs (specify technologies)
d. ECMs installation/design

7. Have you worked with the utility on other DSM programs? Have you done any work in NMPC or Con Ed service territories? (PROBE: Which ones, and how?) 
8. Did your experience affect your decision to not submit a bid?
a. Yes
b. No

(Probe: In what ways?)

\section{Overall Reactions of Non-respondents}

9. What statement best explains your initial response to solicitation?

a. Received RFP for information only, no intention to apply (Terminate Interview)

b. Interested in responding to supply-side RFP (Terminate Interview)

c. Interested in program but had no time to prepare a proposal

d. Interested in program and tried to prepare a proposal

e. Other

10. What was the single factor that most influenced your decision not to respond to the solicitation?

11. (If appropriate ask:) Is there anything which could be changed in DSM bidding program which would lead you to willing to submit a proposal?

12. Were there reasons other than those directly related to the program that led to your decision not to participate (e.g., not enough time, too much of a hassle doing business in NYC, etc.)?

13. Do you have any final comments?

Thanks again for your cooperation. [Terminate interview] 


\section{Appendix C \\ Questionnaire to Niagara Mohawk Staff Involved in Bidding Program}

Respondent

Date
Title

Interviewer

1) What stages of the bidding program were you involved with?

\section{Bidding Program Design}

2) Are you satisfied with the way the two-stage approach to bid selection worked? Was the self-scoring system useful in producing a "short list" of bids for more detailed evaluation?

3) How well did the "all-sources" integrated auction work in practice? Was this approach well suited to evaluate DSM bids $(\mathrm{Y} / \mathrm{N})$ ? Supply-side projects $(\mathrm{Y} / \mathrm{N})$ ?

4) In general, how satisfied were you with the ability of the threshold requirements to screen out inadequate projects?

5) Were there any elements of the RFP (threshold requirements or evaluation criteria) that turned out to be particularly confusing, troublesome, or in need of improvement? Would you make any major changes in the relative weights for evaluation criteria?

\section{Bid Evaluation}

6) To what extent were people from the company DSM program area involved in the evaluation of bids?

7) Do you feel that the bid evaluation technique applied in the second phase represented a truly integrated technique? 
8) In your view, has the company formulated and applied a policy (implicit or otherwise) in the bid evaluation process for determining how the DSM bidding and company-sponsored DSM programs are to co-exist?

\section{Contract Negotiations:}

9) What were the major issues that emerged in contract negotiations?

10) Do you see any role for negotiations in resolving outstanding issues that might otherwise result in bids being rejected outright?

11) Could you discuss the measurement/evaluation/verification plans of bidders? Were you satisfied with the plans proposed by bidders?

\section{Overall Impressions and Directions for Future:}

12) Based on the experience of RFP No. 1, is NMPC prepared to pursue integrated bidding in the future or separate auctions for supply and demand, or some other approach?

13) Does NMPC see any significant role for ESCOs in providing DSM services in NMPC service territory in the future? If so, what kind of role? If not, why not?

14) Were there any unanticipated results in terms of the scale of response, types of projects/measures bid, or other things?

15) Turning back the clock, what would you do differently if you were given a chance to issue RFP No. 1 all over again? 

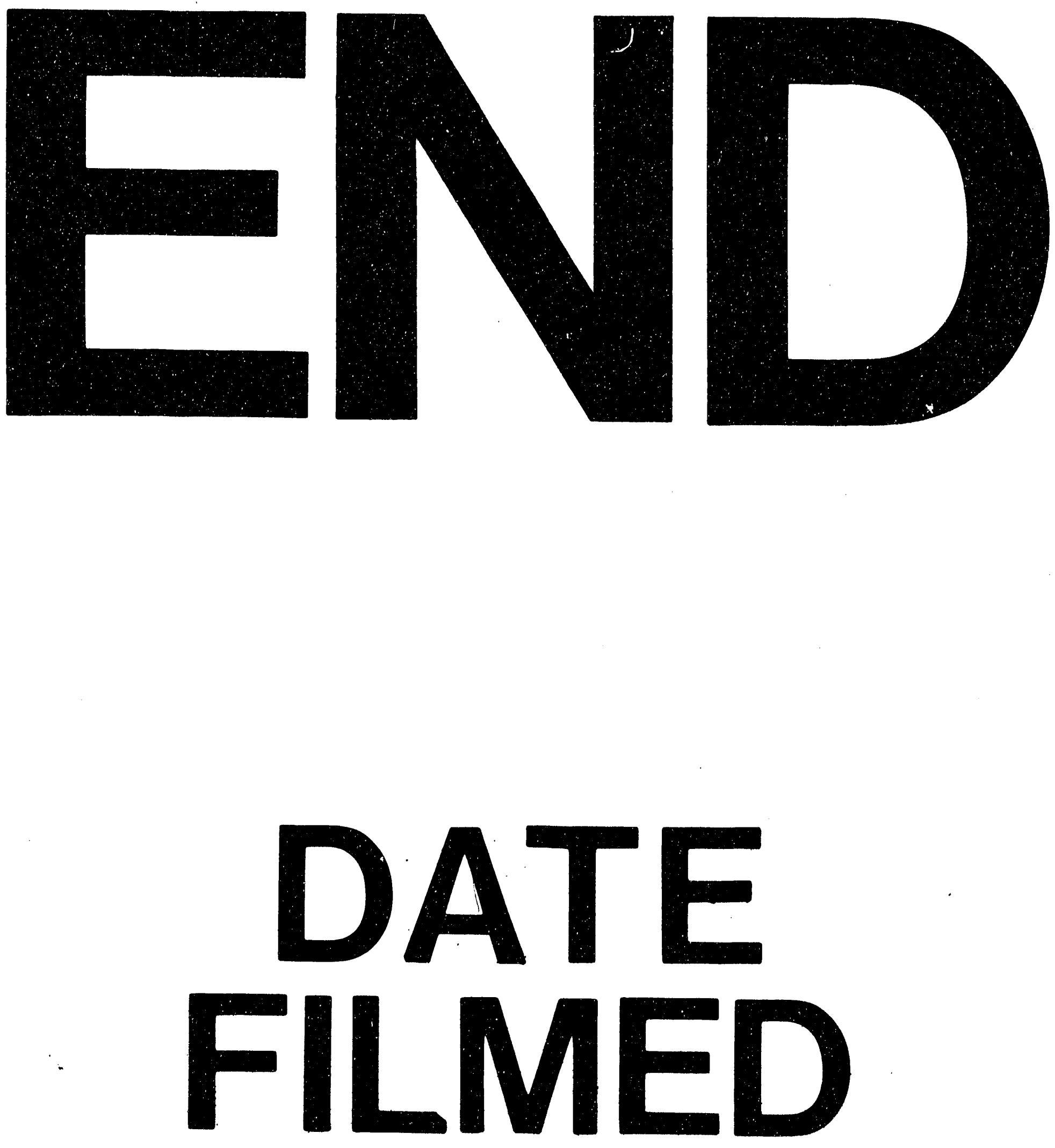

r.

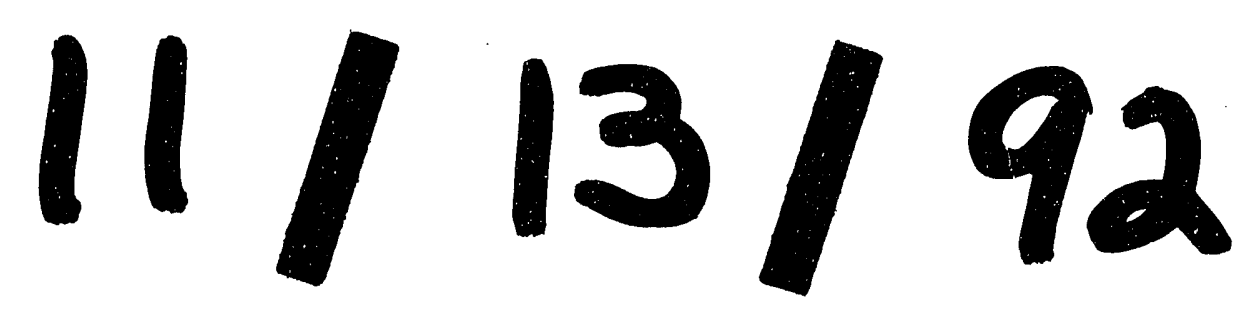


